\title{
OTIMIZAC̣ÃO ECONÔMICA EM CONFINAMENTO DE BOVINOS DE CORTE
}

\author{
NERMANO FRANCO FERREIRA \\ Engenheiro Agrônomo
}

Orientador: Prof. Dr. FERNANDO CURI PERES

Dissertação apresentada à Escola
Superior de Agricultura "Luiz de
Queiroz", da Universidade de São
Paulo, para obtenção do título de
Mestre em Agronomia. Área de
Concentração: Economia Agrária.

PIRACICABA

Estado de São Paulo - Brasil

Janeiro - 1993 
Ferreira, Nermano Franco

F3830 Otimização econômica em confinamento de bovinos de corte. Piracicaba, 1993.

$89 \mathrm{p}$.

Diss. (Mestre) - ESALQ

Bibliografia.

1. Bovino de corte - Confinamento - Aspecto econômico 2. Bovino de corte - Confinamento - Otimização I. Escola Superior de Agricultura Luiz de Queiroz,Piracicaba

$\operatorname{CDD} 338.176213$ 


\title{
OTIMIZAC̣ÃO ECONÔMICA EM
}

\section{CONFINAMENTO DE BOVINOS DE CORTE}

\author{
NERMANO FRANCO FERREIRA
}

Aprovado em: 2 de abril de 1993.

Comissão Julgadora:

Prof. Dr. Fernando Curi Peres

ESALQ/USP

Prof. Dr. Celso Boin

ESALQ/USP

Prof. Dr. Cassio Roberto de Melo Godoi

ESALQ/USP

Prof. Dr. FERNANDO CURI PERES

Orientador 
Aos meus pais,

Nermano e Maria da Glória

ofereço.

À minha esposa,

Renata,

que sempre me apoiou, dedico com muito carinho. 


\section{AGRADECIMENTOS}

Ao Departamento de Economia e Sociologia da ESALQ, pela oportunidade que me concedeu de realizar o curso de mestrado, com seus professores sempre dispostos a ensinar e funcionários prontos para apoiar todas as atividades.

Ao meu orientador, professor Fernando Curi Peres, pela disposição em auxiliar sempre que consultado, com idéias, críticas e sugestões extremamente importantes para que a dissertação pudesse ser realizada.

Ao professor Celso Boin, do Departamento de Zootecnia da ESALQ, pela orientação precisa em relação aos aspectos de nutrição animal utilizados na pesquisa e pelo tempo que dispensou adaptando e testando a consistência do modelo.

Aos professores Cássio Roberto de Melo Godoi e José Antonio Frizzone, da ESALQ, pelas sugestões.

Ao CIAGRI - Centro de Informática na Agricultura, na pessoa de seus ex-coordenadores, Prof. Adriano Azevedo Filho e Prof. José Vicente Caixeta Filho, pela dispensa parcial de tempo para realização do cürso de mestrado e pela disponibilidade de infra-estrutura computacional, sem a qual este trabalho não poderia ter sido realizado como foi. Também a todos demais colegas de trabalho, pelo ambiente agradável proporcionado.

Ao Centro de Pesquisas em Economia Agrícola - especialmente aos colegas Sérgio De Zen e Marcelo Temperini Couto - e à Plano Consultoria Agropecuária, na pessoa do colega Ari Lacorte, pelos dados fornecidos. 
Às bibliotecárias do Departamento de Economia e Sociologia Rural, Angélica e Luciane.

À CAPES e CNPq pelo apoio financeiro.

A todos que, direta ou indiretamente, colaboraram para a realização deste trabalho. 


\section{SUMÁRIO}

Página

LISTA DE FIGURAS..................................................... viii

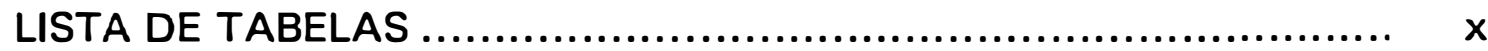

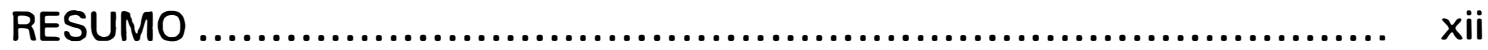

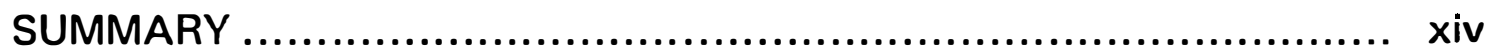

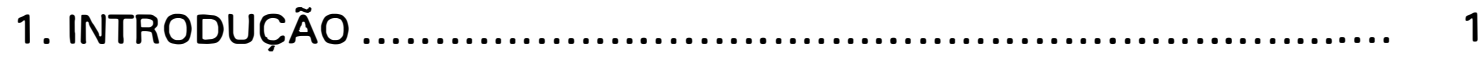

1.1. Considerações Gerais ........................................ 1

1.2. O Problema em Questão ...................................... 4

2. REVISÃO DE LITERATURA ........................................... 6

3. OBJETIVOS ......................................................... 12

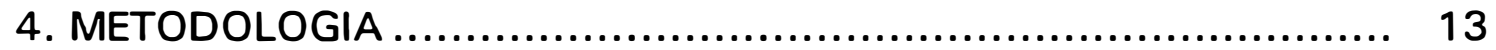

4.1. Estimativas de ganho de peso do gado confinado sob diversas condições nutricionais............................. 13

4.1.1. Energia fornecida ................................... 15

4.1.2. Energia para mantença ............................. 16

4.1.3. Ingestão de matéria seca ........................... 16

4.1.4. Energia para ganho de peso ....................... 17

4.1.5. Ganho de peso em função da energia líquida para ganho $(E L g)$..................................... 17

4.1.6. Exigência de proteína bruta .......................... 17

4.1.7. Exigência de cálcio .................................. 18

4.1.8. Exigência de fósforo ................................ 18

4.2. Estimativas de preço do boi gordo baseadas no preço do boi magro a determinados níveis de confiança 
4.3. Descrição do modelo......................................... 22

4.3.1. Processo 1: Estima ganho de peso................... 24

4.3.2. Processo 2: Calcula ração.............................. 25

4.3.3. Processo 3: Estima preço do boi gordo ............... 26

4.3.4. Processo 4: Contabiliza custos ..................... 27

4.3.5. Processo 5: Maximiza lucro.......................... 28

4.4. Implementação do modelo ................................... 29

4.5. Estudo de um caso hipotético............................. 31

5. RESULTADOS E DISCUSSÃO ................................... 37

5.1. Maximização do lucro ..................................... 37

5.2. O modelo de previsão de preços .......................... 46

5.3. Análise de sensibilidade do modelo ........................ 51

6. CONCLUSÕES .................................................... 58

BIBLIOGRAFIA CONSULTADA ....................................... 61

APÊNDICE ...................................................... 65 


\section{LISTA DE FIGURAS}

Figura $n^{\circ}$

Página

2.1. CONFCOMP - Análise Econômica de Confinamento de Bovinos

2.2. Tela de resultados do software SFR - USP, CIAGRI

4.1. Função empírica de distribuição probabilística de

$R_{t, m}$

4.2. Exemplo de relações mínimas esperadas entre o preços do boi gordo/boi magro para os meses seguintes, em função do preço atual do boi magro (mês 5) a um dado nível de probabilidade de ocorrência.

4.3. Diagrama geral do Sistema ADECONF ................... 23

4.4. Janela do "Solver" do Microsoft Excel 4.0 ................. 31

5.1. Tela principal do ADECONF para o caso $A$ Confinamento com início em maio/92 .......................

5.2. Tela principal do ADECONF para o caso B Confinamento com início em junho/92 ......................

5.3. Modelagem do ganho de peso para o confinamento com início em maio/92 (caso A)

5.4. Modelagem do ganho de peso para o confinamento com início em junho/92 (caso B) 
Figura $n^{0}$

Página

5.5. Relações mínimas de preços boi gordo/(boi magro em maiol esperadas a diversos níveis de probabilidade comparadas com a média das relações observadas entre 1970 e 1992, utilizando o IGP-DI como deflacionador de preços................................

5.6. Relações mínimas de preços boi gordo/(boi magro em maio) esperadas a diversos níveis de probabilidade comparadas com a média das relações observadas entre 1970 e 1992, utilizando o dólar oficial como deflacionador de preços.........................

5.7. Estimativas de ganho de peso $(\mathrm{kg} / \mathrm{dia})$ para animal de $330 \mathrm{~kg}$, com grau de estrutura corporal (GEC) igual a 5, a diferentes pesos finais, em função do NDT presente na ração.

5.8. Custo mínimo das rações formuladas para atender às exigências de porcentagens de $\mathrm{Ca}, \mathrm{P}$ e $\mathrm{PB}$ para animal de $330 \mathrm{~kg}$, com grau de estrutura corporal igual a 5, a diferentes pesos finais, em função do NDT presente na ração e preços dos ingredientes de maio/92 


\section{LISTA DE TABELAS}

Tabela $n^{\circ}$

Página

1.1. Maiores produtores de carne bovina (média de 1988-90).

4.1. Coeficientes para conversão do peso vivo (PVj) em peso equivalente ( $\mathrm{PEq}$ ) para bovinos em crescimento com diferentes GEC

4.2. Coeficientes médios de ajuste para ingestão de matéria seca (CIMS), exigência de energia para mantença (CEM) e eficiência de utilização de energia para ganho de peso (CEGP) em função do peso equivalente.(PEq)

4.3. Características dos animais utilizados nos casos simulados.

4.4. Preços de ingredientes para ração utilizados nos casos simulados (US\$/ton).

4.5. Outros custos considerados nos casos simulados.

4.6. Composição química e valor energético dos ingredientes utilizados no cálculo de ração.

4.7. Exigências nutricionais e restrições adicionais necessárias para os ingredientes utilizados na formulação da ração.

5.1. Preços do boi gordo e relações mínimas previstas para os meses seguintes ao início do confinamento a $70 \%$ de confiança.

5.2. Exigências nutricionais calculadas para atender aos ganho de peso de $1,022 \mathrm{~kg} / \mathrm{dia}$ (caso A) e 0,954 $\mathrm{kg} /$ dia (caso B), calculadas em porcentagem na base seca. 
5.3. Custo e composição da ração ajustada pelo Sistema para o caso A.................................................

5.4. Custo e composição da ração ajustada pelo Sistema para o caso $B$.

5.5. Balanço econômico esperado para os dois casos simulados.

5.6. Probabilidades mínimas estimadas pelo Sistema da ocorrência de relações de preço boi gordo//boi magro em maiol para os preços realmente praticados em 1992 em comparação com os preços estimados no caso $A$.

5.7. Comparação do Balanço Econômico simulado no caso A com preços estimados e com preços praticados em 1992.

5.8. Análise de sensibilidade do peso final com os dados do caso $A$.

5.9. Análise comparativa das soluções encontradas para o caso $A$, e A1, com mudanças nos valores originais das variáveis para um ponto melhor.

5.10. Análise comparativa das soluções encontradas para o caso A, com preços do milho a US\$119,80/ton e A2, com milho a US\$ $85,17 /$ ton 


\title{
OTIMIZAC̣ĀO ECONÔMICA EM \\ CONFINAMENTO DE BOVINOS DE CORTE
}

\author{
Autor: NERMANO FRANCO FERREIRA \\ Orientador: Prof. Dr. FERNANDO CURI PERES
}

\section{RESUMO}

No estudo é concebido e implementado um Sistema para otimização econômica de confinamentos de bovinos de corte que opera em microcomputadores, cujo objetivo é encontrar alternativas para seleção de animais, alimentação e épocas ideais para o confinamento, que proporcionem a maior receita líquida possivel.

Um dos componentes do Sistema é responsável pela modelagem dinâmica da engorda dos animais, considerando suas características físicas, estimando seu ganho de peso e necessidades nutricionais. Um outro módulo é- responsável pelo cálculo de rações a custo mínimo, que atendam às exigências determinadas, utilizando os ingredientes disponíveis. Outro componente do Sistema calcula, dentro de intervalos de confiança determinados pelo usuário, os preços esperados pelo boi gordo em função do mês em que o confinamento pode terminar. As estimativas de preços podem também ser feitas pelo próprio usuário do Sistema. 
A partir da interação com os módulos anteriores, é realizado um cálculo de maximização, através de programação não-linear, que determina a estratégia ótima para alocação dos recursos na atividade.

O Sistema é utilizado para análise de um caso hipotético, utilizando preços reais de insumos na região de Piracicaba/SP, considerando-se a possibilidade de início do confinamento em maio ou junho e um nível de confiança de $70 \%$ na previsão de preços para o boi gordo. Nos dois casos, aponta um período de cinco meses como ideal para engorda dos animais, uma vez que os preços esperados para os meses de outubro e novembro não são muito diferentes.

Com o objetivo de auferir a precisão do "ótimo", a partir da solução calculada como ideal para início em maio, é realizada uma análise de sensibilidade em relação à variável Peso Final, verificando-se que o Sistema pode apresentar soluções "quasi-ótimas", dependendo dos valores iniciais das variáveis. A diferença, todavia, entre as diversas soluções "quasiótimas" é extremamente pequena em relação ao montante de capital investido.

Conclui-se que o Sistema presta-se para ser utilizado por pecuaristas, desde que devidamente treinados $\mathrm{e}$ informados sobre os recursos $\mathrm{e}$ limitações do modelo. É também uma ferramenta bastante útil a pesquisadores de nutrição animal, que podem avaliar, experimentalmente, a aplicabilidade de equações internacionalmente reconhecidas e utilizadas, possibilitando, inclusive, que sejam alteradas pelos próprios especialistas. 


\title{
ECONOMIC OPTIMIZATION IN \\ BEEF CATTLE FEEDLOT
}

\author{
Author: NERMANO FRANCO FERREIRA \\ Adviser: Prof. Dr. FERNANDO CURI PERES
}

SUMMARY

This study presents the design and implementation of a microcomputer system for economic optimization of beef cattle feedlot. Its main goal is to find alternatives to animal selection, feed supply and scheduling that maximize the operation's net income.

One of the system components deals with the dynamic modeling of weight gain, considering the physical characteristics of the cattle and estimating the corresponding values as well as their nutritional requirements. Another module does the minimum cost ration formulation subject to the nutritional requirements, using-available ingredients. A third component does, within confidence intervals, price estimates for the next months, when the feedlot will finish. Price estimates may also be introduced into the system by the user. These components are integrated and a non-linear maximization strategy is used to find the optimal global strategy for resource allocation. 
The system is used to analyze a hypothetical case study using prices of inputs prevailing in the Piracicaba region, SP. The analysis simulates the beginning of a feedlot in May and one in June with a confidence level for price prediction of $70 \%$. In both cases, the system indicates a five month period as ideal for the feedlot duration, due to small difference between October and November prices.

To find the precision reached by the system, starting from the solution calculated to begin in May, a sensitivity analysis was taken of the final weight. It was verified that the system may show "quasi-optimal" solutions, depending on the initial values of the variables. The differences found, however, were very small when compared to the invested capital.

It was concluded that the system is useful for cattle producers, but requires training, and information about its resources and limitations. It is a very useful tool for researchers in animal nutrition, and can also be used to evalue, experimentally, the international equations that have been used, allowing for modifications by the specialists themselves. 


\section{INTRODUÇÃO}

\subsection{Consideracões Gerais}

Embora apresentem uma baixa eficiência em termos de produção de carne, quando comparados a outros animais domésticos como frangos e suínos, os bovinos desempenham um importante papel na alimentação do homem, principalmente devido ao fato de, como ruminantes, conseguirem transformar alimentos impróprios para o consumo humano - como pastagens, resíduos agroindustriais e de outros animais - em proteína de excelente qualidade. Essa característica peculiar, aliada à robustez quanto ao manejo na criação e engorda desses animais leva a uma vantagem competitiva que os colocam em elevado grau de importância no mercado mundial de alimentos. De acordo com os dados da FAO (1990), nos últimos anos o Brasil vem ocupando a $3^{a}$ posição em relação aos outros países que produzem carne bovina para consumo (Tabela 1.1). Segundo HADDAD (1983), baseando-se na ampla disponibilidade de área agricultável e clima relativamente favorável, acredita-se que futuramente o Brasil deverá tornarse o maior produtor e fornecedor de carne bovina do mundo. 
Tabela 1.1. - Maiores produtores de carne bovina (média de 1988-90).

\begin{tabular}{|c|c|c|c|}
\hline \multirow[b]{2}{*}{ País } & \multicolumn{2}{|c|}{ Produção } & \multirow{2}{*}{$\begin{array}{r}\text { Peso } \\
\text { carcaça } \\
(\mathrm{kg})\end{array}$} \\
\hline & $\begin{array}{l}\text { de carne } \\
(1.000 \mathrm{t})\end{array}$ & $\begin{array}{l}\text { de carcacasas } \\
\text { (1.000 unid.) }\end{array}$ & \\
\hline U.S.A & 10.658 & 36.483 & 292 \\
\hline U.R.S.S (extinta) & 8.705 & 43.133 & 202 \\
\hline Brasil & 2.737 & 13.218 & 207 \\
\hline Argentina & 2.633 & 12.266 & 214 \\
\hline Alemanha & 2.093 & 7.103 & 277 \\
\hline México & 1.932 & 9.363 & 206 \\
\hline França & 1.864 & 6.764 & 276 \\
\hline Austrália & 1.586 & 7.531 & 211 \\
\hline Itália & 1.161 & 4.861 & 239 \\
\hline Reino Unido & 976 & 3.452 & 283 \\
\hline Canadá & 958 & 3.679 & 260 \\
\hline Polônia & 679 & 3.748 & 182 \\
\hline Mundo & 51.152 & 241.283 & 198 \\
\hline
\end{tabular}

Fonte: Adaptado de FAO PRODUCTION YEARBOOK, 1990 - p.199-201

Para produção de carne bovina com o aproveitamento das pastagens como fonte exclusiva de alimentação, processo utilizado pela maioria dos produtores brasileiros, encontram-se entraves principalmente na região centro-sul do país. Eles decorrem de fenômenos climáticos desfavoráveis (precipitação e temperatura baixas) que ocorrem no período compreendido entre os meses de maio a setembro. Devido ao fato das forrageiras apresentarem estacionalidade de produção, onde cerca de $80 \%$ do total produzido coincide com a época quente e chuvosa e também à falta de tradição dos pecuaristas, na prática de conservação de forragens, ocorre um período do ano onde o gado encontra fartura de alimento e outro onde há escassez e consequente perda de peso. Isso gera uma produção estacional de carne, uma vez que no final da estação chuvosa ("águas") ou no início do período crítico ("seca"), os produtores procuram negociar os animais terminados, visto que é baixa a probabilidade de que o gado ganhe ou mesmo mantenha o peso já adquirido (HADDAD, 1983). 
A estacionalidade na produção de carne acarreta sérios problemas de abastecimento elevando o preço do produto e aumentando as condições de risco e incerteza tanto a nível de produção como de comercialização. Ela leva os órgãos governamentais à formação de estoques frigorificados ou mesmo à importação de carne em períodos de menor oferta sem que, no entanto, consiga-se eliminar os efeitos oscilatórios do mercado. 0 produtor individual, por outro lado, como agente passivo no processo de formação de preços, pode minimizar ou mesmo beneficiar-se do problema da estacionalidade da produção evitando vender seus animais em épocas de baixo preço, ou melhor, comprando bois magros nessa época, engordandoos através de confinamento e ofertando animais em peso de abate na época em que os preços estão mais altos.

A opção pela manutenção do gado vivo, na entressafra, deve considerar que o custo de alimentação suplementar necessária nas nossas condições, ainda é bastante elevado, comparativamente à pastagem, abundante na época "das chuvas", acarretando sensível redução na margem de lucro e tornando a atividade de confinamento inviável, não fosse a variação no preço real da carne na entressafra (ANDRADE, 1983). No caso do confinamento visando o ganho de peso = quando são adquiridos bois magros na época de preços baixos - a alimentação coloca-se como componente ainda mais importante, devendo o produtor tomar extremo cuidado para determinar a melhor combinação dos alimentos de modo a satisfazer a exigências dos animais de tal modo que seja atingido peso de abate quando o preço da carne estiver favorável. 
Ao tomar a decisão sobre qual alimentação deverá ser utilizada, é preciso que o produtor tenha uma previsão para o preço futuro do boi gordo, analisando assim a lucratividade esperada para seu investimento. Normalmente a ferramenta utilizada pelo produtor resume-se a sua própria intuição ou baseia-se em experiências passadas. Os produtores novos no ramo, que constituem maioria em atividades recentes e em crescimento, nem mesmo dispõe de experiências para se apoiar. Metodologias de análise econômica para tomada de decisão possibilitariam ao produtor a disponibilidade de informações mais concretas para se decidir sobre a atividade de confinamento. Todavia, esse tipo de análise exige seqüências de cálculos exaustivos, inviáveis de se realizar sem o auxílio de ferramentas computacionais, justificando-se desta forma estudos que venham contribuir para aperfeiçoá-las e implementá-las a nivel de usuário final, ou seja, o próprio produtor.

\subsection{O Problema em Questão}

Devido à pequena tradição existente na terminação de gado de corte em regime de confinamento, são fracas as bases onde o produtor pode se apoiar para decidir sobre qual a melhor forma de aplicar seu capital na atividade ou mesmo, quais as técnicas mais adequadas a serem empregadas. Esse fato é reforçado pela elevada instabilidade econômica do Brasil, que não propicia adequadas condições para aplicação de experiências passadas no planejamento futuro, pois gera expressivas oscilações nos preços, tanto dos insumos (boi magro, alimentação e outros componentes do custo de produção) quanto do produto final, ou seja, o boi gordo. Como se sabe, existem oscilações estacionais e plurianuais nos preços do boi 
gordo e magro que podem ser verificadas através da observação de séries históricas (KASSOUF, 1988).

Sendo o confinamento caracterizado pelo arraçoamento intensivo dos animais, torna-se necessária a utilização de métodos sofisticados para balanceamento das rações, de modo a apreveitar, além dos alimentos existentes no mercado, também aqueles disponíveis na propriedade. No entanto, não basta ao modelo apenas a minimização do custo da ração para determinado ganho de peso, mas também a determinação de qual deverá ser o ganho de peso ideal para que se obtenha máximo lucro. Para cada situação específica, onde o produtor dispõe de oferta de bois magros em diferentes épocas do ano e também de alimentos para aquisição, o modelo deve avaliar que rentabilidade máxima poderá atingir, indicando a época e peso ideais para a venda dos animais baseando sua previsão de preços em séries históricas ou na expectativa subjetiva do produtor. Esse modelo terá êxito caso possa ser utilizado diretamente pelo produtor final, que é o agente tomador de decisão, possibilitando-Ihe fazer simulações com suas possíveis combinações de recursos para investimento. 


\section{REVISÃO DE LITERATURA}

BULLOCK \& LOGAN (1972) consideraram a incerteza em relação a preços futuros, tanto dos animais como dos alimentos, como um importante aspecto no processo de decisão a ser tomada em confinamento, desenvolvendo um modelo que auxilia o criador a decidir pela venda imediata dos animais ou pela continuidade do confinamento dentro de um horizonte de 6 meses. Por outro lado, WHITSON \& KAY (1978) elaboraram um modelo de otimização, utilizando técnica de programação linear, com o objetivo de prever combinações ótimas de área ocupadas com pastagens nativas e cultivo de cereais utilizados para alimentação de bovinos de corte. Seu modelo foi testado com diversos preços esperados pela venda dos animais e, em função desses preços, determinou-se qual a melhor maneira de utilização da área disponível para produção de alimentos e venda dos animais em diversas épocas do ano. Ambos os modelos, apesar de apresentarem enfoques diferentes para o problema, baseiam-se, principalmente, no fator "preço de insumo/produto", não levando em consideração variações no ganho de peso em função de aspectos nutricionais e seus efeitos sobre a lucratividade.

Existem alguns modelos que buscam a simulação biológica de características que afetam o desempenho da produção de carne bovina. A 
base destes modelos consiste de uma série de equações matemáticas, compiladas basicamente por dois grandes conselhos de pesquisa mundialmente reconhecidos (NRC, 1984; ARC, 1980). O NRC leva em consideração o conceito de energia líquida disponível para mantença e ganho de peso. A partir destas equaçōes são também previstas outras variáveis importantes como ingestão voluntária de matéria seca, crescimento e ganho de peso, assim como descrito por DENHAM \& SPREEN (1986). Esses modelos são ainda deficientes na avaliação dos efeitos econômicos que essas variáveis simuladas podem ter e suas interrelações, ou seja, normalmente se faz a simulação biológica e, posteriormente, avaliase economicamente os resultados que podem ser obtidos.

Modelos complexos de simulação para produção de carne bovina foram analisados por SPREEN \& LAUGHLIN (ed.), 1986. Trata-se dos modelos de Kentucky e Texas A\&M que foram desenvolvidos em linguagem FORTRAN. Esses modelos permitem uma avaliação econômica global da atividade, simulando alternativas para aplicação dos diversos insumos disponíveis na propriedade, principalmente no tocante às áreas de produção de alimentos. O enfoque adotado não é adequado para atividades de confinamento, onde a principal-preocupação reside na questão de produção de carne associada à escolha da alimentação mais adequada, sendo no entanto, bastante indicado para criação extensiva de gado de corte.

No Brasil, NORONHA (1982) considerou o fator risco em projetos de investimento para análise de projetos governamentais em um programa para incentivo à pecuária (PROPEC) e SÁ (1985) utilizou-a na avaliação de projetos de confinamento como alternativa à análise determinista. $\mathrm{Na}$ 
ocasião, a autora desenvolveu, juntamente com colaboradores, um software relativamente simples para o tratamento dos dados da dissertação sem objetivos de torná-lo disponível para ser usado por produtores de gado de corte.

Preocupado com o tempo dispendido na elaboração de programas específicos para análise de risco em projetos de investimento, AZEVEDO FILHO (1988) desenvolveu um software genérico para microcomputadores que faz simulações com variáveis definidas pelo usuário e avalia o comportamento de variáveis dependentes daquelas cujas distribuição é conhecida, através do método de Monte Carlo. Em seu estudo não são considerados casos onde algumas variáveis são obtidas através de modelos de programação matemática, como na formulação de ração. Também não são previstas as etapas posteriores à análise, quando o produtor decide realmente executar o projeto (o confinamento no presente caso) e necessita controlar as atividades em andamento.

AZEVEDO FILHO (1987), desenvolveu um Sistema para microcomputadores que permite a contabilização dos principais insumos necessários à atividade de confinamento. Esse Sistema faz uma análise determinista do problema, supondo que todas as variáveis que compõem os custos e as receitas são conhecidas e produz um gráfico relacionando o preço final do boi com o retorno sobre o investimento. Embora as informações produzidas sejam úteis ao produtor, esse Sistema parte do pressuposto que o produtor já conhece a ração adequada, admite também que o ganho de peso durante o processo de engorda é constante e trabalha com o método de tentativa e erro (ver Figura 2.1). 


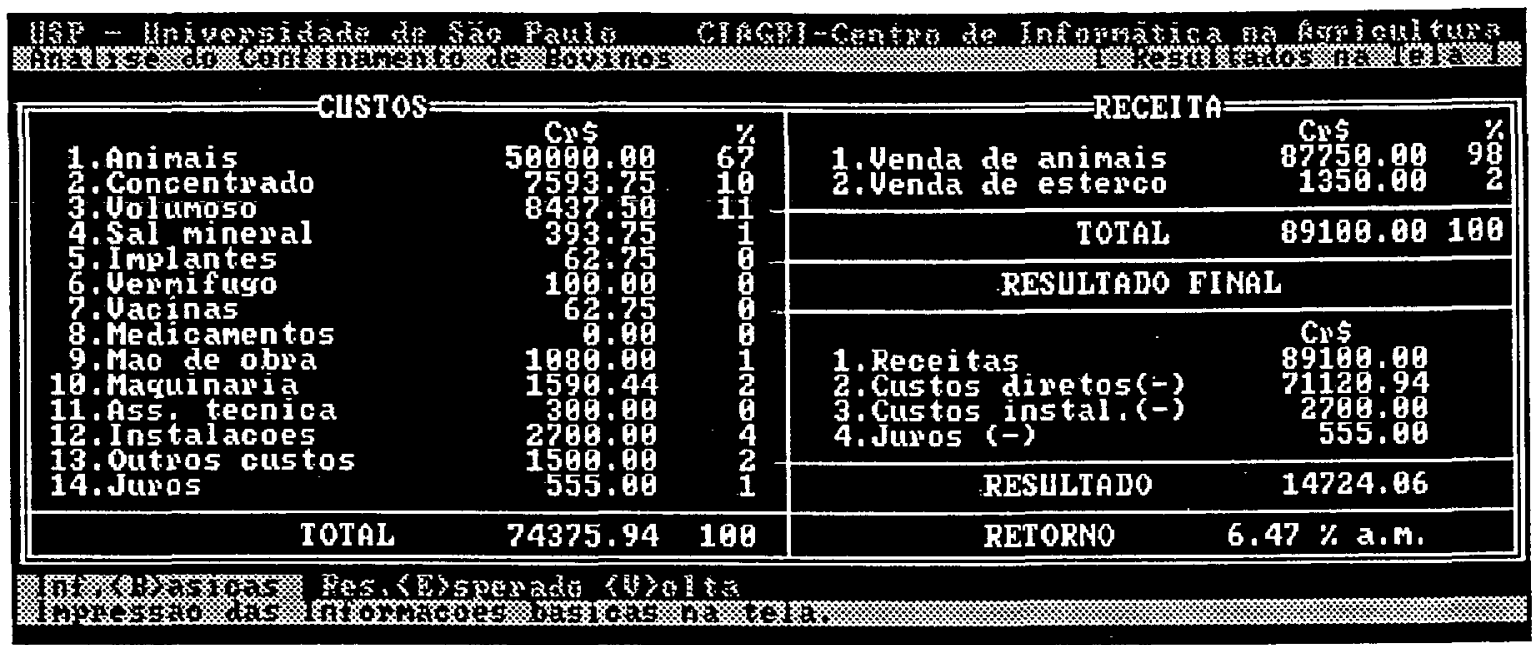

Figura 2.1. CONFCOMP - Análise Econômica de Confinamento de Bovinos

Um modelo interessante para a decisão sobre confinamento foi proposto por PERES (1990) e implementado parcialmente através do software ARBORIST. O modelo prevê a construção de uma árvore de decisão baseada em diversas opções de alimentação considerando ao mesmo tempo probabilidades alternativas de ganho de peso para cada uma delas e também distribuições probabilísticas para preços futuros do boi gordo. O objetivo no caso é a maximização da utilidade, baseando-se em uma curva de indiferença do produtor, construída com base na própria situação. Embora eficiente, esse modelo exige a construção de um software para que possa ser aplicado e parte de rações previamente formuladas de maneira discreta quanto ao ganho de peso. Não considera também a curva de ganho de peso do animal de maneira a atingir o ponto ótimo de relação ganho de peso / ingestão.

Programas para formulação de rações de custo mínimo usando técnicas de programação linear são largamente utilizados. Alguns são sistemas genéricos, tais como DHLLP, LP88 e MPSX e não se prestam ao produtor 
pouco familiarizado com técnicas de modelagem matemática. Outros, por serem mais epecíficos, como o SFR (Figura 2.2), contém mecanismos que permitem a construção de bancos de dados com composições de alimentos, suas restrições e exigências nutricionais dos animais, possuindo uma aceitação maior por parte de produtores rurais e, principalmente, fábricas de rações. O propósito desse software é apenas a combinação ótima dos alimentos, visando ração de mínimo custo; não considera aspectos relevantes para a tomada de decisão em confinamento tais como reflexos do ganho de peso sobre a rentabilidade do investimento ou alternativas com diferentes graus de risco e incerteza.

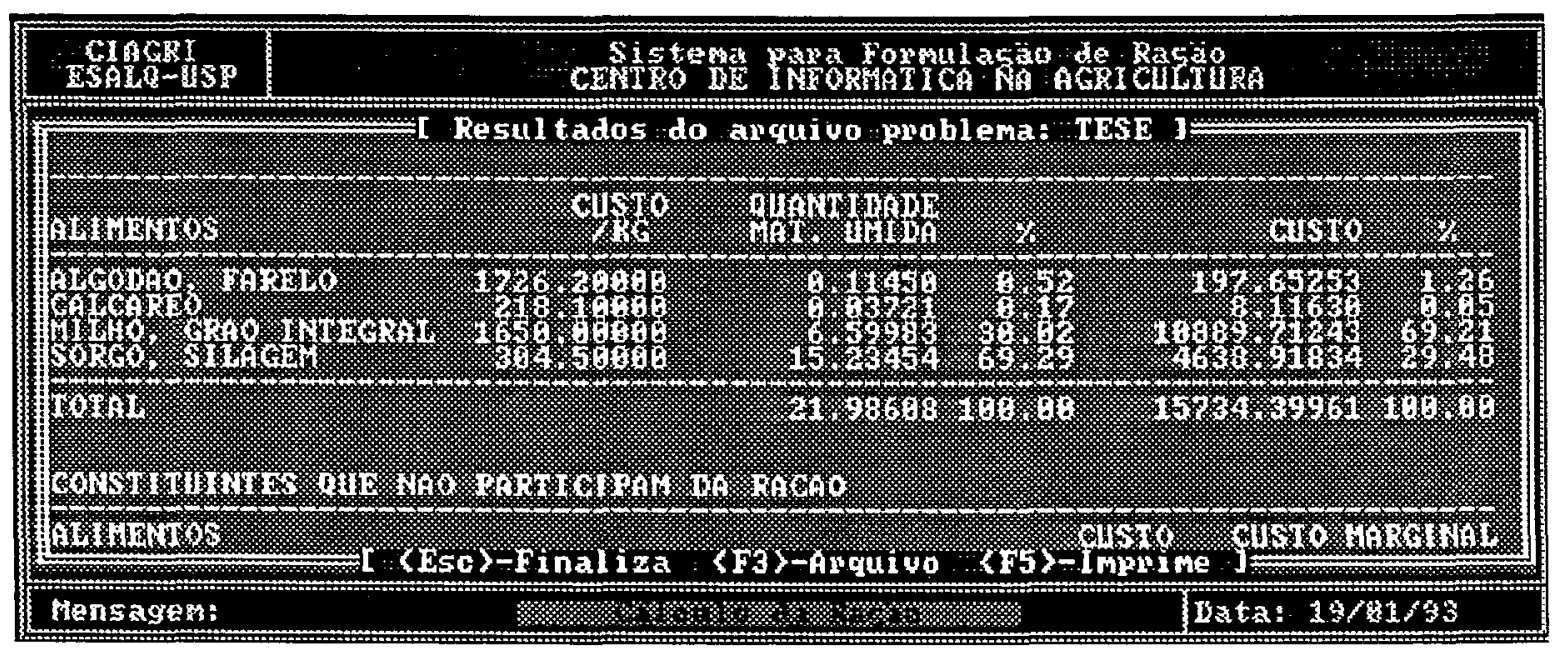

Figura 2.2 - Tela de resultados do software SFR - USP, CIAGRI

Em pesquisa realizada pela EMBRAPA ${ }^{1}$, buscando levantar o software disponível para Agropecuária no Brasil, dentro do universo de 102 títulos

1 - embrapa - CENTRO NACIONAL dE PESQUisa EM GADO DE LEITE. Comunicação Pessoal, 1990. 
recebidos pelas software houses, constatou-se que apenas 12 sistemas eram realmente específicos para agropecuária, 2 sistemas tratavam de bovinocultura de corte e 1 era específico para análise econômica de confinamento (apresentado na Figura 2.1).

O Departamento Nacional de Informática - DEPIN, órgão governamental brasileiro responsável pelo registro de comercialização de software no país conta atualmente com 25 títulos para agropecuária. Dentre esses, apenas dois relacionam-se à pecuária de corte: um aplica-se ao controle de rebanhos e outro serve para formulação de ração. Embora esses números não reflitam precisamente o número real de sistemas existentes, todavia, servem para dar uma idéia da situação em que se encontra a atividade no Brasil.

Não existe, portanto, um software adequado para ajudar o agricultor em sua tomada de decisão no confinamento de animais para engorda, que leve em consideração tanto aspectos econômicos como zootécnicos. Embora existam modelos mais ou menos sofisticados em alguns aspectos, eles não permitem aos agricultores decidir, a curto prazo, sobre qual a melhor maneira de investir seus recursos na atividade de confinamento. 


\section{OBJETIVOS}

O objetivo deste trabalho é proporcionar ao produtor rural subsídios que permitam maior eficácia ao processo de tomada de decisão na atividade de terminação de bovinos de corte sob o regime de confinamento. Será desenvolvido um modelo conceitual que permita ao confinador escolher alternativas ótimas para investimento de seus recursos na atividade sob risco, calculado a partir de estimativas de preços futuros do boi gordo. 0 modelo será implementado em um software que possibilitará sua aplicação prática em uma propriedade, podendo ser operado pelo próprio produtor. 


\section{METODOLOGIA}

4.1. Estimativas de ganho de peso do gado confinado sob diversas condicões nutricionais.

Os animais domésticos, quando submetidos a dietas alimentares controladas, apresentam diferentes níveis de desempenho em função da composição da dieta e/ou de fatores como herança genética, sanidade, estresse e muitas outras. Para os bovinos de corte em confinamento, o desempenho pode ser avaliado pelo ganho de peso obtido pelo animal em curto espaço de tempo e os principais fatores que podem afetar esse desempenho sob o ponto de vista do animal são o grau de estrutura corporal (GEC) e a condição corporal (CC). Em relação aos aspectos nutricionais, considera-se importante a ingestão de matéria seca e a composição alimentar da dieta em termos energéticos, protéicos e de minerais. O GEC representa a situação do animal no início do processo de alimentação, apontando seu potencial em termos de ganho de peso e influenciando diretamente o cálculo das necessidades nutricionais para que - ganho de peso seja obtido ao nível esperado. Maiores detalhes na determinação do GEC podem ser encontrados em BOIN (1992) e FOX et alii (1988). A condição corporal (CC) é um fator dependente da situação do 
animal durante o processo de ganho de peso, e deve ser avaliada dinamicamente enquanto ocorre a variação no peso do animal.

Uma vez determinado o GEC e o peso vivo, é possivel estimar o peso equivalente através dos coeficientes apresentados na Tabela 4.1, propostos por FOX et alli (1988). O conceito de peso equivalente permite o uso de uma única equação básica para estimar as exigências de energia para ganho de peso para animais de diferentes GEC e sexos.

Tabela 4.1. Coeficientes para conversão do peso vivo (PVj) em peso equivalente (PEq) para bovinos em crescimento com diferentes GEC.

Grau de Estrutura Corporal

\begin{tabular}{lrrrrrrrrr} 
Categoria & 1 & 2 & 3 & 4 & 5 & 6 & 7 & 8 & 9 \\
\hline Macho inteiro & 1,04 & 0,98 & 0,93 & 0,88 & 0,83 & 0,79 & 0,76 & 0,73 & 0,69 \\
Macho castrado & 1,25 & 1,19 & 1,13 & 1,06 & 1,00 & 0,95 & 0,91 & 0,87 & 0,83 \\
Novilha & 1,56 & 1,47 & 1,39 & 1,32 & 1,25 & 1,19 & 1,14 & 1,09 & 1,04 \\
\hline
\end{tabular}

Fonte: FOX et alii (1988).

A Tabela 4.2 contém coeficientes que serão utilizados para ajustar, de acordo com a composição corporal (CC), as diversas equações que estimam exigências e desempenho dos animais. Quando o peso equivalente se encontra entre as faixas especificadas, o cálculo dos coeficientes é realizado por interpolação linear entre os limites inferiores e superiores. 
Tabela 4.2. Coeficientes médios de ajuste para ingestão de matéria seca (CIMS), exigência de energia para mantença (CEM) e eficiência de utilização de energia para ganho de peso (CEGP) em função do peso equivalente (PEq).

Idade do início do confinamento

\begin{tabular}{cccccc}
\hline $\begin{array}{c}10-14 \\
\text { meses }\end{array}$ & $\begin{array}{c}15-24 \\
\text { meses }\end{array}$ & $\begin{array}{c}30-36 \\
\text { meses }\end{array}$ & CIMS & CEM & CEGP \\
\hline & peso equivalente & & & & \\
\hline Até 250 & Até 350 & Até 400 & 1,000 & 0,970 & 1,060 \\
$250-300$ & $350-400$ & $400-450$ & 1,000 & 0,980 & 1,040 \\
$300-350$ & $400-450$ & $450-500$ & 1,000 & 0,990 & 1,020 \\
$350-400$ & $450-500$ & $500-550$ & 0,970 & 1,000 & 1,000 \\
$400-450$ & $500-550$ & $550-600$ & 0,940 & 1,010 & 0,975 \\
$450-500$ & $550-600$ & $600-650$ & 0,830 & 1,020 & 0,950 \\
$500-550$ & $600-650$ & $650-700$ & 0,720 & 1,030 & 0,925 \\
$>550$ & $>650$ & $>750$ & 0,500 & 1,045 & 0,900 \\
\hline
\end{tabular}

Fonte: BOIN, comunicação pessoal.

\subsubsection{Energia fornecida}

A necessidade energética dos bovinos de corte pode ser dividida em energia para mantença (ELm) e energia para ganho de peso (ELg). Com base na porcentagem de nutrientes digestíveis totais da dieta (NDT) são estimadas as quantidades de energia por quilograma de matéria seca (MS) através das seguintes equações:

Energia Metabólica Total / kg MS:

[EM] (Mcal/kg MS) $=3,61 . \mathrm{NDT} / 100$

Energia Líquida de Mantença / kg MS:

$[\mathrm{Elm}](\mathrm{Mcal} / \mathrm{kg} \mathrm{MS})=0,0105 \cdot[\mathrm{EM}]^{3}-0,138 \cdot[\mathrm{EM}]^{2}+1,37 .[\mathrm{EM}]-1,12$ (4.2) 
Energia Líquida para Ganho de Peso / kg MS:

[Elg] $(\mathrm{Mcal} / \mathrm{kg} \mathrm{MS})=0,0122 \cdot[\mathrm{EM}]^{3}-0,174 \cdot[\mathrm{EM}]^{2}+1,42 \cdot[\mathrm{EM}]-1,65$

\subsubsection{Energia para mantenca}

A necessidade de energia para mantença do animal é estimada, segundo o NRC (1984) pela equação:

ELm (Mcal/dia) $=0,077 \cdot P V_{j}^{0,75}$

calculada em Mcal/dia, onde $P V_{j}$ representa o peso vivo do animal em jejum. Em função de outros fatores que afetam as exigências, BOIN (1992) propõe o ajuste da equação com a inclusão de dois outros fatores:

$$
\text { ELm (Mcal/dia) }=0,077 \cdot P_{j}^{0,75} \cdot \text { FR. CEM }
$$

onde FR é o fator da raça, cujo valor é 0,89 para zebuínos e seus cruzamentos. O CEM é o coeficiente de ajuste para eficiência de utilização de energia para mantença para condição corporal, apresentado na Tabela 4.2

\subsubsection{Ingestão de matéria seca}

A ingestão voluntária de matéria seca é estimada pela equação:

IMS $(\mathrm{kg} / \mathrm{dia})=P V 0,75 \cdot\left(-0,046 \cdot[E l m]^{2}+0,1493 \cdot[E I m]-0,0196\right) \cdot 0,94 . ;$

$$
(1,0125+0,05 . \text { Idade })
$$


sendo a idade fornecida em anos.

\subsubsection{Energia para ganho de peso}

Subtraindo-se a quantidade de matéria seca necessária para suprir a energia de mantença do total de matéria seca ingerido, é possível estimar a energia líquida total para ganho de peso (Elg), através da seguinte equação:

$$
\operatorname{ELg}(\mathrm{Mcal} / \mathrm{dia})=(\mathrm{IMS}-(\mathrm{Elm} /[\mathrm{ELm}]) \cdot[\mathrm{Elg}] . \text { CEGP }
$$

onde CEGP é o coeficiente de eficiência de utilização de energia para ganho de peso (Tabela 4.2).

4.1.5. Ganho de Peso em funcão da energia líquida para ganho (Elg)

Em função da disponibilidade de energia para ganho (Elg) e do peso vivo $\left(P V_{j}\right)$ do animal, é estimado o ganho de peso diário, de acordo com a equação a seguir:

$$
\mathrm{GPV}_{\mathrm{j}}(\mathrm{kg} / \mathrm{dia})=15,54 \cdot \mathrm{Elg}^{0,9116} \cdot \mathrm{PVj}^{-0,6837} \cdot 0,958
$$

\subsubsection{Exigência de proteína bruta}

A necessidade diária de proteína bruta é calculada em função da ingestão de matéria seca (IMS), peso vivo (PVj) e ganho de peso vivo (GPV) de acordo com a seguinte equação:

$$
\begin{aligned}
\mathrm{PB}(\mathrm{g} / \mathrm{dia}) & =(33,4 . \mathrm{IMS}+2,75 . \mathrm{PVj} .0,5+0,2 . \mathrm{PVj} \cdot 0,6+; \\
& (268-29,4 . \mathrm{ELg} / \mathrm{GPV}) . \mathrm{GPV}) / 0,5940
\end{aligned}
$$


Dividindo-se (4.9) pela ingestão de matéria seca, obtém-se a necessidade de proteína bruta como porcentagem na ração ([P]):

$[P B](\%)=P B /(I M S .10)$

\subsubsection{Exigência de cálcio}

A necessidade diária de cálcio (Ca) é calculada em função da ingestão de matéria seca (IMS), peso vivo (PVj) e ganho de peso vivo (GPV) de acordo com a seguinte equação:

$\mathrm{Ca}(\mathrm{g} / \mathrm{dia})=2 \cdot(0,0154 \cdot \mathrm{PVj}+0,071 \cdot(268-29,4 \cdot \mathrm{ELg} / \mathrm{GPV}) . \mathrm{GPV})(4.10)$

Dividindo-se (4.10) pela ingestão de matéria seca, obtém-se a necessidade de cálcio como porcentagem na ração ([P]):

[Ca] $(\%)=\mathrm{Ca} /($ IMS.10)

\subsubsection{Exigência de fósforo}

A necessidade diária de Fósforo $(P)$ é calculada em função da ingestão $=$-. de matéria seca (IMS), peso vivo (PVj) e ganho de peso vivo (GPV) de acordo com a seguinte equação:

$P(g / d i a)=(0,028 . P V j+0,039 .(268-29,4 . E L g / G P V) . G P V) / 0,85$ 
Dividindo-se 4.11 pela ingestão de matéria seca, obtém-se a necessidade de Fósforo como porcentagem na ração ([P]):

$[P](\%)=P /(I M S .10)$

4.2. Estimativas de preco do boi gordo baseadas no preco do boi magro a determinados niveis de confianca.

Previsões de preços no mercado agrícola brasileiro são objetos de grandes discussões nos meios acadêmicos. Devido à natureza incerta do mercado, mesmos os modelos matemáticos mais sofisticados, que utilizam exaustivos cáiculos computacionais, são, em geral, menos eficientes que previsões obtidas na Bolsa de Mercadorias, como aconteceu com KASSOUF (1988), o que todavia, não inviabiliza a utilização destes modelos.

A eficiência de previsões em Bolsas de Mercadorias poderia ser justificada pelo fato de que é tão mais fácil prever um preço futuro quanto mais próximo esse futuro se encontra, ou em outras palavras, o risco de uma previsão errada aumenta em função da antecipação com que essa previsão é realizada.

Tratando-se o confinamento de uma atividade realizada em horizontes de tempo relativamente curtos, em média de 3 a 6 meses e, considerandose o fato de que, no momento de tomar a decisão sobre a estratégia a ser adotada para confinar, é conhecido o preço do boi magro no mês $t\left(M_{t}\right)$, torna-se mais simples estimar o preço do boi gordo $\left(G_{(t+m)}\right)$, onde $m$ indica o número de meses que o animal ficará confinado, observando-se os valores históricos das relações: 


$$
R_{n}(\mathrm{t}, \mathrm{m})=G_{n}(\mathrm{t}+\mathrm{m}) / M_{n}(\mathrm{t})
$$

para os $n$ anos que se dispõe de informações. Os valores de $G_{n}(t+m)$ e $M_{n}(t)$ são previamente divididos por um deflacionador, que no presente caso pode ser o dólar oficial ou o Índice Geral de Preços - Disponibilidade Interna (IGP-DI) da Fundação Getúlio Vargas - São Paulo.

Dispondo os valores de $R_{t, m}$ para os $N$ anos passados em ordem crescente, é possível determinar uma função empírica de distribuição probabilística que estima a função de distribuição de $R_{t, m}$

$$
F_{t, m}\left(r_{t, m}\right)=\mathrm{P}\left\{R_{t, m} \leq r_{t, m}\right\}
$$

Quando se deseja o valor da relação mínima de preços, a um dado nível de probabilidade de ocorrência, recorre-se ao processo inverso, ou seja, localiza-se o valor $F_{R_{t, m}}\left(r_{t, m}\right)$ que está na posição (n/N = probabilidade) no "ranking".

Se o valor $\mathrm{n} / \mathrm{N}$ não for exatamente aquele que se deseja, então é feita uma interpolação linear entre os valores de $R_{t, m}$ que determinam os limites inferior e superior do intervalo onde se encontra a probabilidade $n / N$. (Figura 4.1). 


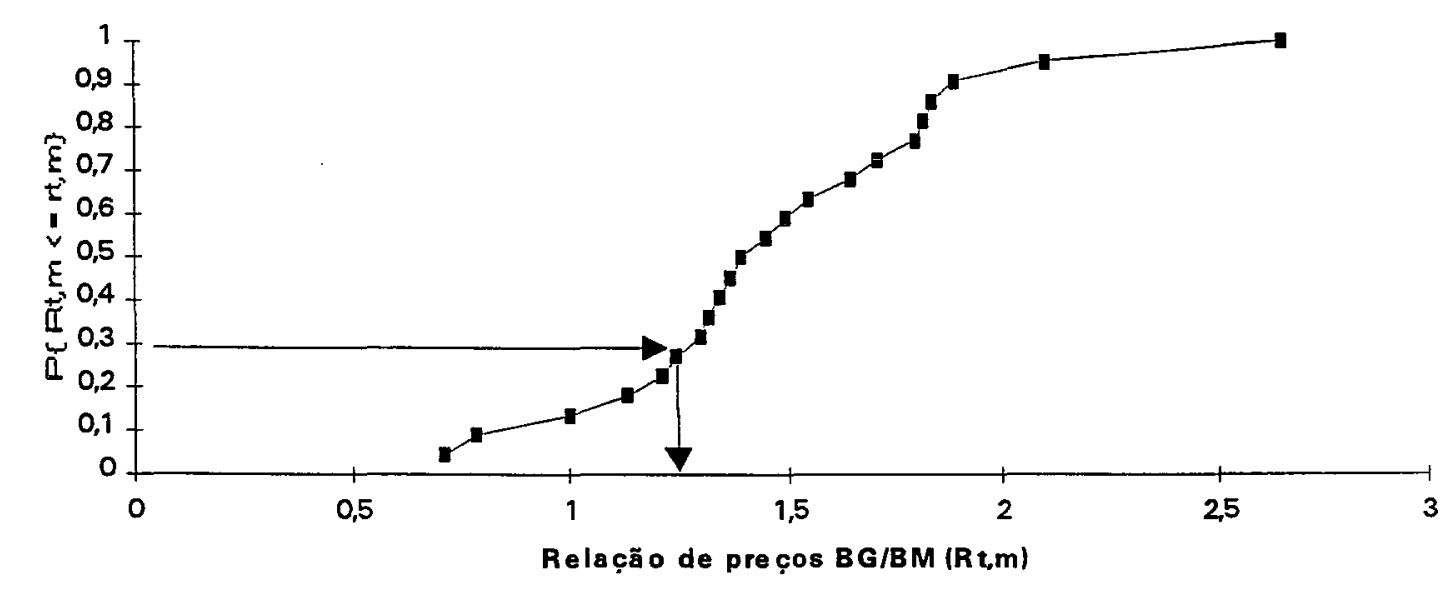

Figura 4.1. Função empírica de distribuição probabilística de $R_{t, m}$.

Através deste método pode-se estimar, baseando-se em posições históricas, os preços mínimos esperados para o boi gordo para os próximos meses, a um dado nível de confiança (Figura 4.2). Evita-se, dessa forma, grandes interferências que poderiam ser provocadas por variações plurianuais ou por deficiências quanto à eficácia dos índices deflacionadores dos preços, já que estes índices serão utilizados para deflacionar preços que se encontram bastante próximos entre si em relação ao fator tempo. 
Preço boi gordo/pre ço boi magro

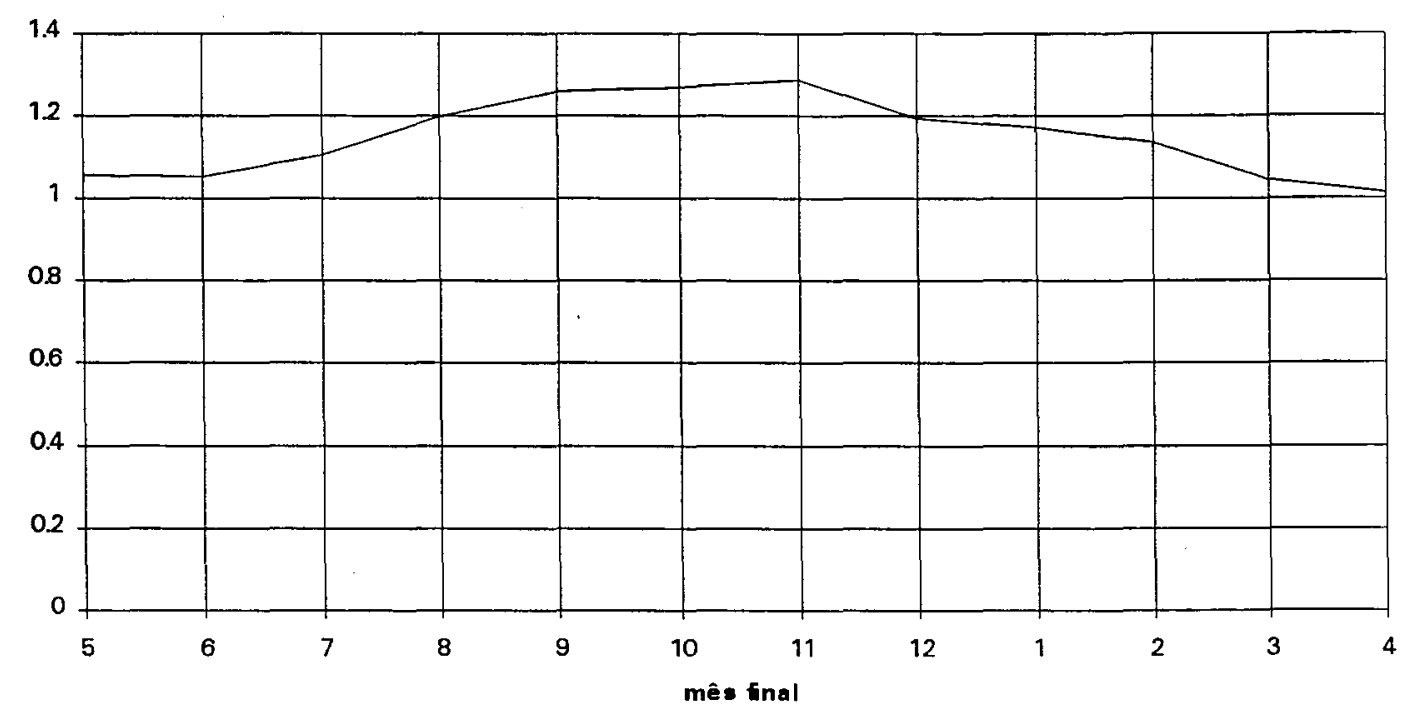

Figura 4.2. Exemplo de relações mínimas esperadas entre o preços do boi gordo/boi magro para os meses seguintes, em função do preço atual do boi magro (mês 5) a um dado nível de probabilidade de ocorrência.

Outra possibilidade oferecida pelo modelo é a possibilidade de que o usuário forneça os preços previstos para os próximos meses diretamente ao Sistema, baseando-se em critérios próprios, sejam eles subjetivos ou que obedeçam a qualquer outra metodologia de cálculo.

\subsection{Descrição do modelo}

O diagrama geral de fluxo de dados do Sistema é apresentado na Figura 4.3. São colocados em retângulos os dados externos ao Sistema, sendo que retângulos de linha delgada representam os dados que devem ser inseridos pelo usuário e os de linha espessa são dados de saída do Sistema. Os processos são representados através de caixas com borda arredondada e 
numerados de 1 a 5 . As setas mostram os fluxos dos dados, alguns dos quais são gerados e utilizados pelo próprio Sistema. As barras duplas representam arquivos de dados internos ao Sistema mas que também podem, eventualmente, ser alterados pelo usuário. Em seguida, é feita uma descrição resumida de cada um dos processos e de seus dados de entrada e saída.

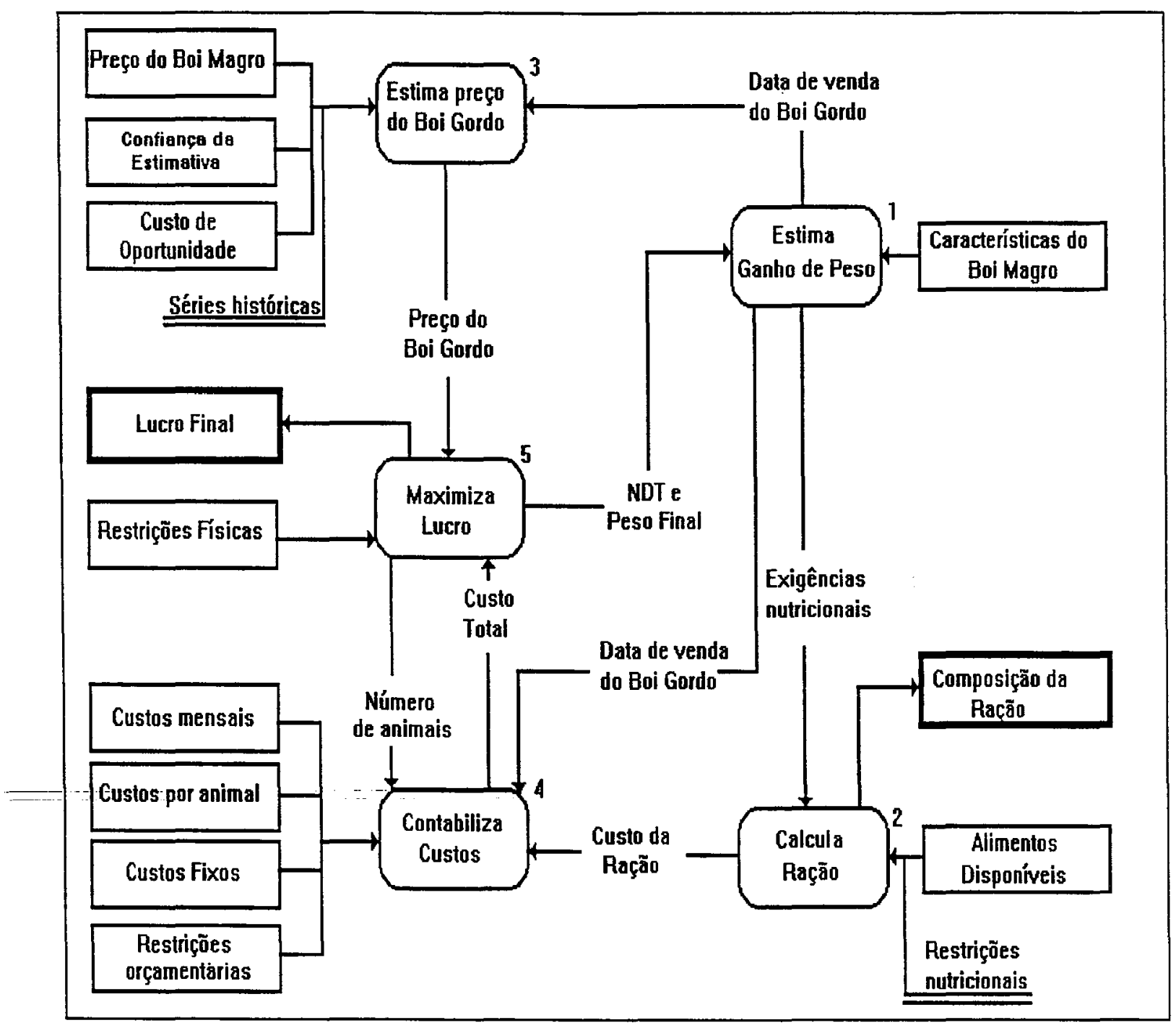

Figura 4.3 - Diagrama geral do Sistema ADECONF. 


\subsubsection{Processo 1: Estima ganho de Peso}

Calcula dinamicamente o ganho de peso diário dos animais (em $\mathrm{kg} / \mathrm{dia}$ ) durante o período de confinamento através das equações apresentadas no item 4.1. Em função do ganho de peso estimado é realizada a previsão do tempo necessário para que seja atingido o peso final (Data de Venda do Boi Gordo).

Dados de entrada:

Características do Boi Magro - Fatores que influem no desempenho do animal (ver item 4.1) como idade (em anos), peso (em arrobas), grau de estrutura corporal (1 a 9), rendimento da carcaça (em porcentagem sobre o peso vivo) e categoria, que pode ser macho inteiro (1), macho castrado (2) ou novilha (3).

NDT - Nutrientes Digestíveis Totais, representa a energia existente na ração. É o ponto de partida para uma seqüência de equações que permite uma estimativa dinâmica do ganho de peso do animal. Esse dado é gerado pelo processo 5 (Maximiza Lucro) durante a otimização.

Peso Final - Expresso em $\mathrm{kg}$ de peso vivo, juntamente com a estimativa de ganho de peso, serve para estimar o Prazo para Engorda. É gerado pelo processo 5 durante a otimização.

Dados de saída:

Data de Venda do Boi Gordo - Data provável para término do confinamento e venda dos animais gordos. Calculada em função do período 
necessário para que seja atingido o Peso Final a um determinado ganho de peso. É repassada aos processos 3 (Estima Preço do Boi Gordo) e 4 (Contabiliza Custos).

\subsubsection{Processo 2: Calcula Racão}

Descrição: Efetua o cálculo das quantidades relativas de cada alimento, com base em matéria seca e matéria original a serem oferecidas ao animal durante o período de confinamento visando atender às exigências determinadas pelo processo 1 (Estima Ganho de Peso) e adequando-se às restrições nutricionais impostas pela ingestão voluntária de matéria seca e palatabilidade da ração.

\section{Dados de entrada:}

Alimentos Disponíveis - Preços e composição nutricional (NDT, proteína bruta, cálcio, fósforo e porcentagem de matéria seca) de todos os alimentos disponiveis.

Exigências Nutricionais - Quantidades de matéria seca, NDT, proteína bruta, cálcio e fósforo para que seja atingido o ganho de peso calculado pelo processo 1 (Estima Ganho de Peso).

\section{Dados de saída:}

Custo da Ração - Custo total de alimentação para o lote de animais durante o período de confinamento.

Composição da Ração - Quantidades relativas de cada alimento na ração em base seca e de matéria original. 


\subsubsection{Processo 3: Estima Preco do Boi Gordo}

Descrição: Calcula a estimativa para os próximos doze meses do Preço do Boi Gordo a um dado nível de probabilidade baseando-se em séries históricas de preços deflacionadas como descrito no item 4.2.

Dados de entrada:

Preço do Boi Magro - Deve ser informado o preço e o peso do animal no mês de início do confinamento.

Confiança de Estimativa - Probabilidade admitida de que o preço real do boi gordo seja maior que o estimado pelo sistema, no momento de venda dos animais. (ver item 4.2).

Custo de Oportunidade - Taxa mensal de desconto para o preço futuro do boi gordo a ser estimado.

Data de Venda do Boi Gordo

Vide processo 1 (Estima Ganho de Peso).

Dados de saída:

Preço do Boi Gordo - Valor estimado do preço do boi gordo na Data de Venda do Boi Gordo. 


\subsubsection{Processo 4: Contabiliza Custos}

Descrição: Calcula todos os custos envolvidos na atividade sejam eles fornecidos pelo usuário ou estimados pelo Sistema.

\section{Dados de entrada:}

Custos Mensais - São todos os custos que variam em função do tempo de confinamento como por exemplo, Assistência Técnica e Mão-de-obra.

Custos por Animal - São os custos que variam em função do número de animais confinados como por exemplo, Vacinas e Medicamentos.

Custos Fixos - Independem do tempo ou da quantidade de animais, como por exemplo, Seguros e Depreciação Anual de Instalações.

Restrições Orçamentárias - Montante de capital disponivel para investir no confinamento.

Custo da Ração - Calculado pelo processo 2 (Calcula Ração).

Data de Venda do Boi Gordo - Vide Processo 1 (Estima Ganho de Peso). É aqui utilizado para cálculo dos Custos Mensais.

Número de animais - Fornecido pelo processo 5 (Maximiza Lucro) durante a otimização. É utilizado para cálculo do Custos por Animal.

Dados de saída:

Custo Total - Somatório de todos os custos envolvidos. 


\subsubsection{Processo 5: Maximiza Lucro}

Descrição: Estima, através do método descrito no item 4.4, o maior lucro possivel pela interação com os processos 1, 2, 3 e 4 gerando valores para as variáveis NDT, Peso Final e Número de Animais.

Dados de entrada:

Restrições Físicas - Número máximo de animais que podem ser confinados nas instalações disponiveis.

Preço do Boi Gordo - Descrito no processo 3 (Estima Preço do Boi Gordo).

Custo Total

Descrito no processo 4 (Contabiliza Custos)

Dados de saída:

NDT - Nutrientes Digestivos Totais, descrito no processo 1.

Peso Final - Gerado dentro deste processo. É o peso final esperado para o boi gordo.

Número de Animais - Total de animais confinados. Não são considerados animais mortos durante o confinamento.

Lucro Final - Receitas com vendas dos animais com peso e preços esperados menos Custo Total. É maximizado pelo modelo durante a otimização. 


\subsection{Implementacão do modelo}

A programação matemática é um conjunto de técnicas direcionadas para encontrar soluções ótimas para os problemas. Suas aplicações normalmente são voltadas para alocação de recursos escassos em modelos que na verdade são sub-problemas abstraídos de grandes problemas. Seguese então que as soluções encontradas são na realidade "quasi-ótimas" dentro do contexto global, aproximando-se cada vez mais da realidade quanto melhores forem os modelos que procuram representar essa realidade. A natureza biológica da engorda de bovinos leva à formulação de modelos onde nem sempre há linearidade entre a causa e o efeito, direcionando a solução do problema a modelos de programação não-linear, diferentes daqueles normalmente utilizados quando se deseja simplesmente a formulação de uma ração de custo mínimo.

A disponibilidade de software para programação não-linear não é tão grande como para a programação linear. Como exemplos de programas genéricos para essa aplicação, pode-se citar o MINOS, GAMS e EXCEL 4.0, este último escolhido para a implementação, por apresentar bastante flexibilidade quanto à montagem das diversas equações que compõem o modelo e servir de front-end, através de uma interface gráfica - sob ambiente WINDOWS operando em microcomputadores - ao usuário final do Sistema. Apresenta também vantagens tanto no modo de apresentação dos resultados na tela como em impressora, seja de maneira textual ou gráfica e facilidade para realizar cálculos estatísticos necessários ao modelo como percentis e percentis inversos. 
O método utilizado pelo EXCEL 4.0 é o do vetor gradiente, o qual encontra soluções para os problemas através do cálculo de derivadas parciais da função objetivo em relação a todas as variáveis, a partir do ponto de origem. Os valores das variáveis parciais são dispostos em forma de um vetor, escolhendo-se, sucessivamente, a mudança no valor do ponto que causa maior variação na função objetivo. Maiores detalhes sobre a teoria do método de vetor gradiente podem ser encontrados em McMILLAN (1970).

O EXCEL é uma planilha eletrônica composta por "células", que são intersecções entre suas linhas e colunas. Através do uso de fórmulas e funções, que o programa possui internamente, são construídas uma ou mais planilhas, informando-se ao programa que célula deve ser otimizada (maximizada, minimizada ou igualada a determinado valor), quais são as variáveis (células que podem ser alteradas pelo sistema de otimização) e quais as células que compõem as restrições (vide Figura 4.4). Maiores informações sobre o funcionamento do Solver do EXCEL podem ser encontradas em MICROSOFT (1992b).

Para implementação do modelo foram criadas duas planilhas que trabalham integradas. Uma delas (INDPAR.XLS) é utilizada apenas para o processo 3 (Estima Preço do Boi Gordo) e a outra (ADECONF.XLS) para os demais processos. O usuário pode alterar apenas algumas células das planilhas, deixando-se todo o restante na forma protegida de modo a evitar prováveis erros de entrada de dados em células que contém fórmulas, o que poderia comprometer a confiabilidade dos cálculos. A apresentação do Sistema implementado é feita no Capítulo 5, juntamente com os resultados. 


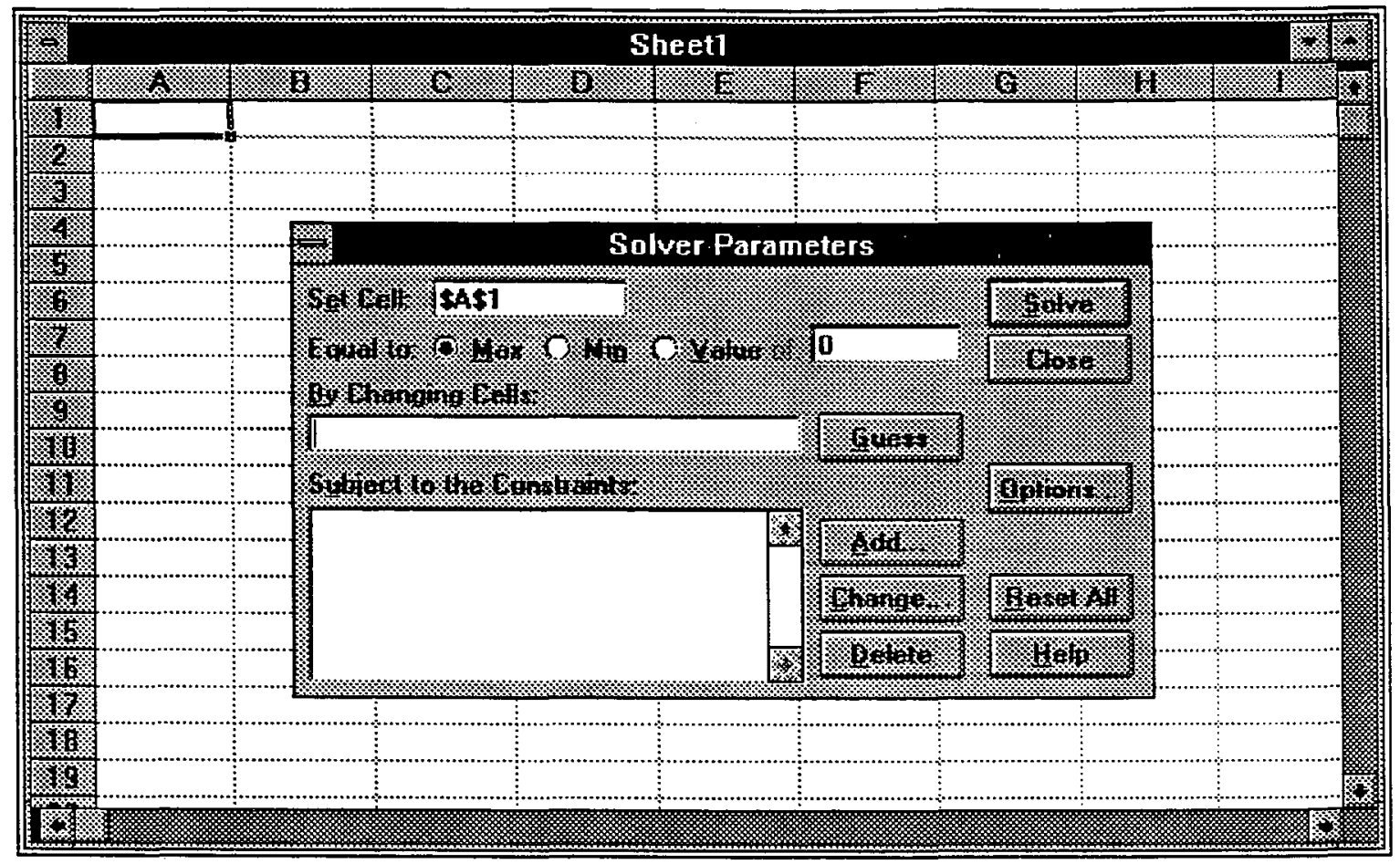

Figura 4.4 - Janela do "Solver" do Microsoft Excel 4.0

\subsection{Estudo de um caso hipotético}

Para efeito de avaliação do modelo serão simuladas situações de confinamento com animais geralmente utilizados nessa atividade, com idade de 18 meses e 11,5 arrobas, equivalente a $332 \mathrm{~kg}$ de peso vivo, para um rendimento de carcaça de $52 \%$. Os animais são machos castrados com grau

-- de estrutura corporal igual a 5. São projetadas situações com o início do confinamento em maio e junho, conforme a Tabela 4.3. Considera-se que a capacidade física das instalações comporta até 200 animais. 
Tabela 4.3. Características dos animais utilizados nos casos simulados.

\begin{tabular}{lrr}
\hline Característica & CASO A - Maio & CASO B - Junho \\
\hline Peso (@) & 11,5 & 11,5 \\
Rendimento da carcaça & $52 \%$ & $52 \%$ \\
Preço do animal (US\$) & 232,36 & 223,34 \\
Mês de aquisição & 5 & 6 \\
Idade (anos) & 1,5 & 1,5 \\
Grau de Estrutura Corporal & 5 & 5 \\
Categoria 1 & 2 & 2 \\
\hline
\end{tabular}

Fonte: Dados para simulação

1 Categoria 1-macho inteiro, 2-macho castrado e 3-novilha

Os preços dos bois magros foram calculados com base nos preços de maio e junho de 1992 (CEPEA/FEALQ) de US\$242,46 e US\$233,05 respectivamente, para um animal de 12 arrobas, convertidos para o peso de 11,5 arrobas. Os preços dos ingredientes para ração e de outros insumos, apresentados na Tabela 4.4, foram levantados para os meses de maio e junho de 1992 através de consulta a fornecedores de matéria-prima. Para milho e alguns volumosos (capim napier, feno de gramínea e silagens), foi realizado um levantamento de custos de produção das culturas. Embora não representem obrigatoriamente médias da região, os preços considerados tem apenas o objetivo de servir de exemplo para a simulação. As despesas com manutenção das instalações foram extraídas de PERES (1990); as de mão-de-obra e operação de máquinas foram levantadas de um confinamento de porte equivalente ao simulado e são apresentadas na Tabela 4.5. 
Tabela 4.4. Preços de ingredientes para ração utilizados nos casos simulados (US\$/ton matéria original).

\begin{tabular}{|c|c|c|}
\hline & MAIO/92 & JUNHO/92 \\
\hline \multicolumn{3}{|l|}{ Alimentos Volumosos } \\
\hline BAGAÇO HIDROLISADO $^{\top}$ & 8,92 & 9,09 \\
\hline CAMA DE FRANGO ${ }^{1}$ & 18,86 & 18,86 \\
\hline CANA DE ACÚCAR ${ }^{1}$ & 8,92 & 9,09 \\
\hline CAPIM NAPIER, 60 DIAS $^{2}$ & 5,40 & 5,40 \\
\hline GRAMINEA, FENO (MÉDIO) ${ }^{2}$ & 82,11 & 82,11 \\
\hline MILHO, SILAGEM ${ }^{2}$ & 23,02 & 23,02 \\
\hline NAPIER, SILAGEM ${ }^{2}$ & 8,71 & 8,71 \\
\hline SORGO, SILAGEM ${ }^{2}$ & 20,30 & 20,30 \\
\hline \multicolumn{3}{|l|}{ Alimentos Concentrados } \\
\hline ALGODÃO, FARELO (MIN $30 \%)^{\top}$ & 83,45 & 92,06 \\
\hline ALGODÃO, FARELO (MIN $40 \%)^{1}$ & 104,32 & 115,08 \\
\hline ALGODÃO, SEMENTE ${ }^{1}$ & 70,00 & 70,00 \\
\hline CALCÁREO CALCITICO ${ }^{1}$ & 15,97 & 14,54 \\
\hline FOSFATO BICÁLCICO ${ }^{1}$ & 166,67 & 166,67 \\
\hline LEVEDURA DESIDRATADA ${ }^{1}$ & 164,34 & 164,34 \\
\hline MELAC̣O DE CANA ${ }^{1}$ & 141,44 & 141,44 \\
\hline MILHO, GRĀO MOÍDO2 & 118,19 & 118,19 \\
\hline MILHO ROLÃO 2 & 88,65 & 88,65 \\
\hline SAL MINERAL 1 & 332,44 & 332,44 \\
\hline SOJA, FARELO $45 \% 1$ & 202,06 & 220,22 \\
\hline TRIGO, FARELO ${ }^{1}$ & 61,20 & 68,70 \\
\hline URÉIA 1 & 270,72 & 253,97 \\
\hline
\end{tabular}

Fonte: ${ }^{1}$ Levantamento de preços.

2 Cálculo de custo de produção.

Täbèla 4.5. Outros custos considerados nos casos simulados.

\begin{tabular}{lrr}
\hline & Valor (US\$) & unidade \\
\hline Manutenção de instalações & \\
Mão-de-obra $^{2}$ & $1.325,00$ & confinamento \\
Máquinas e equipamentos $^{2}$ & 460,02 & por mês \\
Medicamentos $^{2}$ & 275,44 & por mês \\
\hline
\end{tabular}

Fonte: 1PERES, 1990.

${ }^{2}$ Entrevista com dono de confinamento. 
As previsões de preços para o boi gordo foram realizadas pelo próprio Sistema, segundo o método descrito no Capítulo 4, assumindo-se um grau de confiança de $70 \%$, ou seja, as relações preços boi gordo/boi magro estimadas (ou maiores) ocorreram em pelo menos $70 \%$ dos anos dentro do período 1970-92. Para deflacionar os preços no cálculo dessas relações em cada ano foi utilizado o IGP-DI (Índice Geral de Preços - Disponibilidade Interna) da Fundação Getúlio Vargas, cujos valores encontram-se no Apêndice. O peso mínimo considerado para o boi gordo foi de 16,5 arrobas $(476 \mathrm{~kg})$.

Em relação à disponibilidade de capital, considerou-se um limite de US\$100.000,00 para aplicação no confinamento e uma taxa de juros de $0,5 \%$ ao mês, que é utilizada para o cálculo do valor atual da receita proveniente da venda dos bois gordos.

Para formulação da ração foram considerados disponiveis ingredientes normalmente utilizados na região, assumindo-se a composição química e valor energético mostrados na Tabela 4.6. Além das exigências que são calculadas pelo próprio Sistema, devem também ser consideradas restrições quanto ao uso dos ingredientes, apontadas na Tabela 4.7. 
Tabela 4.6. Composição química e valor energético dos ingredientes utilizados no cálculo de ração.

\begin{tabular}{|c|c|c|c|c|c|c|}
\hline \multirow[t]{2}{*}{ Descrição } & \multicolumn{6}{|c|}{ Composição (\% sobre M.S.)* } \\
\hline & MS & PB & $\mathrm{Ca}$ & $\mathrm{P}$ & $\mathrm{EE}$ & NDT \\
\hline \multicolumn{7}{|l|}{ Alimentos Volumosos } \\
\hline BAGACCO HIDROLISADO & 40,00 & 1,60 & 0,04 & 0,03 & 1,00 & 53,00 \\
\hline CAMA DE FRANGO & 75,00 & 20,00 & 3,16 & 1,72 & 3,00 & 55,00 \\
\hline CANA DE ACÚCAR & 28,00 & 2,50 & 0,22 & 0,06 & 1,00 & 60,00 \\
\hline CAPIM NAPIER, 60 DIAS & 20,00 & 8,80 & 0,82 & 0,22 & 2,50 & 58,00 \\
\hline GRAMINEA, FENO (MÉDIO) & 88,00 & 6,50 & 0,35 & 0,18 & 2,20 & 52,00 \\
\hline MILHO, SILAGEM & 33,00 & 7,00 & 0,28 & 0,22 & 3,10 & 68,00 \\
\hline NAPIER, SILAGEM & 20,00 & 8,50 & 0,80 & 0.20 & 2,80 & 58,00 \\
\hline SORGO, SILAGEM & 30,00 & 6,00 & 0,35 & 0,21 & 2,80 & 60,00 \\
\hline \multicolumn{7}{|l|}{ Alimentos Concentrados } \\
\hline ALGODÃO, FARELO (MIN 30\%) & 92,00 & 33,00 & 0,19 & 1,00 & 1,60 & 62,00 \\
\hline ALGODÃO, FARELO (MIN 40\%) & 92,00 & 44,00 & 0,22 & 1,21 & 1,60 & 74,00 \\
\hline ALGODÃO, SEMENTE & 92,00 & 23,90 & 0,16 & 0,75 & 23,10 & 96,00 \\
\hline CALCÁREO CALCÍTICO & 99,00 & 0,00 & 38,00 & 0,00 & 0,00 & 0,00 \\
\hline FOSFATO BICÁLCICO & 99,00 & 0,00 & 24,00 & 18,00 & 0,00 & 0,00 \\
\hline LEVEDURA DESIDRATADA & 90,00 & 30,00 & 0,12 & 0,83 & 1,20 & 80,00 \\
\hline MILHO, GRÃO MOÍDO & 88,00 & 9,90 & 0,02 & 0,29 & 4,20 & 90,00 \\
\hline MILHO ROLÃO & 88,00 & 8,00 & 0,04 & 0,29 & 3,50 & 74,00 \\
\hline SAL MINERAL & 99,00 & 0,00 & 0,00 & 4,00 & 0,00 & 0,00 \\
\hline SOJA, FARELO $45 \%$ & 88,22 & 50,83 & 0,36 & 0,75 & 1,50 & 85,00 \\
\hline TRIGO, FARELO & 88,00 & 17,10 & 0,13 & 1,38 & 4,80 & 70,00 \\
\hline URÉIA & 99,00 & 280,0 & 0,00 & 0,00 & 0,00 & 0,00 \\
\hline
\end{tabular}

Fonte: BOIN (1988).

* MS - matéria seca, - proteína bruta, Ca - cálcio, P - fósforo, EE - extrato etéreo, NDT - nutrientes digestíveis totais. 
Tabela 4.7. Exigências nutricionais e restrições adicionais necessárias para os ingredientes utilizados na formulação da ração.

\begin{tabular}{ll}
\hline PB máxima & $\leq$ Exigência de PB $+15 \%$ \\
Ca máximo & $\leq 1,5 \%$ da M.S. \\
Relação Ca / P máxima & $\leq 4$ \\
Relação Ca / P mínima & $\geq 1$ \\
Uréia + 0,0248.cama de frango & $\leq 1 \%$ da M.S. \\
Cama de frango máxima & $\leq 25 \%$ da M.S. \\
Cana-de-açúcar máxima & $\leq 75 \%$ do volumoso em base seca \\
Bagaço de cana máximo & $\leq 75 \%$ do volumoso em base seca \\
M.S. mínima & $\geq 40 \%$ da matéria original \\
Sal mineral total & $=0,5 \%$ M.S. \\
Volumoso mínimo & $\geq 25 \%$ (Volumoso total $-0,5$. cama de \\
& $\leq 10 \%$ da M.S. \\
Melaço máximo & $\leq 6 \%$ da M.S. \\
EE máximo &
\end{tabular}

Fonte: BOIN, comunicação pessoal.

Os dados levantados foram introduzidos no Sistema, efetuando-se os cálculos em um microcomputador IBM-PC compatível modelo 386-SX sob ambiente WINDOWS. Os resultados encontrados são apresentados no Capítulo 5. 


\section{RESULTADOS E DISCUSSÃO}

\subsection{Maximizacão do lucro.}

Efetuado o processamento dos dois casos, que levou, em média, cerca de 15 minutos cada um, obteve-se diferentes previsões de estratégias que maximizariam o resultado esperado dos projetos (os resultados completos estão no APÊNDICE). As telas principais que resumem a entrada e saída dos dados para cada um dos casos são apresentadas nas Figuras 5.1, para 0 caso $A$ e 5.2, para o caso B. Em sua seção esquerda, a tela mostra os dados que foram fornecidos pelo usuário, anteriormente descritos no capítulo 4. Na seção direita, encontram-se os parâmetros estimados pelo Sistema, dividindo-se em quatro partes: Boi Gordo, Previsão de Preços, Ração e Balanço Econômico. Em razão da estreita interação existente entre as variáveis do modelo, não é possível analisá-las separadamente. Por exemplo, um aumento no peso final pode refletir no ganho de peso, no preço e composição da ração, no prazo de engorda e assim por diante. Será então feita uma análise comparativa entre os dois casos, ressaltando-se os principais pontos.

No caso A foi estimado um peso final de $491 \mathrm{~kg} ; 15 \mathrm{~kg}$ a mais que o limite mínimo especificado. Isso indica que houve certa folga para a engorda 
no confinamento iniciado em maio, pois havia "flexibilidade" quanto ao mês do término (outubro ou novembro), deixando que a solução fosse direcionada mais pelos aspectos zootécnicos que em função do diferencial de preços entre esses dois meses. As relações de preços esperadas, a 70\% de confiança, neste caso, (Tabela 5.1), para outubro e novembro, foram, respectivamente, 1,2126 e 1,2131, apresentando uma diferença muito pequena nos preços previstos para esses dois meses, respectivamente US $\$ 24,50$ e US $\$ 24,51$. Isso fez com que o Sistema ajustasse o término do confinamento para o mês 10,1 (154 dias após o início). 


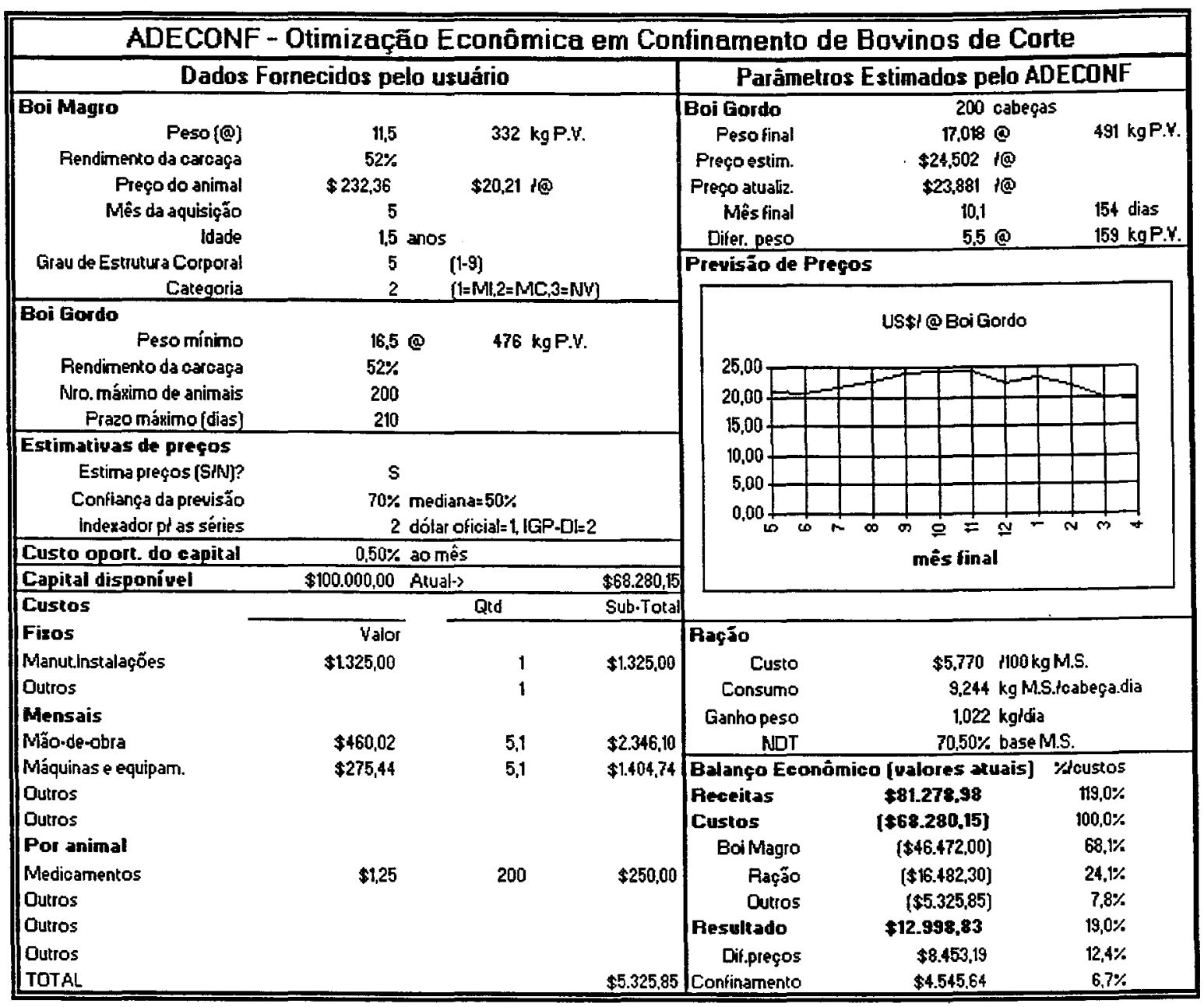

Figura 5.1. Tela principal do ADECONF para o caso A - Confinamento com início em maio/92. 


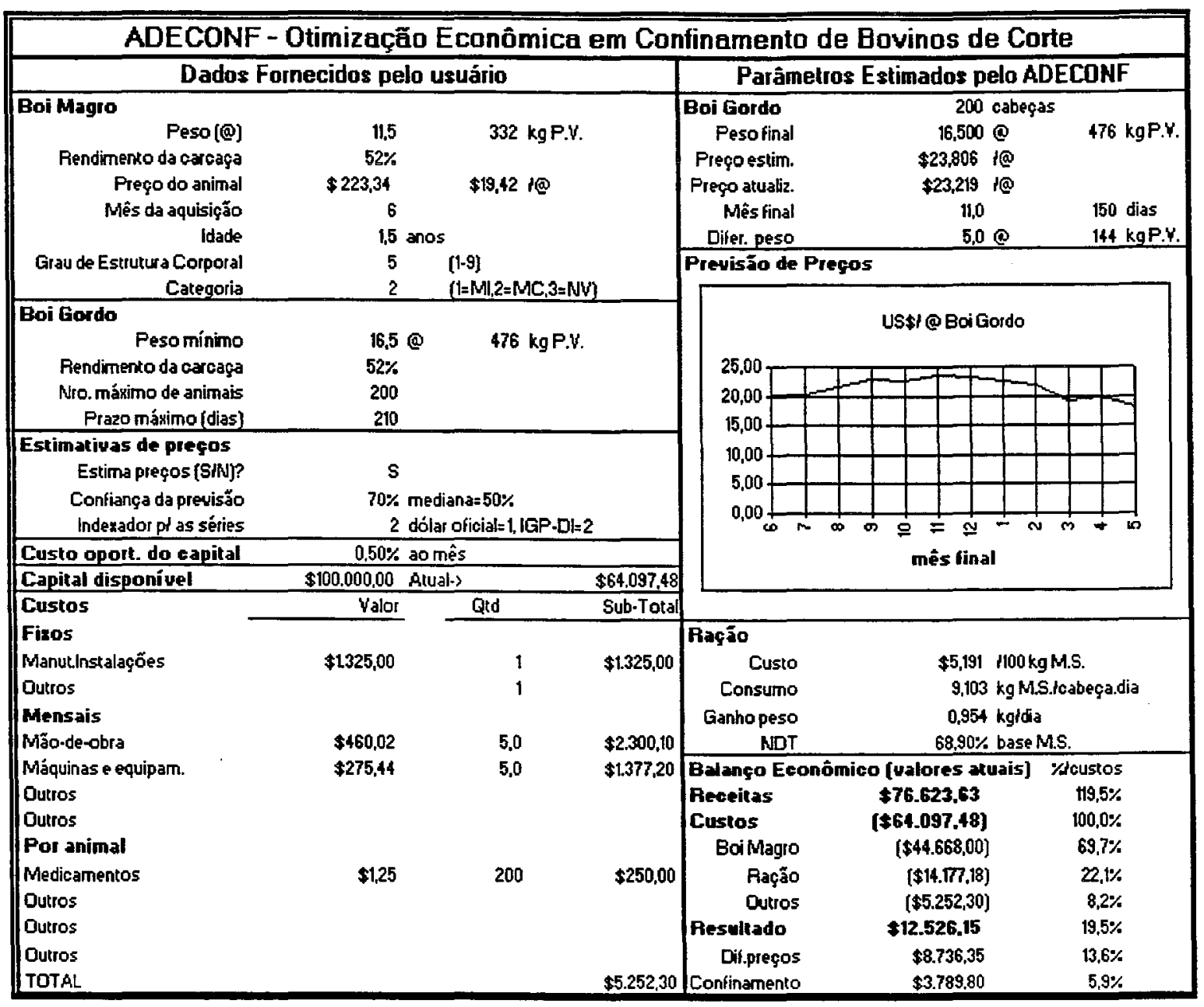

Figura 5.2. Tela principal do ADECONF para o caso B - Confinamento com início em junho/92.

No caso B, o peso final calculado ficou no limite mínimo estipulado de $476 \mathrm{~kg}(16,5$ arrobas) e o mês final foi precisamente 11,0 , onde a relação de preços esperada era a maior $(1,226)$, indicando um preço previsto de US\$ 23,81 por arroba. Em diversas simulações realizadas, iniciando o confinamento em maio/junho, na maioria dos casos, o Sistema apontou o término para o mês de relação de preços mais alta - normalmente outubro ou novembro. Esse fato indica que o diferencial de preços é um fator importante em relação a outros, como o custo de manutenção ou ganho de 
peso, ou mesmo, receitas extras, obtidas a partir de ganho de peso que compensassem a venda dos animais a preços mais baixos que o máximo previsto.

Tabela 5.1. Preços do boi gordo e relações mínimas previstas para os meses seguintes ao início do confinamento a $70 \%$ de confiança.

\begin{tabular}{rrrrrr}
\hline \multicolumn{2}{c}{ CASO A } & & \multicolumn{3}{c}{ CASO B } \\
\cline { 5 - 7 } mês final & US\$/@ & BG/BM & mês final & US\$/@ & BG/BM \\
\cline { 5 - 6 } 5 & 21,11 & 1,045 & 6 & 20,16 & 1,038 \\
6 & 20,61 & 1,020 & 7 & 20,30 & 1,045 \\
7 & 21,73 & 1,075 & 8 & 21,42 & 1,103 \\
8 & 22,17 & 1,097 & 9 & 22,90 & 1,179 \\
9 & 24,01 & 1,188 & 10 & 22,58 & 1,163 \\
10 & 24,50 & 1,213 & 11 & 23,81 & 1,226 \\
11 & 24,51 & 1,213 & 12 & 23,31 & 1,200 \\
12 & 22,31 & 1,104 & 1 & 22,67 & 1,167 \\
1 & 23,23 & 1,150 & 2 & 21,96 & 1,131 \\
2 & 21,85 & 1,081 & 3 & 19,31 & 0,994 \\
3 & 19,96 & 0,988 & 4 & 19,94 & 1,027 \\
4 & 19,43 & 0,962 & 5 & 18,33 & 0,944 \\
\hline
\end{tabular}

Fonte: Série histórica (1970-92) CEPEA/FEALO com preços deflacionados pelo IGP-DI.

$\mathrm{Na}$ modelagem de ganho de peso são feitos todos os cálculos que prevêem o ganho de peso, necessidades nutricionais e ingestão da ração. Esses parâmetros são estimados a partir do NDT e peso final, que tem seus valores gerados pelo próprio Sistema durante o processo de otimização. Para evitar a necessidade do cálculo integral nas funções que estimam esses parâmetros em relação ao tempo, processo que demandaria elevada capacidade computacional, procedeu-se a estratificação dessa variável em 11 classes fixas, calculando-se os totais e as médias de cada uma delas (Figuras 5.3 e 5.4). Esse número de categorias mostrou-se suficiente, 
apresentando resultados bastante próximos daqueles obtidos com a integração numérica das funções.

As médias de proteína, cálcio e fósforo são utilizadas, juntamente com o valor do NDT para o cálculo da ração. Para compensar o efeito do nível de ingestão na digestibilidade da ração, o NDT da ração deve ser em torno de $6 \%$ maior que o NDT calculado como necessário pois, de acordo com BOIN (1988), os dados de valor nutritivo dos ingredientes, baseados na composição bromatológica, são calculados a partir de ensaios de digestibilidade onde a ingestão de matéria seca é próxima ao nível de mantença ou pouco acima. Dessa forma tem-se: NDT ração $=$ NDT / 0,94.

\begin{tabular}{|c|c|c|c|c|c|c|c|c|c|c|c|c|c|c|c|c|c|}
\hline \multicolumn{18}{|c|}{ Modelagem do ganho de peso } \\
\hline & & tor jiustep & $\begin{array}{l}\text { TT Base: } \\
\text { soFinal: } \\
\text { Jra MS: }\end{array}$ & $\begin{array}{r}66,27 \% \\
491 \\
1,0000\end{array}$ & $\mathrm{~kg}$ & Rạ̧̧̃a: & $70,50 \%$ & & & & & & & & & & \\
\hline \multirow[t]{3}{*}{ Dias } & PW & PEquiv. & NDT & {$[E[M]$} & ELLm] & EELgl & MSS & ELm & ELg & GPV & NDT & PROT & $\mathrm{C}_{3}$ & $P$ & PROT & $\mathrm{Cs}$ & $P$ \\
\hline & $\mathrm{Kg}$ & $\mathrm{kg}$ & $\%$ & Malt & Moall & Meall & kgld & Moalld & Mcalld & Kold & Kold & gifd & gidd & gidd & $\%$ & $\%$ & $\%$ \\
\hline & & & & $\mathrm{KgMS}$ & KgMS & $\mathrm{KgMS}$ & & & & & & & & & & & \\
\hline & 331,731 & 331,731 & 86,265 & 2,392 & 1,511 & 0,918 & 8.023 & 5,167 & 4,481 & 1,105 & 5,32 & 938,16 & 33,54 & 18,4643 & 11,69 & 0,418 & 0,357 \\
\hline 14 & 347,648 & 347,648 & 66,265 & 2,392 & 1,511 & 0,918 & 8,310 & 5,352 & 4,642 & 1,105 & 5,51 & 950,15 & 33,36 & 18,7724 & 11,43 & 0,401 & 0,351 \\
\hline 29 & 363,564 & 363,564 & 66,265 & 2,392 & 1,511 & 0,918 & 8,594 & 5,606 & 4,642 & 1,071 & 5,69 & 953,81 & 32,59 & 18,8876 & 11,10 & 0,379 & 0,337 \\
\hline 44 & 379,481 & 1379,481 & 66,265 & 2,392 & 1,511 & 0,918 & 8.875 & 5,808 & 4,752 & 1,063 & 5,88 & 963,77 & 32,30 & 19,1598 & 10,86 & 0,364 & 0,330 \\
\hline 59 & 395,398 & 395,398 & 66,265 & 2,392 & 1,511 & 0,918 & 9,152 & 6,009 & 4,859 & 1,055 & 6,06 & 973,74 & 32,02 & 19,4376 & $10,64^{\circ}$ & 0,350 & 0,323 \\
\hline 74 & 411,315 & $5 \quad 41,315$ & 66,265 & 2,392 & 1,511 & 0,918 & 9,369 & 6,209 & 4,907 & 1,036 & 6,21 & 977,85 & 31,80 & 19,6656 & 10,43 & 0,337 & 0,317 \\
\hline 89 & 427,232 & 427,232 & 66,265 & 2,392 & L,511 & 0,918 & 9,547 & 6,409 & 4,918 & 1,0011 & 6,33 & 978,26 & 31,11 & 19,8748 & 10,25 & 0,326 & 0,310 \\
\hline 105 & 443,149 & 443,149 & 66,265 & 2,392 & 1,511 & 0,918 & 9,717 & 6,609 & 4,923 & 0,987 & 6.44 & 978,83 & 30,66 & 20,0959 & 10,07 & 0,316 & 0,304 \\
\hline 121 & 459,066 & 6459,066 & 66265 & 2,392 & 2511 & 0,918 & 9,880 & 6,807 & 4,916 & 0,962 & 6,55 & 979,23 & 30,24 & 20,3253 & 9,91 & 0,306 & 0,299 \\
\hline 138 & 174,982 & 2474,982 & 66,265 & 2,392 & 1,511 & 0,918 & 10,036 & 7,006 & 4899 & 0,937 & 6.65 & 979,48 & 29,85 & 20,5632 & 9.76 & 0,297 & 0,294 \\
\hline 154 & 490,888 & 9490,899 & 66,265 & 2,392 & 1,511 & 0,918 & 10,184 & 7,204 & 4,875 & 0,912 & 6,75 & 979,72 & 29.49 & 20,8128 & 9,62 & 0,290 & 0,289 \\
\hline Médias & 41,3 & 411,3 & 66,265 & 2,392 & 1,511 & 0,918 & 9,244 & 6,1988 & 4,8012 & 1,022 & 6,1258 & 968,44 & 31,52 & $19,64 \pi$ & 10,52 & 0,344 & 0,319 \\
\hline Totais & $\overline{159,2}$ & 159,2 & 10238,0 & 3416,6 & 2158,5 & 1311,4 & 1428,2 & 957,71 & 741,78 & 157,93 & 946,44 & 149623,23 & 4870,48 & 3034,65 & & & \\
\hline
\end{tabular}

Figura 5.3. Modelagem do ganho de peso para o confinamento com início em maio/92 (caso A). 
Em função dos resultados apresentados no processo de modelagem, são especificados os niveis de exigência nutricional e restrições alimentares, apresentados na Tabela 5.2. São também calculadas rações que atendam às exigências com custo mínimo. As rações calculadas para os dois casos foram relativamente semelhantes, com NDT de $70,50 \%$ para o caso $A$ e $68,90 \%$ para o caso B. Seus custos foram de US\$5,770 e US\$5,211 por 100 quilogramas de MS, respectivamente. A energia da ração é diretamente relacionada ao ganho de peso proporcionado. Nos caso $A, 0$ ganho de peso foi maior $(1,022 \mathrm{~kg} / \mathrm{dia})$, atingindo um peso final maior que no caso B, em espaços de tempo semelhantes. A composição e os custos totais das rações calculadas para os dois casos encontram-se na Tabela $\mathbf{5 . 3}$ e 5.4 .

\begin{tabular}{|c|c|c|c|c|c|c|c|c|c|c|c|c|c|c|c|c|c|}
\hline \multicolumn{18}{|c|}{ Modelagem do ganho de peso } \\
\hline & & Nor ajustep & $\begin{array}{l}\text { IT Base: } \\
\text { so Final: } \\
\text { aralMS: }\end{array}$ & $\begin{array}{r}64.76 \% \\
476 \\
10000\end{array}$ & NDT & Raçäo: & $68,90 \%$ & & & & & & & & & & \\
\hline \multirow[t]{3}{*}{ Dias } & PV & PEquiv. & MDT & [EM] & [ELm] & [Elg] & MSS & ELm & ELg & GPY & NDT & PROT & $\mathrm{Ca}$ & $\mathrm{P}$ & PROT & $\mathrm{Ca}$ & $P$ \\
\hline & $\mathrm{Kg}$ & $\mathrm{kg}$ & $\%$ & Meall & Mcall & Mcall & kgld & Mealld & Mcalld & Kgid & Kgld & gld & $\mathrm{g} / \mathrm{d}$ & gld & $\%$ & $\%$ & $\%$ \\
\hline & & & & KaMS & Kalys & Kolvs & & & & & & & & & & & \\
\hline & 331,731 & 1331,731 & 64,762 & 2,338 & 1,463 & 0,875 & 7,975 & 5,187 & 4,119 & 1,023 & 5.16 & 913,51 & 31,95 & 17,9486 & 11,45 & 0,401 & 0,347 \\
\hline H & 346,154 & 346,154 & 64,762 & 2,338 & 1,463 & 0,875 & 8,234 & 5,335 & 4,253 & 1,023 & 5,33 & 924,94 & 31,83 & 18.2435 & 11,23 & 0,387 & 0,342 \\
\hline 28 & 360,577 & 360,577 & 64,762 & 2,338 & 1,463 & 0,875 & 8,490 & 5.568 & 4,245 & 0,993 & 5,50 & 928,77 & 31,17 & 18,3620 & 10,94 & 0,367 & 0,330 \\
\hline 43 & 375,000 & 375,000 & 64,762 & 2,338 & 1,463 & 0,875 & 8,743 & 5,751 & 4,337 & 0,986 & 5,66 & 938,43 & 30,96 & 18,6246 & 10,73 & 0,354 & 0,324 \\
\hline 57 & 389,423 & 389,423 & 64,762 & 2,338 & 1,463 & 0,875 & 8,994 & 5,934 & 4,425 & 0,979 & 5,82 & 948,07 & 30,76 & 18,8916 & 10,54 & 0,342 & 0,318 \\
\hline 72 & 403,846 & 403,846 & 64,762 & 2,338 & 1,463 & 0,875 & 9,227 & 6,115 & 4,497 & 0,969 & 5,98 & 956,06 & 30,53 & 19,1478 & 10,36 & 0,331 & 0,313 \\
\hline 87 & 418,269 & 418,269 & 64,762 & 2,338 & 1,463 & 0,875 & 9,391 & 6,297 & 4,507 & 0,948 & 6,08 & $.957,35$ & $\therefore 30,13$ & 19,3506 & 10,19 & 0,321 & 0,307 \\
\hline 102 & 432,692 & 2432,692 & 64,762 & 2,338 & 1,463 & 0,875 & 9,549 & 6,478 & 4,511 & 0,927 & 6.18 & 958,60 & 29,76 & 19,5628 & 10,04 & 0,312 & 0,302 \\
\hline 118 & 447,155 & $5 \quad 447,115$ & 64,762 & 2,338 & 1,463 & 0,875 & 9,700 & 6.658 & 4,510 & 0,906 & 6,28 & 959.79 & 29,42 & 19,7841 & 9.89 & 0,303 & 0,297 \\
\hline But & 461,538 & $8 \quad 467,538$ & 64,762 & 2,338 & 1,463 & 0.875 & 9,845 & 6,838 & 4,499 & 0,884 & 6,38 & 960,77 & 29,09 & 20,0103 & 9,76 & 0,295 & 0,293 \\
\hline 150 & 475,962 & 475,962 & 64,762 & 2,338 & 1,463 & 0.875 & 9,985 & 7,018 & 4,480 & 0,863 & 6,47 & 961,65 & 28,79 & 20,2441 & 9,63 & 0,288 & 0,288 \\
\hline Médias & 4038 & 403,8 & 64,762 & 2,338 & 1,463 & 0,875 & 9,103 & 8,1054 & 44,3985 & 0,954 & 5,8953 & 946,18 & 30,40 & 19,1064 & 10,43 & 0,336 & 0,315 \\
\hline Totais & 144,2 & 144,2 & 9714,3 & 3182,3 & 1997,4 & 1194,3 & 1365.4 & 915,81 & 659,78 & 143,17 & 884,29 & 141926,37 & 4559,79 & 2865,95 & & & \\
\hline
\end{tabular}

Figura 5.4 - Modelagem do ganho de peso para o confinamento com início em junho/92 (caso B). 
Tabela 5.2. Exigências nutricionais calculadas para atender aos ganho de peso de $1,022 \mathrm{~kg} / \mathrm{dia}$ (caso A) e $0,954 \mathrm{~kg} / \mathrm{dia}$ (caso B), calculadas em porcentagem na base seca.

\begin{tabular}{lrr}
\hline Requisito & CASO A & CASO B \\
\hline NDT mínimo & 70,50 & 68,90 \\
Protéína Bruta mínima & 10,52 & 10,43 \\
Cálcio & 0,34 & 0,34 \\
Fósforo & 0,32 & 0,31 \\
Proteina Bruta máxima & 12,10 & 12,00 \\
Cálcio máximo & 1,50 & 1,50 \\
MS total & 100,00 & 100,00 \\
\hline
\end{tabular}

Fonte: Dados calculados pelo Sistema.

Tabela 5.3. Custo e composição da ração ajustada pelo Sistema para o caso A.

\begin{tabular}{lrrrrrrrr}
\hline $\begin{array}{l}\text { Componentes } \\
\text { Alimentos Volumosos }\end{array}$ & MS & Custo & M.0.\% & PB & Ca & EE & P & NDT \\
\hline CAPIM NAPIER, 60 DIAS & 5,18 & 0,140 & 10,37 & 0,46 & 0,04 & 0,13 & 0,01 & 3,01 \\
CANA DE ACÚCAR & 47,38 & 1,509 & 67,69 & 1,18 & 0,10 & 0,47 & 0,03 & 28,43 \\
CAMA DE FRANGO & 10,61 & 0,267 & 5,66 & 2,12 & 0,34 & 0,32 & 0,18 & 5,84 \\
& & & & & & & & \\
\hline Alimentos Concentrados & & & & & & & & \\
\hline CALCÁREO CALCITICO & 0,41 & 0,007 & 0,16 & & 0,15 & & & \\
ALGODÃO FARELO (40\%) & 1,56 & 0,177 & 0,68 & 0,69 & & 0,02 & 0,02 & 1,15 \\
MILHO, GRÃO MOÍDO & 15,26 & 2,049 & 6,94 & 1,51 & & 0,64 & 0,04 & 13,73 \\
ALGODÃO, SEMENTE & 19,10 & 1,453 & 8,31 & 4,57 & 0,03 & 4,41 & 0,14 & 18,34 \\
SAL MINERAL & 0,50 & 0,168 & 0,20 & & & & 0,02 & \\
\hline Total Volumoso & 63,18 & 1,916 & 83,72 & 3,76 & 0,48 & 0,92 & 0,22 & 37,27 \\
Total Concentrado & 36,82 & 3,854 & 16,28 & 6,76 & 0,19 & 50,08 & 0,23 & 33,22 \\
Total Geral & 100,00 & 5,770 & 100,00 & 10,52 & 0,67 & 6,00 & 0,45 & 70,50 \\
\hline
\end{tabular}

Fonte: Cálculos realizados pelo Sistema. 
Tabela 5.4. Custo e composição da ração ajustada pelo Sistema para o caso B.

\begin{tabular}{|c|c|c|c|c|c|c|c|c|}
\hline Componentes & MS & Custo & M.O\%. & PB & $\mathrm{Ca}$ & $\mathrm{EE}$ & $\mathrm{P}$ & NDT \\
\hline \multicolumn{9}{|l|}{ Alimentos Volumosos } \\
\hline CAPIM NAPIER, 60 DIAS & 0,36 & 0,010 & 0,73 & 0,03 & & 0,01 & & 0,21 \\
\hline CANA DE AC̣ÚCAR & 51,88 & 1,684 & 76,05 & 1,30 & 0,11 & 0,52 & 0,03 & 31,13 \\
\hline CAMA DE FRANGO & 16,93 & 0,426 & 9,27 & 3,39 & 0,54 & 0,51 & 0,29 & 9,31 \\
\hline \multicolumn{9}{|l|}{ Alimentos Concentrados } \\
\hline CALCÁREO CALCÍTICO & 0,25 & 0,004 & 0,10 & & 0,10 & & & \\
\hline MILHO, GRÃO MOÍDO & 10,50 & 1,410 & 4,90 & 1,04 & 0,00 & 0,44 & 0,03 & 9,45 \\
\hline ALGODÃO, SEMENTE & 19,58 & 1,490 & 8,74 & 4,68 & 0,03 & 4,52 & 0,15 & 18,80 \\
\hline SAL MINERAL & 0,50 & 0,168 & 0,21 & & & & 0,02 & \\
\hline Total Volumoso & 69,17 & 2,120 & 86,05 & 4,72 & 0,65 & 1,04 & 0,32 & 40,65 \\
\hline Total Concentrado & 30,83 & 3,072 & 13,95 & 5,72 & 0,13 & 4,96 & 0,20 & 28,25 \\
\hline Total Geral & 100,00 & 5,191 & 100,00 & 10,43 & 0,78 & 6,00 & 0,52 & 68,90 \\
\hline
\end{tabular}

Fonte: Cálculos realizados pelo Sistema

A Tabela 5.5 mostra o balanço econômico previsto em US\$ para cada um dos casos. A restrição orçamentária imposta de US\$100.000,00 não foi limitante, pois os níveis de investimento calculados estão bem abaixo disto. A limitação ocorreu nos dois casos em função da restrição imposta quanto ao número máximo de animais confinados, que foi de 200 cabeças para os dois casos. A receita é proveniente da venda dos 200 animais no meses e pesos previstos, descontada da taxa mensal de juros, que foi estipulada em $0,5 \%$.

Os custos são divididos em custo de aquisição dos bois magros, custo de alimentação (ração) e outros, que incluem custos fixos (manutenção de instalações) e variáveis (mão-de-obra, operação de máquinas e medicamentos).

O resultado é obtido pela diferença entre receitas e custos, sendo também dividido nos componentes de "diferença de preços" - que é a fatia 
do lucro decorrente apenas da variação de preços esperada, calculada através da multiplicação do peso inicial dos animais pelo diferencial nos preços da arroba nas datas de compra e venda, descontados os juros - e "confinamento", que é obtido subtraindo-se a "diferença de preços" do "resultado".

Tabela 5.5. Balanço econômico esperado para os dois casos simulados.

\begin{tabular}{|c|c|c|c|c|c|}
\hline & \multicolumn{3}{|c|}{ CASO A - MAIO } & \multicolumn{2}{|c|}{ CASO B - JUNHO } \\
\hline & US\$ & $\%$ & / custos & US\$ & $\% /$ custos \\
\hline Receitas & $\$ 81.278,98$ & & $119,0 \%$ & $\$ 76.623,63$ & $119,5 \%$ \\
\hline Custos & $(\$ 68.280,15)$ & & $100,0 \%$ & $(\$ 64.097,48)$ & $100,0 \%$ \\
\hline Boi Magro & $(\$ 46.472,00)$ & & $68,1 \%$ & $(\$ 44.668,00)$ & $69,7 \%$ \\
\hline Ração & $(\$ 16.482,30)$ & & $24,1 \%$ & $(\$ 14.177,18)$ & $22,1 \%$ \\
\hline Outros & $(\$ 5.325,85)$ & & $7,8 \%$ & $(\$ 5.252,30)$ & $8,2 \%$ \\
\hline Resultado & $\$ 12.998,83$ & & $19,0 \%$ & $\$ 12.526,15$ & $19,5 \%$ \\
\hline Dif.preços & $\$ 8.453,19$ & & $12,4 \%$ & $\$ 8.736,35$ & $13,6 \%$ \\
\hline Confinamento & $\$ 4.545,64$ & & $6,7 \%$ & $\$ 3.789,80$ & $5,9 \%$ \\
\hline
\end{tabular}

Fonte: Cálculos realizados pelo Sistema.

O caso $A$ apresentou um resultado maior que o $B$, todavia, em termos de retorno sobre o investimento, o caso B foi melhor, com $19,5 \%$ contra $19,0 \%$ do caso $A$. No geral, pode-se dizer que não há diferenças significativas entre uma ou outra alternativa, restando ao próprio usuário (agente tomador de decisão), fazer a opção.

\subsection{O modelo de previsão de precos.}

Como considerado anteriormente e afirmado por outros autores como PERES (1990) e KASSOUF(1989), no Brasil, o diferencial de preços entre a arroba do boi gordo e arroba do boi magro é um dos fatores mais importantes para a rentabilidade da atividade de confinamento. Embora não seja o objetivo principal deste Sistema, uma vez que o mesmo permite que o 
próprio usuário indique os preços futuros esperados para o boi gordo, foi realizada uma breve avaliação no método de previsão de preços adotado.

A primeira dúvida que pode ocorrer ao usuário do Sistema, no que diz respeito ao modelo de previsão de preços, é em relação ao nível de confiança a ser adotado. Um nível de $50 \%$, que a primeira vista pode parecer baixo, indica a mediana da distribuição de probabilidade das relações, com valores próximos à média, que é um parâmetro adotado por muitos tomadores de decisão como aceitável. O uso de indicadores de posição, como é aqui realizado, desde que baseado em um número razoável de amostras, pode ser preferível em relação ao uso de médias, uma vez que esses indicadores não são tão afetados por valores discrepantes, muito altos ou muito baixos, que influenciariam, com maior intensidade, a estimativa da média.

Nas Figuras 5.5 e 5.6 podem ser observadas as previsões aos níveis de 50 a $80 \%$ de probabilidade comparadas com as médias, utilizando os dois deflacionadores disponíveis no Sistema, o IGP-DI e o dólar oficial, respectivamente. Percebe-se que a média é sempre maior que os outros indicadores, mesmo em relação a mediana, indicando uma distribuição assimétrica à esquerda, ou seja, mais da metade dos valores são menores que a média, sendo essa influenciada por poucos valores muito altos que podem causar esse desvio. Quando o deflacionador adotado é o dólar oficial (Figura 5.6), aparentemente, existe maior diferença entre as médias e as medianas (50\%), do que quando é utilizado o IGP-DI, principalmente no mês de novembro. 


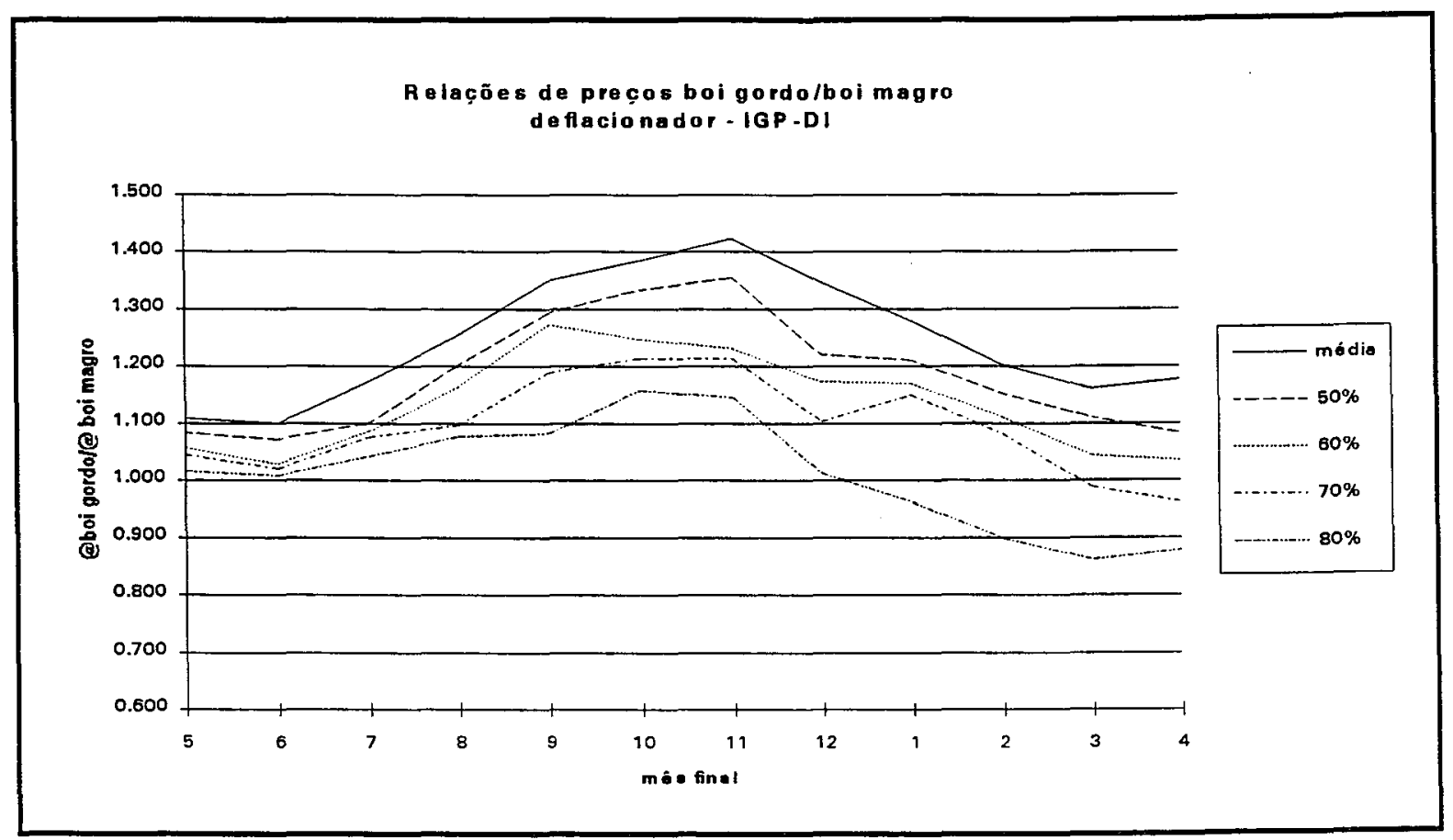

Figura 5.5. Relações mínimas de preços boi gordo/(boi magro em maio) esperadas a diversos níveis de probabilidade comparadas com a média das relações observadas entre 1970 e 1992, utilizando o IGP-DI como deflacionador de preço. 


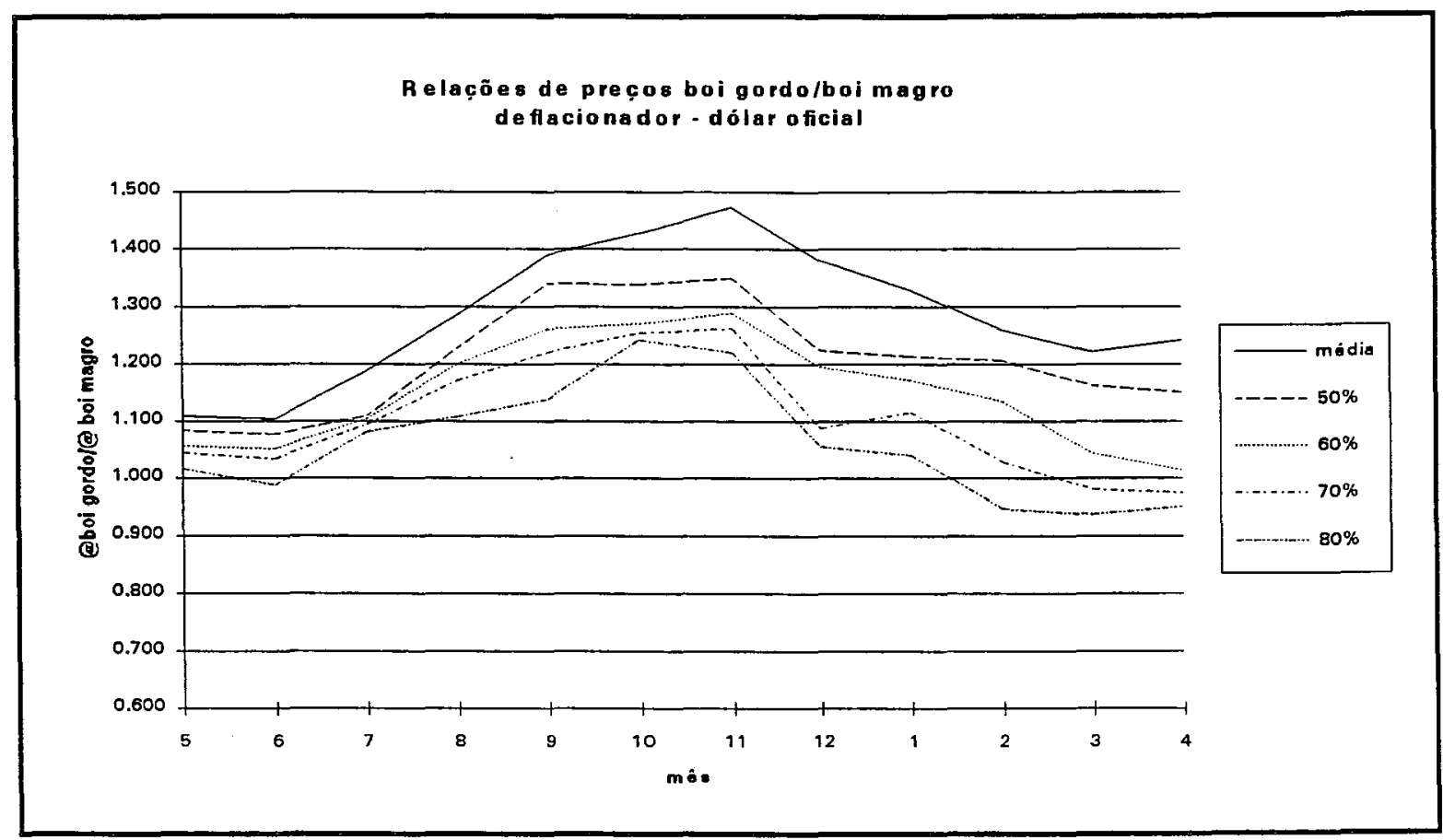

Figura 5.6. Relações mínimas de preços boi gordo/(boi magro em maio) esperadas a diversos níveis de probabilidade comparadas com a média das relações observadas entre 1970 e 1992, utilizando o dólar oficial como deflacionador de preços.

Outra alternativa prevista no Sistema é a possibilidade de que sejam fornecidos pelo usuário os preços esperados para o boi gordo nos meses seguintes ao início do confinamento. Nesse caso, o Sistema utiliza os preços fornecidos, apontando o nível de probabilidade para que a suposta relação de preços BG/BM ocorra. Utilizando os preços reais ocorridos em 1992 a partir de maio, foram obtidos os resultados apresentados na Tabela 5.6. 
Tabela 5.6. Probabilidades mínimas estimadas pelo Sistema da ocorrência de relações de preço boi gordo/(boi magro em maio) para os preços praticados em 1992, em comparação com os preços estimados no caso A.

\begin{tabular}{|c|c|c|c|c|c|c|}
\hline \multirow{3}{*}{$\frac{\text { mês final }}{5}$} & \multicolumn{3}{|c|}{ Preços reais de 1992} & \multicolumn{3}{|c|}{ Preços estimados no caso A } \\
\hline & \multirow{2}{*}{$\begin{array}{r}\text { US\$/@ } \\
20,13\end{array}$} & \multicolumn{2}{|c|}{$\mathrm{BG} / \mathrm{BM} \mathrm{P}\{\mathrm{BG} / \mathrm{BM}\}^{*}$} & \multirow{2}{*}{$\begin{array}{r}\text { US\$/@ } \\
21,11\end{array}$} & \multicolumn{2}{|c|}{$\mathrm{BG} / \mathrm{BM} \mathrm{P}\{\mathrm{BG} / \mathrm{BM}\}^{*}$} \\
\hline & & 0,996 & $85,7 \%$ & & 1,045 & $70,0 \%$ \\
\hline 6 & 18,61 & 0,921 & $98,1 \%$ & 20,61 & 1,020 & $70,0 \%$ \\
\hline 7 & 18,37 & 0,909 & $98,5 \%$ & 21,73 & 1,075 & $70,0 \%$ \\
\hline 8 & 21,68 & 1,073 & $82,6 \%$ & 22,17 & 1,097 & $70,0 \%$ \\
\hline 9 & 24,10 & 1,193 & $67,1 \%$ & 24,01 & 1,188 & $70,0 \%$ \\
\hline 10 & 23,50 & 1,163 & $79,5 \%$ & 24,50 & 1,213 & $70,0 \%$ \\
\hline 11 & 20,74 & 1,026 & $91,4 \%$ & 24,51 & 1,213 & $70,0 \%$ \\
\hline 12 & 21,18 & 1,048 & $77,7 \%$ & 22,31 & 1,104 & $70,0 \%$ \\
\hline
\end{tabular}

Fonte: CEPEA/FEALQ, deflacionador IGP-DI.

${ }^{*} \mathrm{P}\{B G / B M\}$ - Probabilidade de ocorrência da relação mínima de preços durante no período 1970-92.

Como é possível observar na Tabela 5.6, o ano de 1992 não foi típico em termos de relações de preços boi gordo/boi magro, as quais apresentaram baixos valores comparativamente às médias históricas, nem mesmo quanto ao mês de pico nos preços. O mês que apresentou a melhor relação $(1,193)$ foi setembro. O mês de outubro apresentou uma relação de 1,163 , inferior àquela simulada no caso $A$ a $70 \%$ de probabilidade $(1,213)$. A probabilidade de ocorrerem valores iguais ou maiores que o ocorrido em outübro, calculada pelo Sistema é de $79,6 \%$, colocando o preço real um pouco abaixo do estimado a $70 \%$. Se o caso A estudado fosse efetivado e todos os fatores de previsão de ganho de peso respondessem como esperado, o resultado seria inferior ao previsto, como pode ser observado na Tabela 5.7 que faz a comparação do caso A com o que ocorreria se o confinamento fosse realizado dessa forma em 1992 (caso A1). 
Tabela 5.7. Comparação do Balanço Econômico simulado no caso A com preços estimados e com preços praticados em 1992.

\begin{tabular}{|c|c|c|c|c|}
\hline & \multicolumn{2}{|c|}{$\begin{array}{c}\text { CASO A } \\
\text { Precos estimados }\end{array}$} & \multicolumn{2}{|c|}{$\begin{array}{c}\text { CASO A1 } \\
\text { Precos de } 1992 \\
\end{array}$} \\
\hline & US\$ & $\%$ / custos & US\$ & $\% /$ custos \\
\hline Receitas & $\$ 81.278,98$ & $119,0 \%$ & $\$ 76.582,24$ & $112,2 \%$ \\
\hline Custos & $(\$ 68.280 .15)$ & $100,0 \%$ & $(\$ 68.280,15)$ & $100,0 \%$ \\
\hline Boi Magro & $(\$ 46.472,00)$ & $68,1 \%$ & $(\$ 46.472,00)$ & $68,1 \%$ \\
\hline Ração & $(\$ 16.482,30)$ & $24,1 \%$ & $(\$ 16.482,30)$ & $24,1 \%$ \\
\hline Outros & $(\$ 5.325,85)$ & $7,8 \%$ & $(\$ 5.325,85)$ & $7,8 \%$ \\
\hline Resultado & $\$ 12.998,83$ & $19,0 \%$ & $\$ 8.302,09$ & $12,2 \%$ \\
\hline Dif.preços & $\$ 8.453,19$ & $12,4 \%$ & $\$ 5.279,31$ & $7,7 \%$ \\
\hline Confinamento & $\$ 4.545,64$ & $6,7 \%$ & $\$ 3.022,78$ & $4,4 \%$ \\
\hline
\end{tabular}

Fonte: Cálculos realizados pelo Sistema.

\subsection{Análise de sensibilidade do modelo}

Modelos de programação matemática não lineares com diversas variáveis podem apresentar mais de uma solução para um mesmo problema, que pode ser ótima ou "quasi-ótima", dependendo dos valores iniciais das mesmas variáveis. Devido à complexidade do modelo, não é trivial descobrir se a solução apontada é reaimente a melhor alternativa possível. Em função disso, tomando-se o caso A, foram feitas análises seccionais, modificando valores de algumas variáveis julgadas importantes e deixando as demais com seus valores calculados como ótimos. Assumiu-se que a duração do confinamento deveria permanecer fixa em 154 dias, apontada como solução para o caso $A$, fazendo alterações apenas nos valores do peso final, NDT e composição da ração.

A estimativa de ganho de peso é diretamente proporcional ao NDT da ração, no entanto, sofre pequenas variações em função do peso final atingido pelo animal, como apresentado na Figura 5.7. Da mesma forma, 
para cada valor de NDT é necessário haver uma ração diferente, de custo proporcionalmente maior e que também varia, embora em menor proporção, de acordo com o peso final do animal, como mostrado na Figura 5.8. 0 custo por quilograma de ração não representa diretamente o custo total de alimentação, devendo ser também considerada a quantidade ingerida. Por exemplo: a ganhos de peso menores é necessário maior tempo para que o animal atinja o peso final e, conseqüentemente, o volume de ração ingerida também é maior. A ingestão diária de matéria seca também varia em função do peso do animal e da energia presente na ração (NDT). O limite de $82 \%$ de NDT é imposto pela impossibilidade de se calcular, a partir dos ingredientes disponíveis, rações com concentração superior a esse valor.

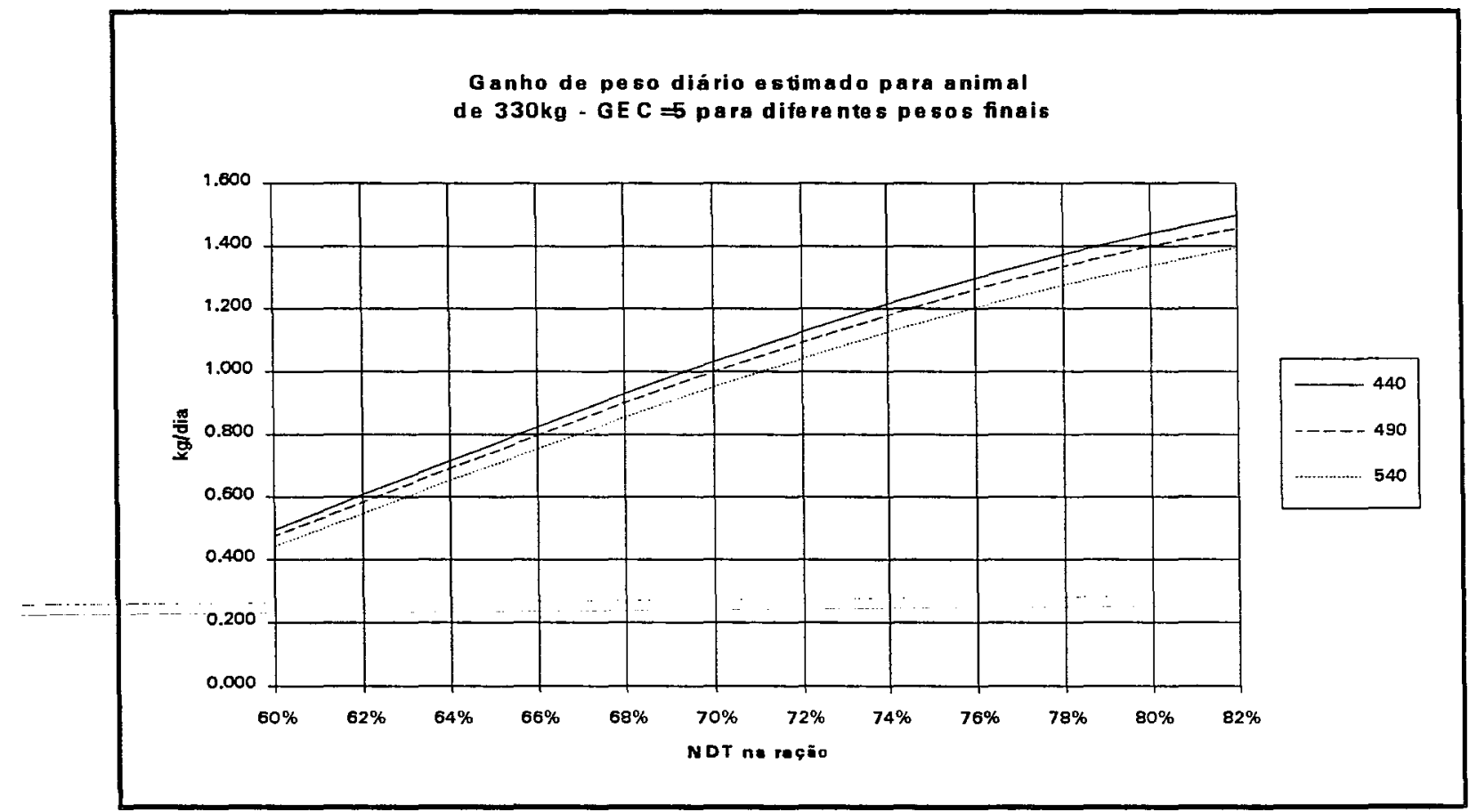

Figura 5.7. Estimativas de ganho de peso ( $\mathrm{kg} / \mathrm{dia}$ ) para animal de $330 \mathrm{~kg}$, com grau de estrutura corporal (GEC) igual a 5, a diferentes pesos finais, em função do NDT presente na ração. 


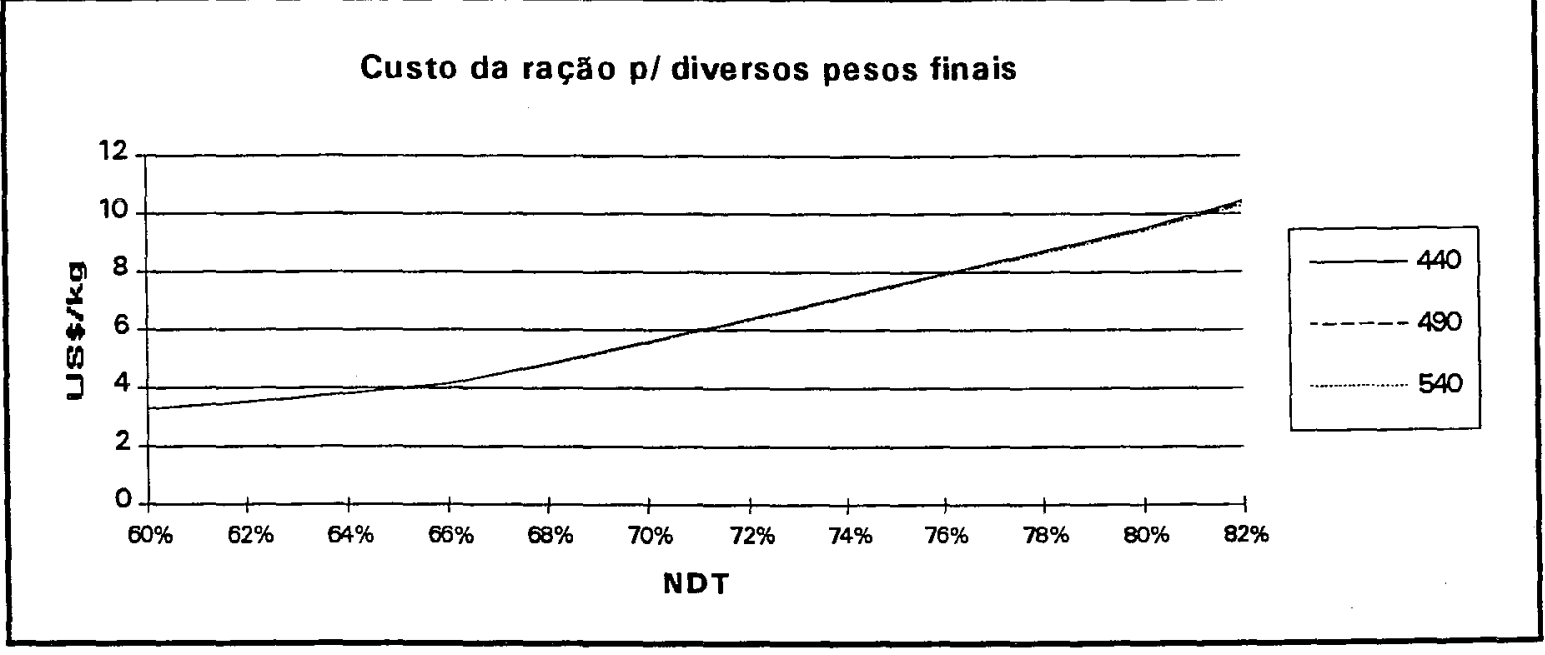

Figura 5.8. Custo mínimo das rações formuladas para atender às exigências de porcentagens de $\mathrm{Ca}, \mathrm{P}$ e para animal de $330 \mathrm{~kg}$, com grau de estrutura corporal igual a 5, a diferentes pesos finais, em função do NDT presente na ração e preços dos ingredientes de maio/92.

O peso final, por sua vez, depende diretamente do ganho de peso diário, criando uma situação recursiva que somente pode ser resolvida por métodos iterativos, por integração numérica ou métodos do tipo "goal seek", que foi escolhido por ser mais simples dentro da planilha utilizada. Dessa forma, assumindo-se constante o número de dias para engorda (154), que faz com que o confinamento termine no mês de outubro $(10,1)$, foram calculados os valores de NDT e demais nutrientes, ganho de peso diárió e ingestấo de matéria seca total para que fossem atingidos pesos finais entre 440 e $540 \mathrm{~kg}$, uma vez que a solução calculada para o caso A, apontou o peso final para $490 \mathrm{~kg}$.

Em uma planilha à parte, foram calculados os custos totais de alimentação e as receitas totais que seriam obtidas com a venda dos bois aos pesos finais fornecidos. Pela diferença, subtraindo-se os custos de 
aquisição dos boi magros e outros custos, pôde-se chegar aos valores estimados de Receita Líquida para cada um dos pesos finais, cujos resultados estão na Tabela 5.8. Observa-se que, o ponto de peso final de $480 \mathrm{~kg}$ e NDT de $68,97 \%$ é o que apresenta maior Receita Líquida. A pesos finais maiores ou menores que esse, a Receita Líquida diminui, indicando ser esse um ponto ótimo, ou bastante próximo do ótimo.

Tabela 5.8. Análise de sensibilidade do peso final com os dados do caso A.

\begin{tabular}{ccccccccc}
\hline $\begin{array}{c}\text { P.Final } \\
\text { (kg) }\end{array}$ & $\begin{array}{c}\text { NDT \% } \\
\text { ração }\end{array}$ & $\begin{array}{c}\text { Custo } \\
\text { US } / \mathrm{kg}\end{array}$ & $\begin{array}{c}\text { GPV } \\
\mathrm{kg} / \text { dia }\end{array}$ & $\begin{array}{c}\text { IMS } \\
\mathrm{kg} / \mathrm{dia}\end{array}$ & $\begin{array}{c}\text { IMS Total } \\
\mathrm{kg}\end{array}$ & $\begin{array}{c}\text { Custo de } \\
\text { aliment. }\end{array}$ & $\begin{array}{c}\text { Receitas } \\
\text { G.peso }\end{array}$ & $\begin{array}{c}\text { Resultado } \\
\text { Final }\end{array}$ \\
\hline 440 & 63,66 & 3,7548 & 0,6989 & 8,5615 & 1318,48 & 9901,35 & 21004,92 & 11103,57 \\
450 & 64,93 & 3,9429 & 0,7631 & 8,7225 & 1343,27 & 10592,64 & 22660,63 & 12068,00 \\
460 & 66,23 & 4,2181 & 0,8272 & 8,8708 & 1366,10 & 11524,76 & 24316,35 & 12791,58 \\
470 & 67,57 & 4,6660 & 0,8914 & 9,0074 & 1387,14 & 12944,82 & 25972,06 & 13027,24 \\
480 & 68,97 & 5,1860 & 0,9555 & 9,1294 & 1405,93 & 14582,40 & 27627,78 & 13045,38 \\
490 & 70,43 & 5,7456 & $1,01979,2373$ & 1422,55 & 16346,93 & 29283,50 & 12936,57 \\
500 & 71,97 & 6,3337 & 1,0839 & 9,3294 & 1436,74 & 18199,59 & 30939,21 & 12739,62 \\
510 & 73,60 & 6,9602 & 1,1458 & 9,3876 & 1445,70 & 20124,60 & 32594,93 & 12470,32 \\
520 & 75,37 & 7,6382 & 1,2073 & 9,4202 & 1450,72 & 22161,86 & 34250,64 & 12088,79 \\
530 & 77,49 & 8,4496 & 1,2694 & 9,4059 & 1448,51 & 24478,83 & 35906,36 & 11427,52 \\
540 & 79,84 & 9,3508 & 1,3319 & 9,3479 & 1439,59 & 26922,69 & 37562,07 & 10639,39 \\
\hline
\end{tabular}

Fonte: Dados calculados pelo Sistema.

Fornecendo esses novos valores (composição da ração, NDT e peso final) ao Sistema, foi encontrada outra solução (Tabela 5.9), que apresentou receita maior que a solução inicialmente adotada no caso $A$. Esse fato demonstra que o Sistema não encontra apenas uma solução para os problemas e que a solução pode ser dependente dos valores iniciais das variáveis que são calculadas pelo "solver". O esquema aqui utilizado para verificar a consistência da solução apontada como "ótima", pode ser utilizado dentro do próprio Sistema, como realmente se procedeu, porém consumindo bastante tempo do operador. No entanto, mesmo quando é 
encontrada outra solução, a diferença observada no resultado final é muito pequena. No caso estudado foi de apenas US\$119,81, ou seja, $0,92 \%$ a mais sobre o resultado anterior.

Tabela 5.9. Análise comparativa das soluções encontradas para o caso $A, e$ $A 1$, com mudanças nos valores originais das variáveis para um ponto melhor.

\begin{tabular}{|c|c|c|c|c|}
\hline \multirow[b]{2}{*}{ Boi Gordo } & \multicolumn{2}{|c|}{ CASO A } & \multicolumn{2}{|c|}{$\begin{array}{l}\text { CASO A1 } \\
\text { outra solução }\end{array}$} \\
\hline & & & & \\
\hline Peso final (kg) & 491 & & 480 & \\
\hline Diferença de peso $(\mathrm{kg})$ & 159 & & 148 & \\
\hline \multicolumn{5}{|l|}{ Ração } \\
\hline Custo (US\$ / 100kg M.S.) & $\$ 5,770$ & & $\$ 5,166$ & \\
\hline $\begin{array}{l}\text { Consumo (kg } \\
\text { M.S./cabeça.dia) }\end{array}$ & 9,244 & & 9,128 & \\
\hline Ganho de peso (kg/dia) & 1,022 & & 0,953 & \\
\hline NDT $(\%)$ & $70,50 \%$ & & $68,92 \%$ & \\
\hline Baianço Econômico & US\$ & $\% /$ custos & US\$ & $\% /$ custos \\
\hline Receitas & $\$ 81.278,98$ & $119,0 \%$ & $\$ 79.485,53$ & $119,8 \%$ \\
\hline Custos & $(\$ 68.280,15)$ & $100,0 \%$ & $(\$ 66.366,89)$ & $100,0 \%$ \\
\hline Boi Magro & $(\$ 46.472 .00)$ & $68,1 \%$ & $(\$ 46.472,00)$ & $70,0 \%$ \\
\hline Ração & $(\$ 16.482,30)$ & $24,1 \%$ & $(\$ 14.569,04)$ & $22,0 \%$ \\
\hline Outros & $(\$ 5.325,85)$ & $7,8 \%$ & $(\$ 5.325,85)$ & $8,0 \%$ \\
\hline Resultado & $\$ 12.998,83$ & $19,0 \%$ & $\$ 13.118,64$ & $19,8 \%$ \\
\hline Dif.preços & $\$ 8.453,19$ & $12,4 \%$ & $\$ 8.453,19$ & $12,7 \%$ \\
\hline Confinamento & $\$ 4.545,64$ & $6,7 \%$ & $\$ 4.665,45$ & $7,0 \%$ \\
\hline
\end{tabular}

Fonte: Cálculos realizados pelo Sistema.

Outra potencial fonte de soluções "quasi-ótimas" são as relações de preços previstos com mais de um pico. Como ocorreu nos casos estudados, além dos preços maiores em outubro/novembro, havia um outro pico de preços em janeiro. Devido ao método utilizado para maximização da função objetivo utilizar cálculo de derivadas parciais, pode ser encontrada uma solução em um ponto de máximo relativo, como por exemplo, solução para venda dos animais em janeiro. Nesses casos, é necessário que sejam 
impostas restrições para que se chegue a outra solução, que eventualmente pode ser melhor ou pior que a anterior. 0 objetivo de se colocar um gráfico na tela principal do Sistema com as previsões de preços é justamente a orientação do usuário quanto aos aspectos desse tipo, que podem direcionar a solução para outro ponto através de sucessivas tentativas, uma vez que o método pode não encontrar solução única.

Para avaliar a sensibilidade do modelo em relação à variações no preços dos insumos, foi simulada uma situação onde se reduziu o preço do milho, que é um dos componentes mais importantes na alimentação (quase $30 \%$ ). O preço da tonelada de milho foi reduzido de US\$118,19 (Custo de produção levantado) para US\$ 85,17 (preços de maio/92 segundo o CEPEA), que é um preço muito abaixo da média de 90-92 (US\$ 115,83). Deixando os outros parâmetros iguais à situação estudada no caso A o Sistema respondeu com uma solução diferente, calculando uma ração para alto ganho de peso $(1,296 \mathrm{~kg} / \mathrm{dia})$ ao custo de US\$7,207/100kg MS e NDT de 79,04\%, que só pode ser conseguida com altos teores de milho grão. A diferença no balanço econômico pode ser observada na Tabela 5.10 . 
Tabela 5.10. Análise comparativa das soluções encontradas para o caso $A$, com preços do milho a US\$119,80/ton e A2, com milho a US\$ 85,17 / ton.

\begin{tabular}{|c|c|c|c|c|}
\hline \multirow{2}{*}{ Boi Gordo } & \multicolumn{2}{|c|}{$\begin{array}{c}\text { CASO A } \\
\text { milho a US } \$ 118.19 / \text { ton }\end{array}$} & \multicolumn{2}{|c|}{$\begin{array}{c}\text { CASO A2 } \\
\text { milho a US\$ } 85,17 / \text { ton }\end{array}$} \\
\hline & & & & \\
\hline Peso final (kg) & 491 & & 547 & \\
\hline Diferença de peso $(\mathrm{kg})$ & 159 & & 215 & \\
\hline \multicolumn{5}{|l|}{ Ração } \\
\hline Custo (US\$ / 100kg M.S.) & $\$ 5,770$ & & $\$ 7,207$ & \\
\hline $\begin{array}{l}\text { Consumo (kg } \\
\text { M.S./cabeça.dia) }\end{array}$ & 9,244 & & 9,386 & \\
\hline Ganho de peso (kg/dia) & 1,022 & & 1,296 & \\
\hline NDT $(\%)$ & $70,50 \%$ & & $79,04 \%$ & \\
\hline Balanço Econômico & US\$ $\%$ & $\%$ / custos & US\$ & $\% /$ custos \\
\hline Receitas & $\$ 81.278,98$ & $119,0 \%$ & $\$ 90.449,47$ & $122,0 \%$ \\
\hline Custos & $(\$ 68.280,15)$ & $100,0 \%$ & $(\$ 74.136,52)$ & $100,0 \%$ \\
\hline Boi Magro & $(\$ 46.472,00)$ & $68,1 \%$ & $(\$ 46.472,00)$ & $62,7 \%$ \\
\hline Ração & $(\$ 16.482,30)$ & $24,1 \%$ & $(\$ 22.118,03)$ & $29,8 \%$ \\
\hline Outros & $(\$ 5.325,85)$ & $7,8 \%$ & $(\$ 5.546,48)$ & $7,5 \%$ \\
\hline Resultado & $\$ 12.998,83$ & $19,0 \%$ & $\$ 16.312,95$ & $22,0 \%$ \\
\hline Dif.preços & $\$ 8.453,19$ & $12,4 \%$ & $\$ 8.375,63$ & $11,3 \%$ \\
\hline Confinamento & $\$ 4.545,64$ & $6,7 \%$ & $\$ 7.937,32$ & $10,7 \%$ \\
\hline
\end{tabular}

Fonte: Cálculos realizados pelo Sistema.

A solução apontada é economicamente mais interessante que o caso $A$, onde o milho era mais caro, todavia, nesse caso o Sistema espera que realmente ocorra o ganho de peso de $1,296 \mathrm{~kg} /$ dia, relativamente alto para nossas condições, trazendo uma rentabilidade adicional em função do maior peso atingido pelo animal. Caso ocorresse o ganho de peso esperado, haveria uma rentabilidade de $22,0 \%$, contra os $19,0 \%$ previstos anteriormente. 


\section{CONCLUSÕES}

O Sistema desenvolvido, enquanto ferramenta de apoio à decisão em confinamento de bovinos de corte, atende aos objetivos que se propõe, podendo ser utilizado por tomadores de decisão, desde que devidamente instruídos sobre os recursos e limitações do mesmo. Contribui, dessa forma, para que decisões sejam tomadas com maior embasamento, ampliando o universo de alternativas de investimento a curto prazo, muitas vezes não imaginadas pelos pecuaristas.

Composto por um conjunto de equações e tabelas de ajuste que são calculadas dinamicamente, o modelo de previsão de ganho de peso e determinação das exigências nutricionais é um dos componentes mais complexos do Sistema, pois deve antever, com exatidão, o comportamento do animal em termos de eficiência na conversão dos alimentos em peso vivo, calculando inclusive a quantidade que será ingerida. Em função das características definidas no estudo de caso realizado, esse modelo apresentou resultados satisfatórios no que se refere ao comportamento previsto para os animais, dentro do que se poderia esperar. Todavia, apesar de utilizar equações consagradas pela literatura, seria importante que o modelo fosse avaliado em condições experimentais reais, com animais de 
diferentes categorias e graus de estrutura corporal, tarefa que compete a especialistas em nutrição animal.

Aos mesmos especialistas em nutrição animal, o Sistema serve como uma ferramenta de modelagem que, pela sua concepção de planilha de cálculo, é totalmente aberta para modificações em qualquer parâmetro técnico adotado, podendo inclusive ser utilizada parcialmente para formulação de ração, modelagem de ganho de peso, ou combinações não previstas no modelo geral. Para tal, faz-se necessário um treinamento que coloque o usuário em condições de operar com confiança a planilha EXCEL.

Os casos simulados, a partir de dados reais, indicaram que, com base no preço do boi magro ocorrido em maio/92, em $70 \%$ dos últimos anos (1970-92), não haveria diferenças significativas entre o início do confinamento em maio ou junho, uma vez que os preços esperados para outubro e novembro seriam muito próximos entre si. Caso essa estratégia fosse adotada no ano de 1992, considerando-se os preços dos insumos utilizados, haveria um retorno líquido de cerca de $12 \%$ sobre um investimento de pouco mais que 68 mil dólares.

O modelo de previsão de preços apresenta-se como uma alternativa em relação à utilização de médias de preços deflacionadas, como fazem atualmente alguns pecuaristas. É limitado em relação ao horizonte futuro da previsão (12 meses) e necessita do preço atual do boi magro para realizá-la. Essas limitações, no entanto, não restringem sua utilização na atividade de confinamento a nível de tomada de decisão a curto prazo, uma vez que o 
preço do boi magro é conhecido no momento da aquisição e o confinamento não tem duração maior que alguns meses para um mesmo lote de animais.

O algorítimo utilizado para maximização do lucro, através de programação não-linear, mostrou-se capaz de encontrar boas soluções para os problemas, que melhor poderiam ser chamadas de "quasi-ótimas", havendo diferenças muito pequenas entre uma e outra solução apresentada para o mesmo problema. Uma forma de minimizar o problema de "multisoluções" seria isolar o problema em partes, como conceitualmente já foi proposto no Diagrama Geral do Sistema (apresentado no capítulo 4).

Constatado que o custo da ração varia pouco em função do peso final, poderiam ser calculadas, através de programação linear, rações para diferentes valores de NDT, em tempo real de execução do Sistema, mas de maneira independente do resto do problema. Com a estimativa do custo da ração em função do NDT, o número de variáveis que fariam parte do problema não-linear seria bastante reduzido, restando apenas as variáveis NDT, peso final e número de animais confinados. Isso poderia simplificar bastante o cálculo e reduzir o número de soluções "quasi-ótimas". Para que seja possível resolver o modelo dessa forma, é necessária a construção de um software em linguagem de programação de nivel mais baixo como " $\mathrm{C}$ " ou Pascal e o acesso ao código fonte ou "bibliotecas" com algorítmos eficientes de programação não-linear. 


\section{BIBLIOGRAFIA CONSULTADA}

ANDRADE, P. Acabamento de Bovinos In: PEIXOTO, A.M. \& MOURA, J.C. de e FARIA, V.P. de (eds.). SIMPÓSIO SOBRE PECUÁRIA DE CORTE, 3., Piracicaba, SP, 1983. Anais. Campinas, Fundação Cargill, 1983. p.127-40

ARC. The Nutrient Requirements of Ruminant Livestock. Commonwealth Agcicultural Bureaux, Farnham Royal. Slough 2L2 3BN, Inglaterra, 1980.

AZEVEDO FILHO, A.J.D.B.V. Análise Econômica de Projetos: Software para Situações Deterministas e de Risco Envolvendo Simulação. Piracicaba, 1988, 127 pag. (Mestrado - Escola Superior de Agricultura "Luiz de Queiroz"/USP).

AZEVEDO FILHO, A.J.D.B.V. Confcomp : Sistema p/ análise Econômica de Confinamento de Bovinos. Piracicaba, Centro de Informática na Agricultura/USP, 1987. 43p.

AZEVEDO FILHO, A.J.D.B.V.; MARTINEZ FILHO, J.G. \& NEVES, E.M. Terminação de Bovinos em Confinamento: Alguns Intrumentos para o aperfeiçoamento do processo de tomada de Decisões. Congresso Brasileiro de Economia e Sociologia Rural, 23., Anais 1987, p.291-95.

BAMELMANS, P.F. Organização administrativa da exploração de gado de corte. In: PEIXOTO, A.M.; MOURA, J.C. de \& FARIA, V.P. de, eds. SIMPÓSIO SOBRE PECUÁRIA DE CORTE, 3., Piracicaba, SP, 1983. Anais. Campinas, Fundação Cargill, 1983. p.33-51.

BIERMAN JR., H.; BONINI, C.P. \& HAUSMAN, W.H. Quantitative analysis for business decisions. Homewood, llinois. Richard $D$. Irwin, Inc., Fifth Edition. 1977, 642p. 
BOAR, B. Application Prototyping.Reading, Massachussets. AddisonWesley, 1984.

BOEHM, B.W. A Spiral Model of Software Development and Enhancement. Computer 1988, Mai, p.61-72.

BOIN, C. Formulação de rações para bovinos de corte em confinamento In: PERES, F.C \& MARQUES, P.V., eds. Manual de Cálculo de Rações de Custo Mínimo com o uso de microcomputadores (v. preliminar), Piracicaba, FEALO, 1988. p.141-66.

BOIN, C. Nutrição e manejo da alimentação de bovinos de corte em confinamento. In Simpósio do Colégio Brasileiro de Nutrição Animal, 4 / Seminário sobre Tecnologia da Produção de Rações, 3. Campinas, 1992. Anais. Campinas, CBNA, 1992. p.27-61.

BULLOCK, J.B. \& LOGAN, S.H. Cattle feedlot marketing decisions under uncertainty. Giannini Foundation Monograph, California Agricultural Experiment Station 1972, No.28, 40 pag.

DENHAM, S.C. \& SPREEN, T.H. Introduction to Simulation of Beef Cattle Peoduction In SPREEN, T.H. \& LAUGHLIN, D.H., eds., Simulation of Beef Cattle Production Systems and its use in Economic Analysis. Westview Press Inc., Boulder, Colorado, 1986, p.13-37.

DEPARTAMENTO NACIONAL DE INFORMÁTICA. Base de Dados sobre Software registrados no país, IBICT/RENPAC, Brasília, 1990.

FAO Production Year Book. Food and Agriculture Organization of United Nations, Rome, 1990. p.199-201.

FARIA, V.P. de. Medidas para o aumento da eficiência de produção de carne bovina In: PEIXOTO, A.M.; MOURA, J.C. de \& FARIA, V.P. de, eds. SIMPÓSIO SOBRE PECUÁRIA DE CORTE, 3., Piracicaba, SP, 1983. Anais. Campinas, Fundação Cargill, 1983. p.177-90.

FOX, D.G.; SNIFFEN, C.J. \& O'CONNOR, J.D. Adjusting nutrient requirements of beef cattle for animal and environmental. Journal of Animal Science, Champaign, 66:1475-1495, 1988.

GOMES, M.R. Confinamento de gado de corte. Secretaria de Agricultura e Abastecimento, RJ. Divisão de Animais de Grande Porte, 1975. 29p. 
GRUPO DE INFORMAC̣ÃO AGRÍCOLA DA FUNDAC̣ÃO GETÚLIO VARGAS. O Brasil e o mercado internacional de carnes. Agroanalysis 1981, 5(7):3.

HADDAD, C.M. A Carne Bovina da Fonte de Produção ao Consumidor: Problemas e Propostas de Soluções In: PEIXOTO, A.M.: MOURA, J.C. de \& FARIA, V.P. de, eds. SIMPÓSIO SOBRE PECUÁRIA DE CORTE, 3., Piracicaba, SP, 1983. Anais. Campinas, Fundação Cargill, 1983. p.317-345.

HADLEY, G. Programação Linear. Rio de Janeiro, Guanabara, 1982, 460p.

KASSOUF, A.L. Previsão de Preços na Pecuária de Corte do Estado de São Paulo. Piracicaba, 1988, 102p. (Mestrado - Escola Superior de Agricultura "Luiz de Queiroz"/USP).

KEELE, J.W., WILLIAMS, C.B. \& G.L. BENNETT. A computer model to predict the effects of level of nutrition on composition of empty body gain in beef cattle: I. theory and development. Journal of Animal Science, Champaign, 70(3):841-857, 1992.

McMILLAN Jr., C. Mathematical Programming. A introduction to the design and Application of optimal decision machines. Wiley Series in Managment and Administration. New York, Wiley, 1970, 496 p.

MICROSOFT. Microsoft Excel for Windows 4.0: User's Guide 1. Redmond, Microsoft Corporation, 1992, 641 p.

MICROSOFT. Microsoft Excel for Windows 4.0: User's Guide 2. Redmond, Microsoft Corporation, 1992, 353 p.

MICROSOFT. Microsoft Excel: for Windows 4.0: Function Reference. Redmond, Microsoft Corporation, 1992, $536 p$.

NORONHA J.F. O Sistema de Avaliação Econômica de Projetos Agropecuários na Política Brasileira de Crédito Rural. Piracicaba, 1982, 120p. (Livre Docência - Escola Superior de Agricultura "Luiz de Queiroz"/USP).

NRC. Nutrient requirements of beef cattle. Washington, National Academy Press, 1984. 90 p. 
PERES, F.C. Confinamento de Gado de Corte: Um modelo de Análise de Decisão. Piracicaba, 1990, 74p. (Livre Docência - Escola Superior de Agricultura "Luiz de Queiroz"/USP).

POULIQUEN, L.Y. Risk Analysis in Project Appraisal. Baltimore, The Jons Hopkins University Press, Baltimore, 1983, 79 p.

SÁ, J.M. Análise Econômica da Engorda de Bovinos em Confinamento, em Goiás. Piracicaba, 1985, 111p. (Mestrado - Escola Superior de Agricultura "Luiz de Queiroz"/USP).

SINN, H.W. Economic Decisions Under Uncertainty, North-Holland Publishing Company, 1983, 359p.

SPREEN, T.H. \& LAUGHLIN, D.H. Simulation of Beef Cattle Production Systems and its use in Economic Analysis. Westview Press Inc., Boulder, Colorado, 1986, 269 p.

VELOSO, L. Terminação de Bovinos em Confinamento In PEIXOTO, A.M.; MOURA, J.C.; FARIA, V.P. de. eds. Bovinocultura de Corte: Fundamentos da Exploração Racional. Piracicaba, Fundação de Estudos Agrários "Luiz de Queiroz", 1986, p.203-19.

WHITSON, R.E. \& KAY, R.D. Beef cattle forage systems analysis under variable prices and forage conditions. Journal of Animal Science, Champaign, 46(3):823-830, 1978. 


\section{APÊNDICE}




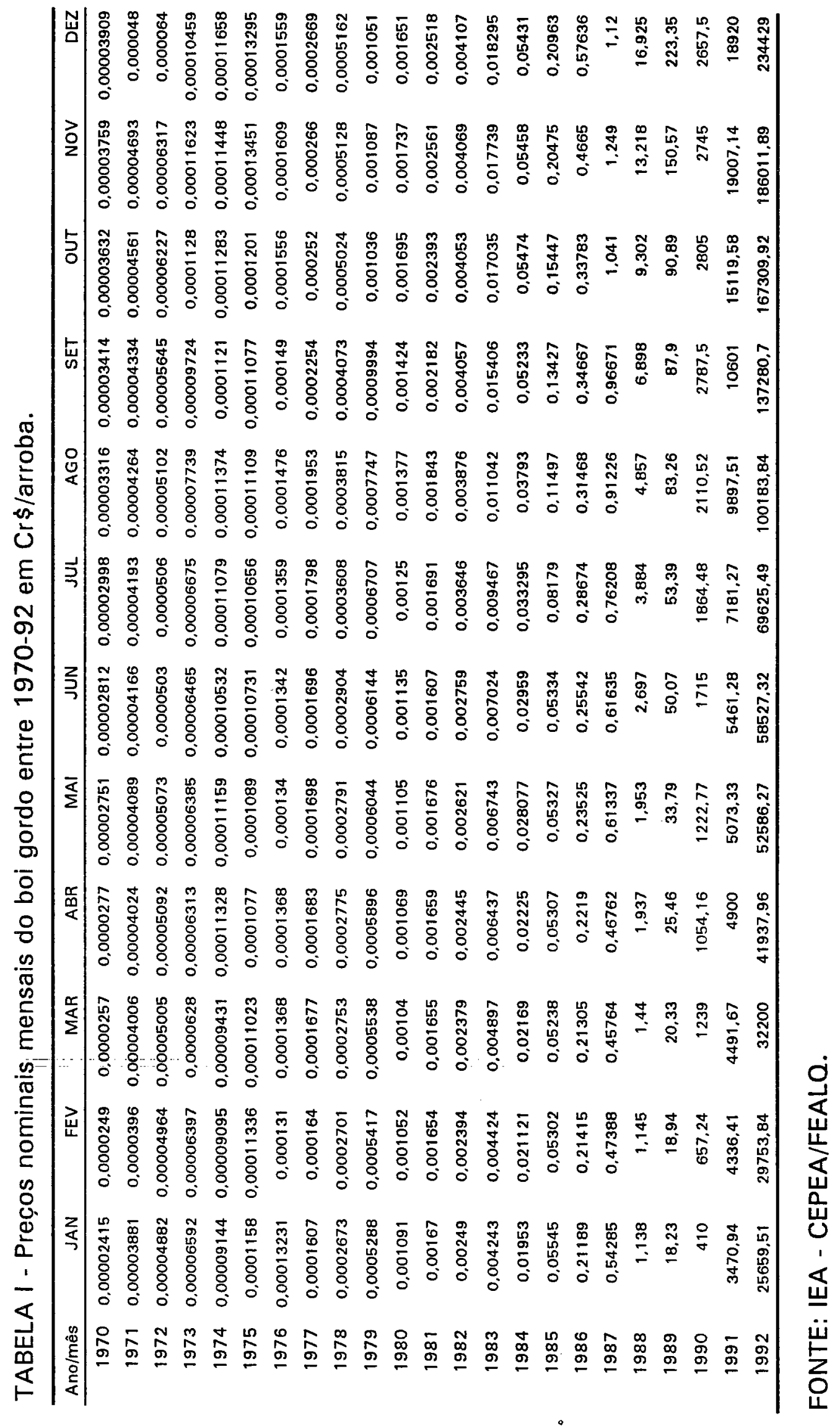









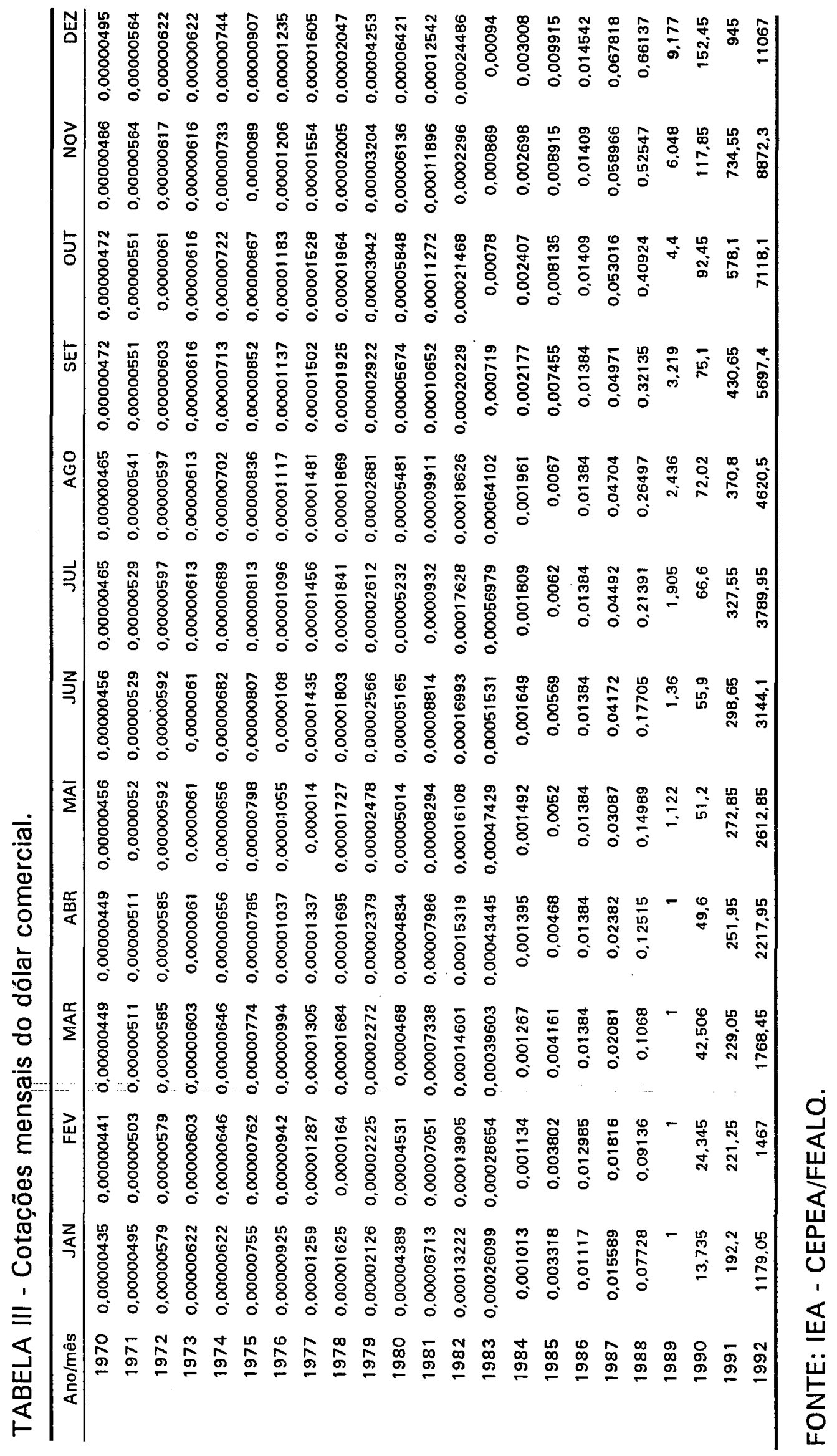




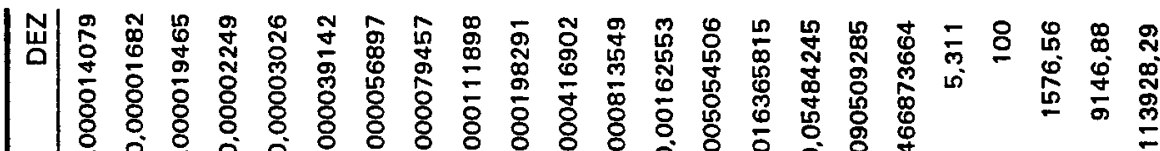

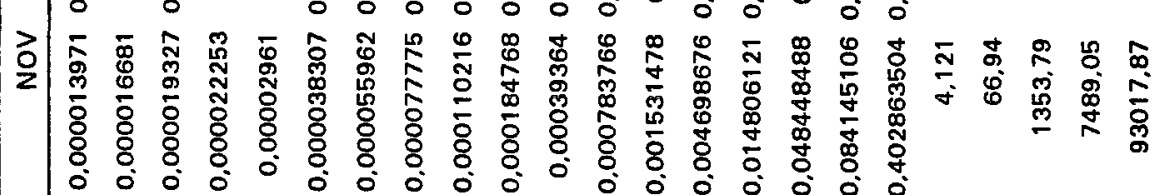

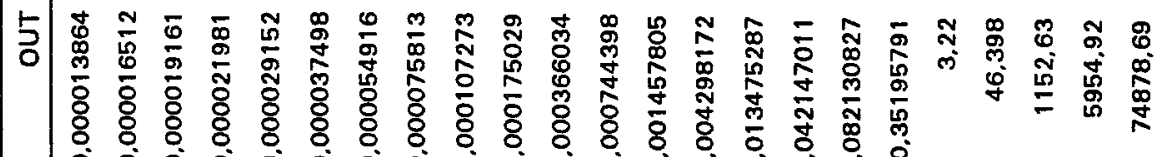

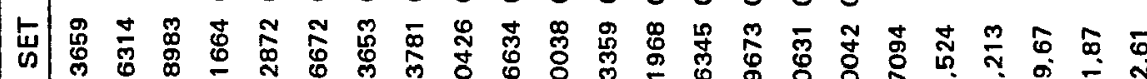

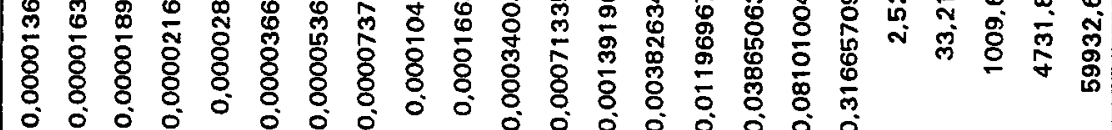

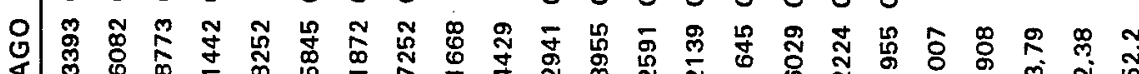

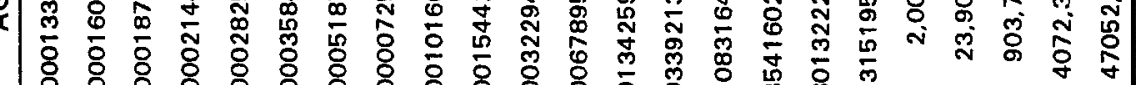

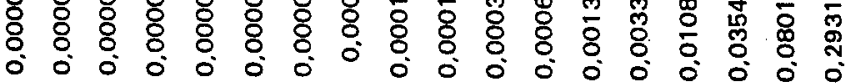

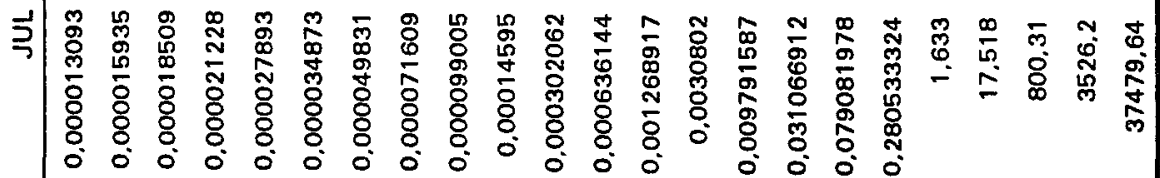

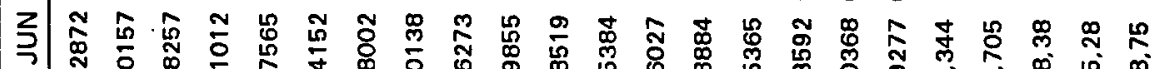
চे

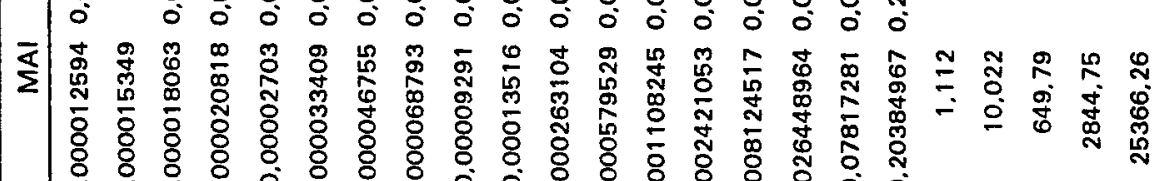

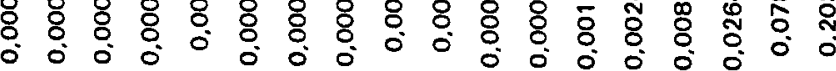

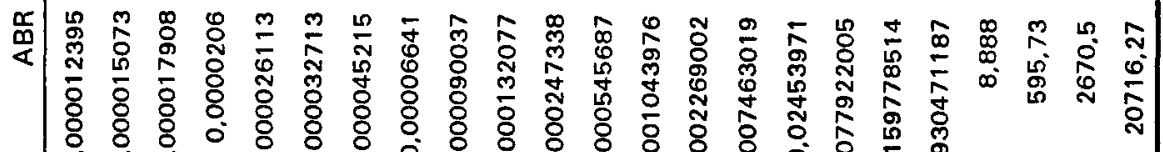

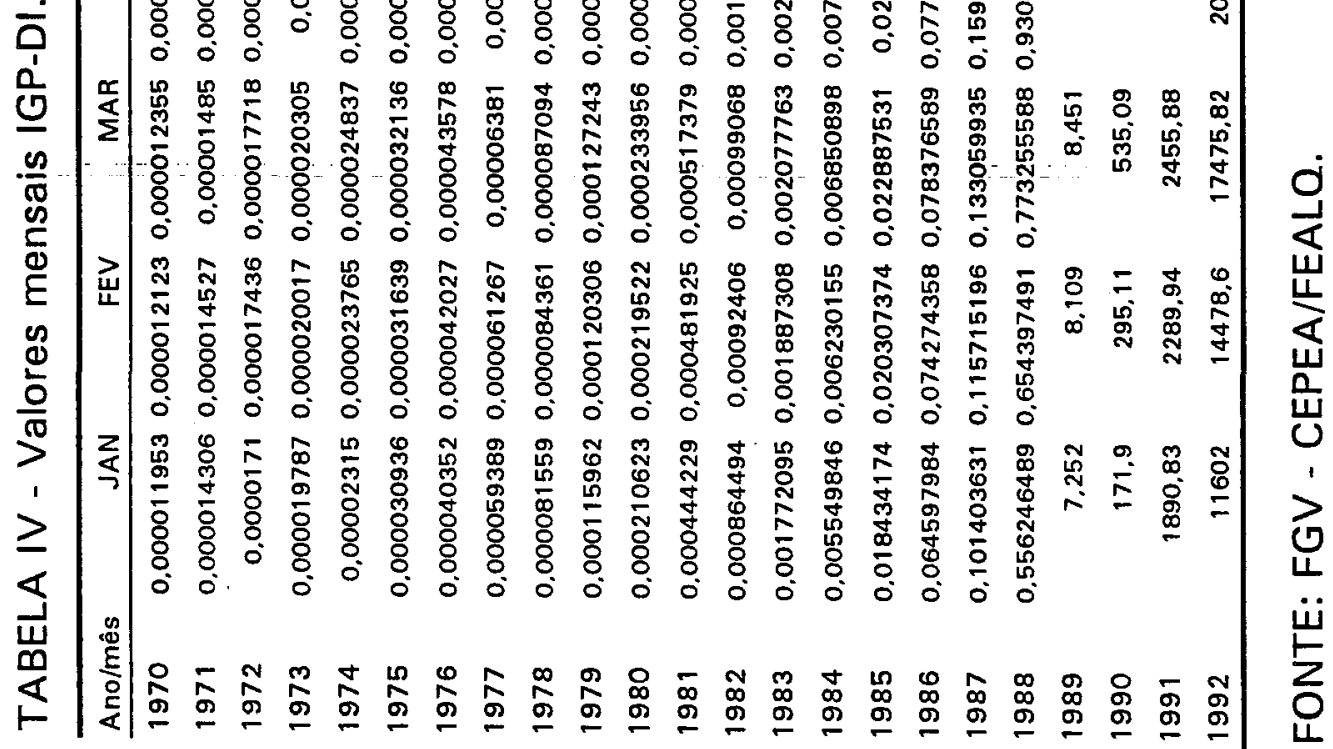




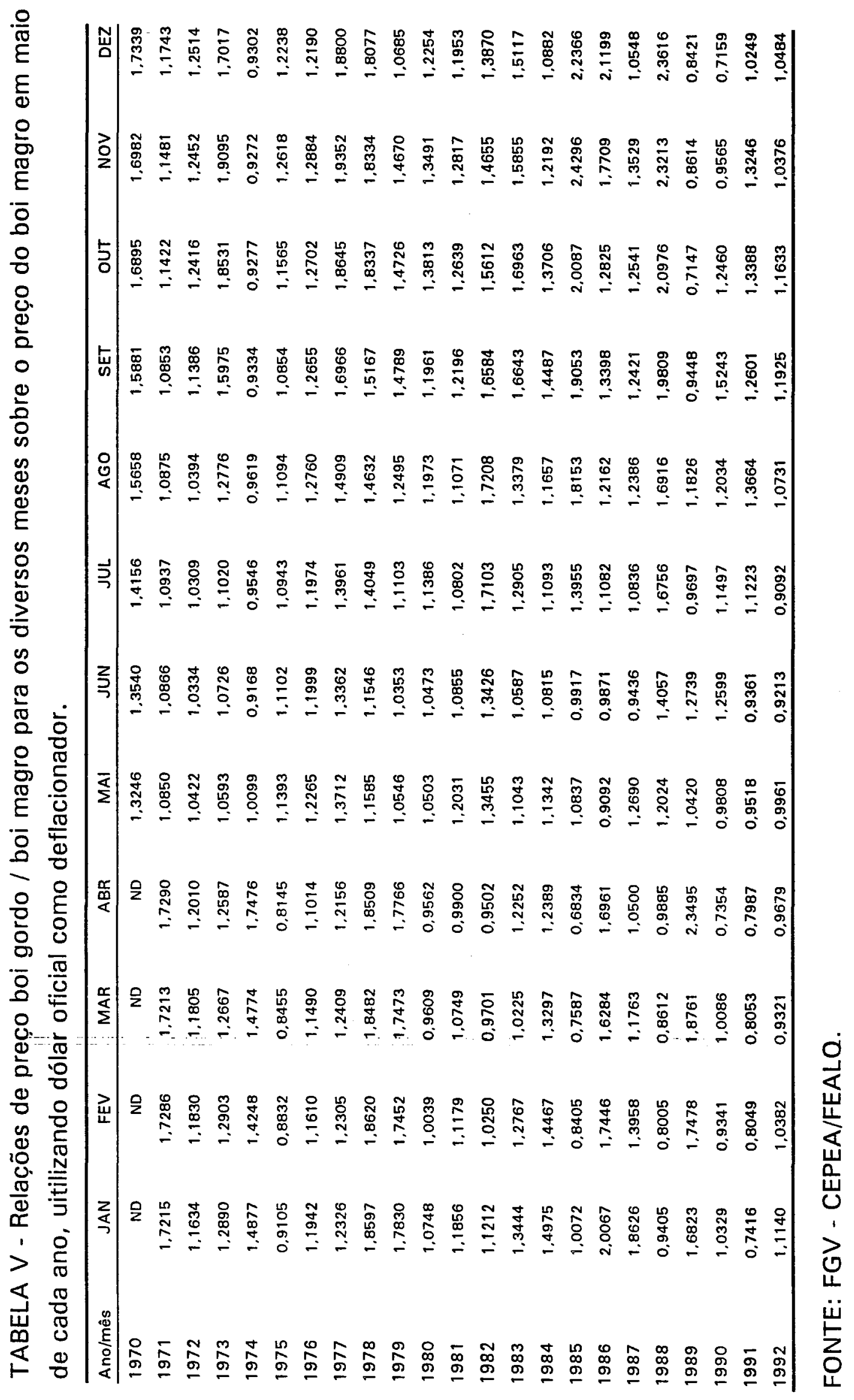




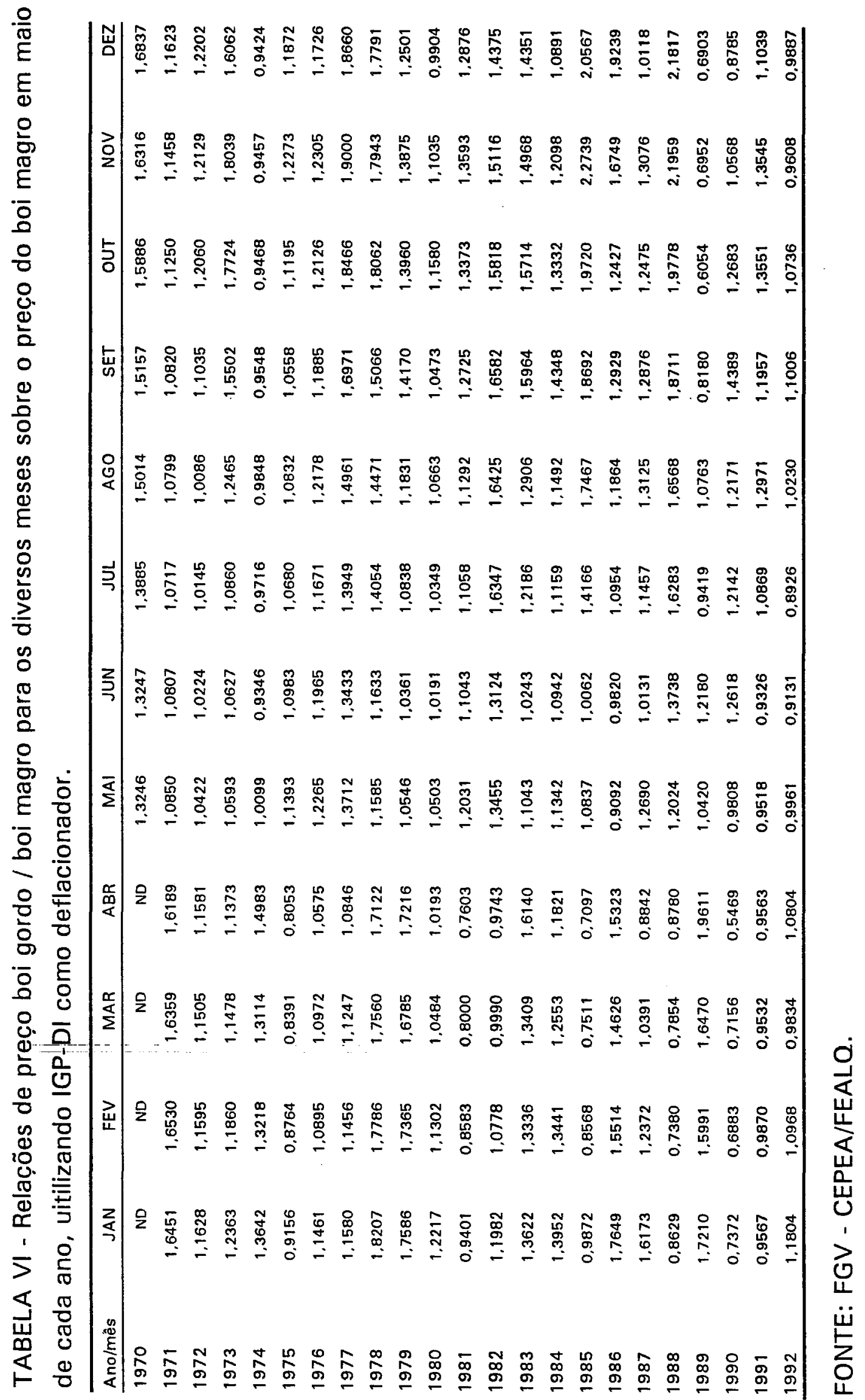


E

覃

¿’

웅

8

:

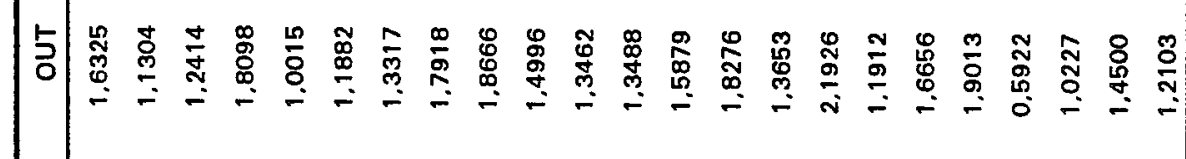

范

s.

总

:

离

(2)

욜

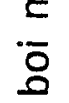

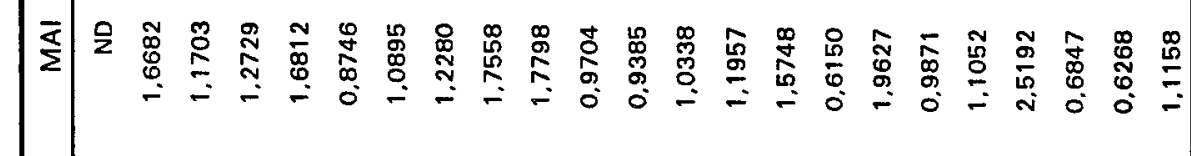

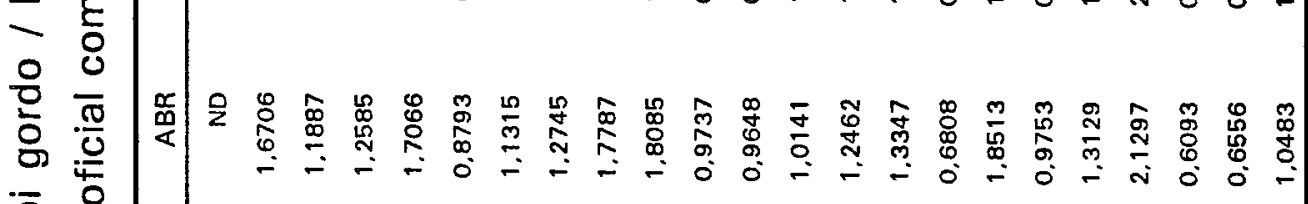

ธo

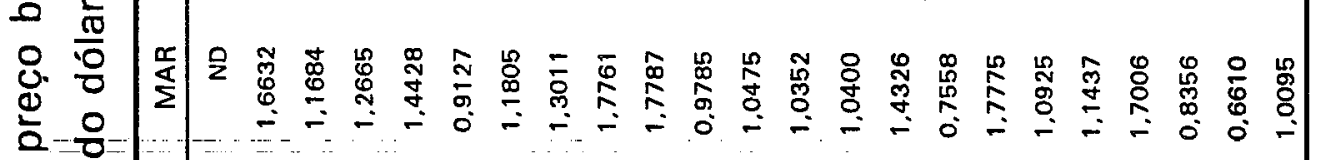

8

.

崖

인

ن른 


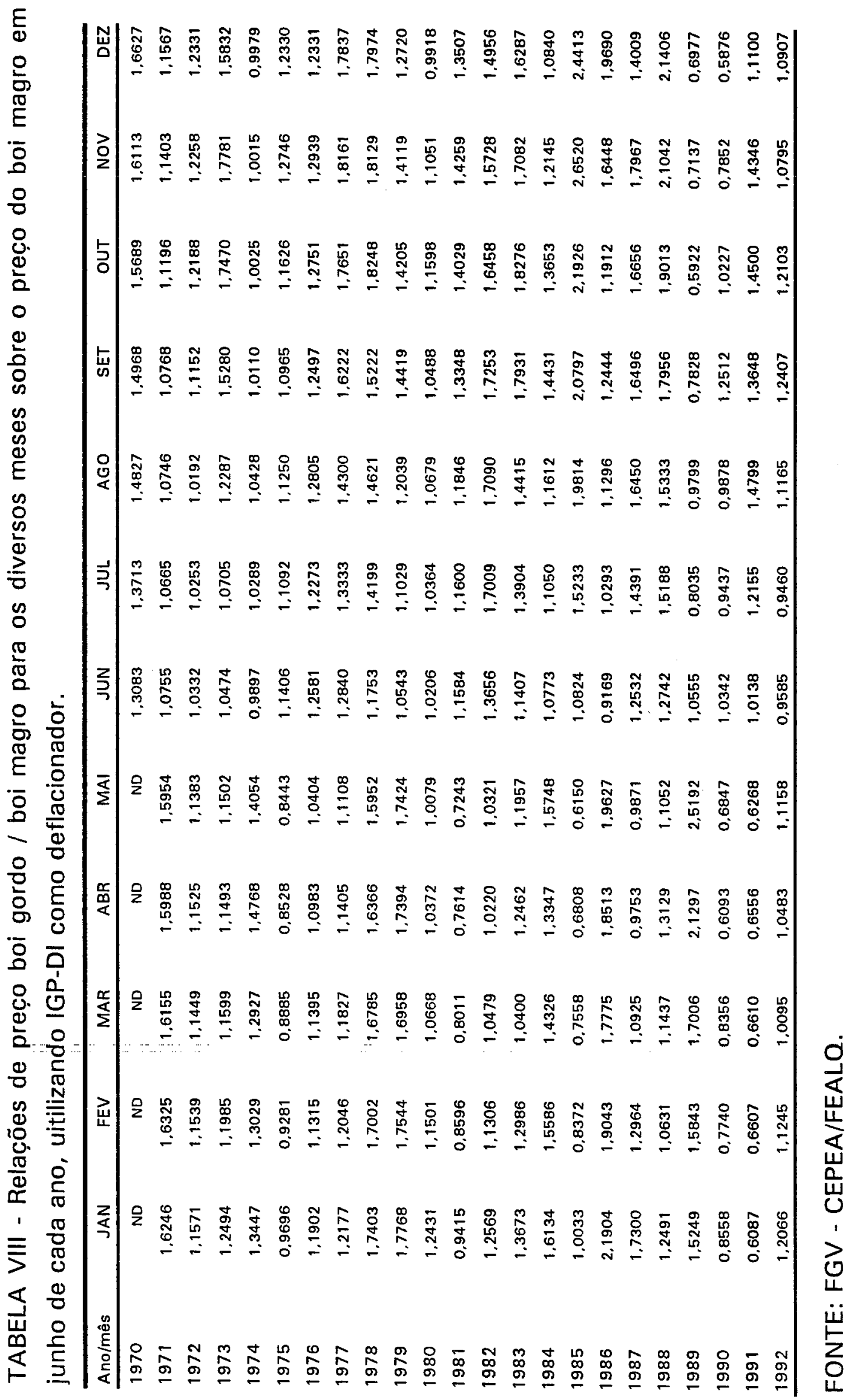




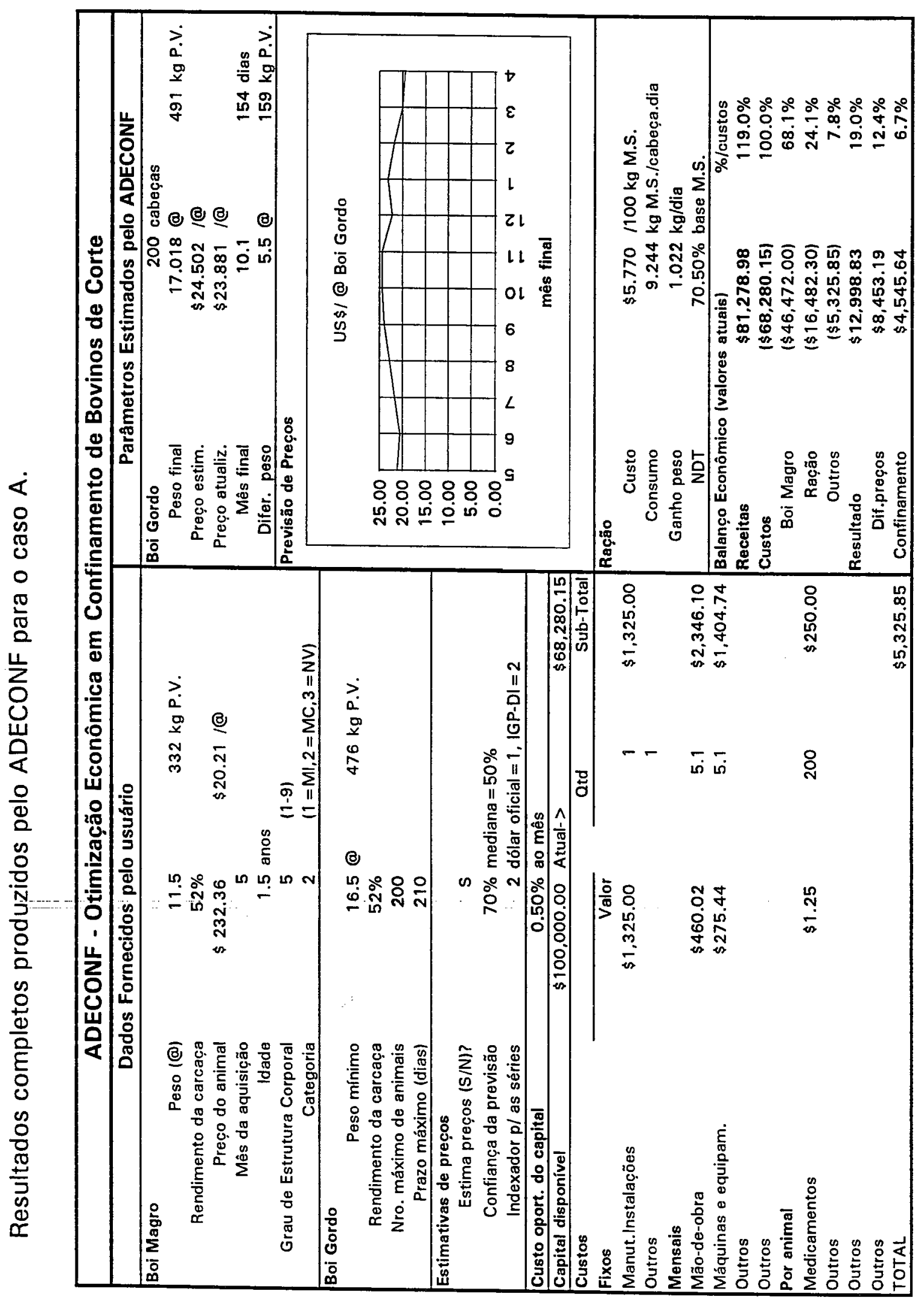




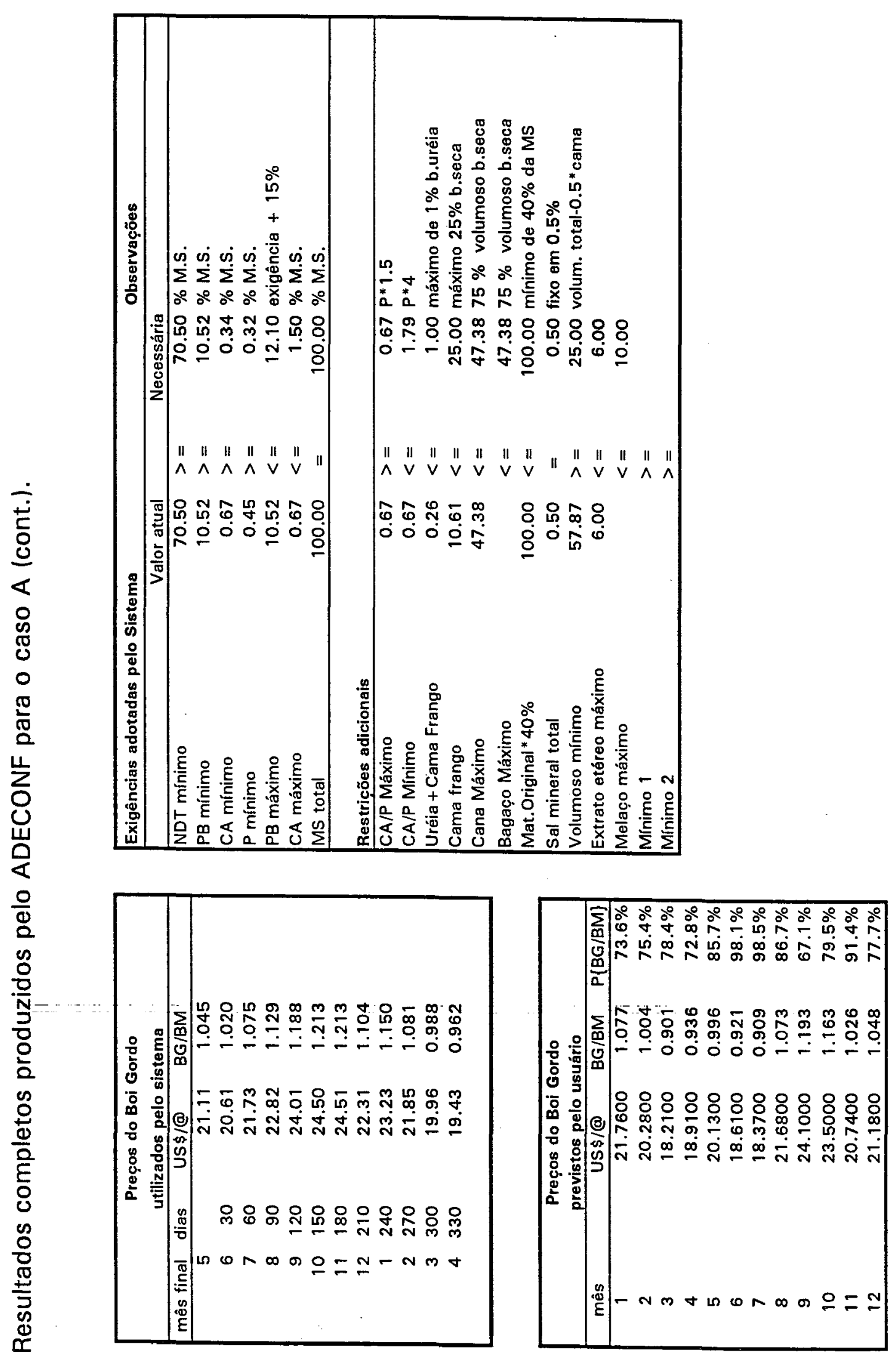




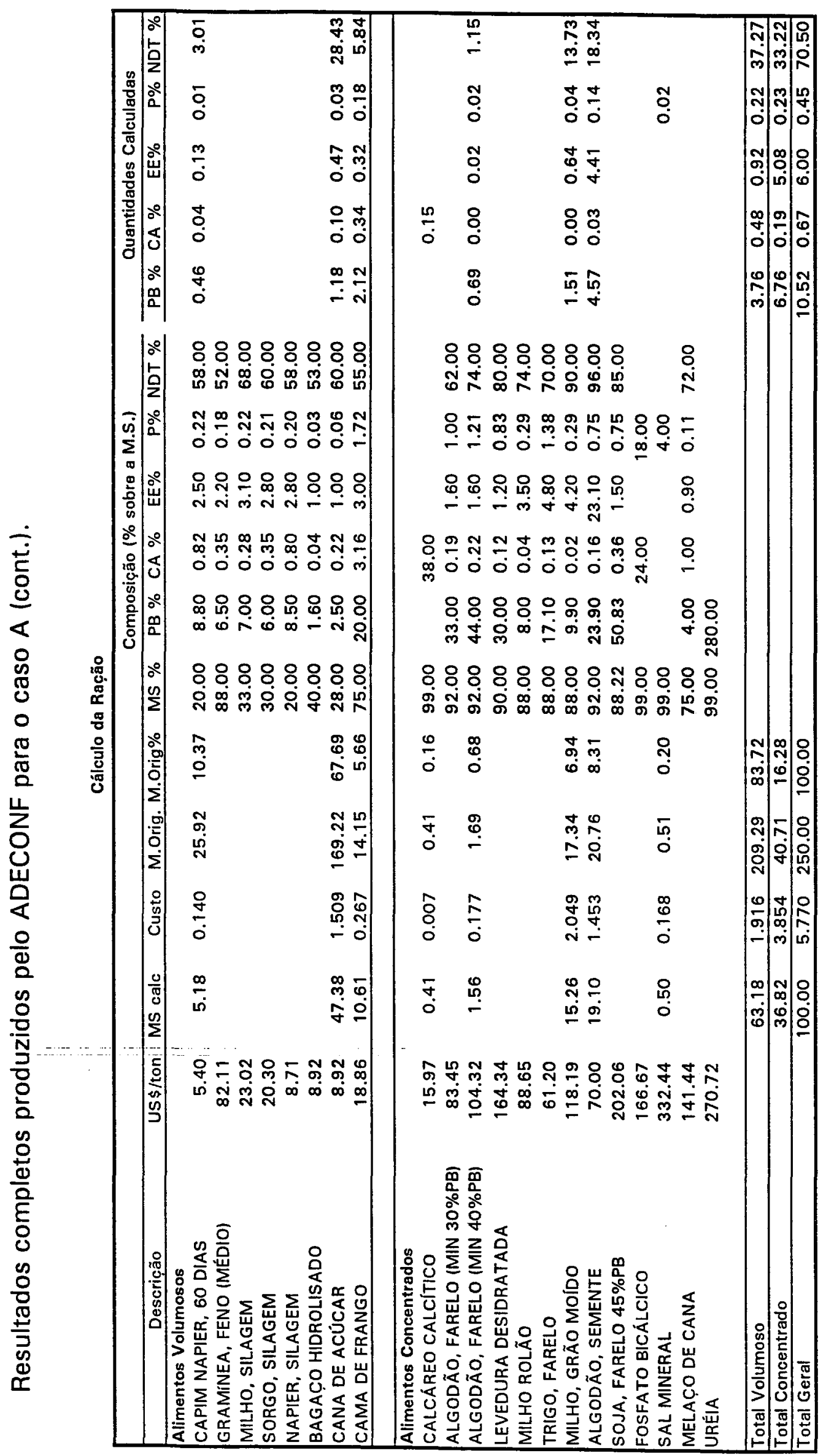




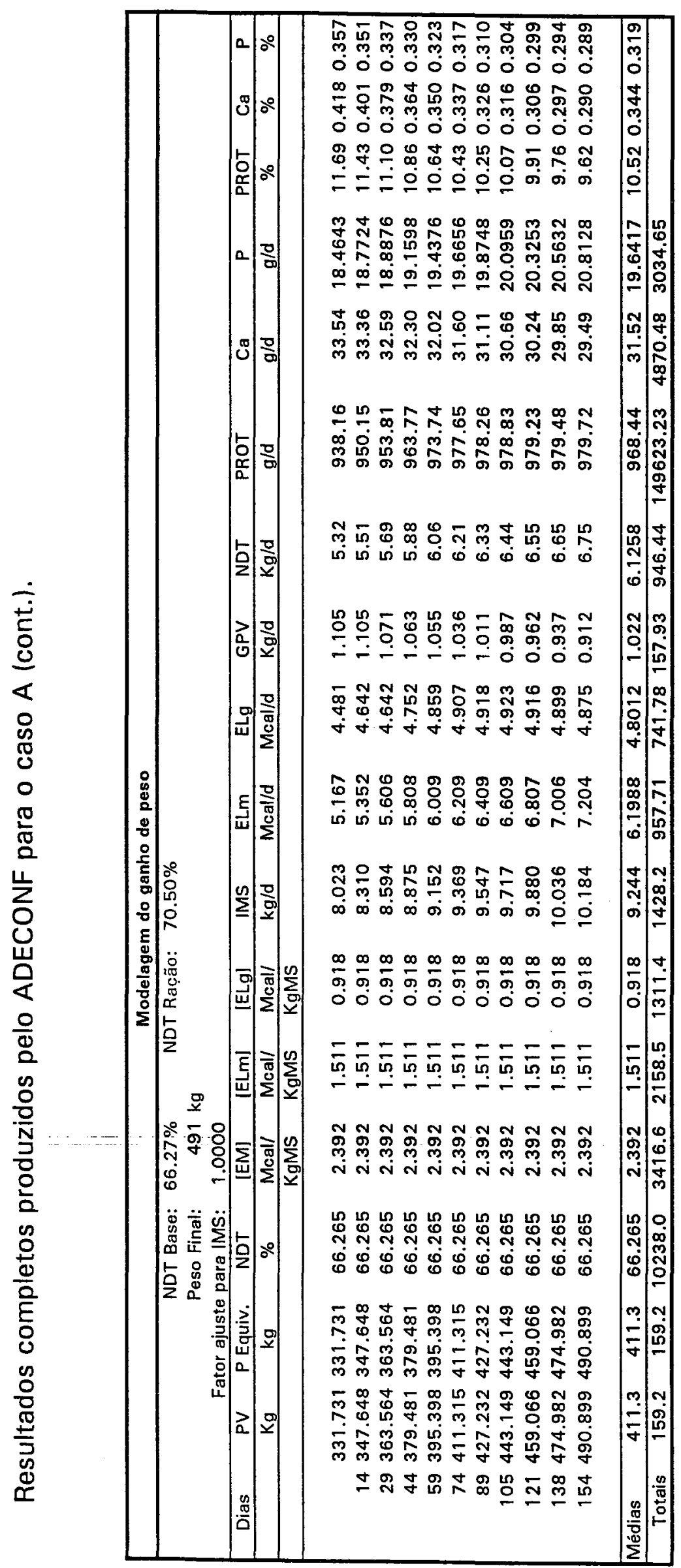




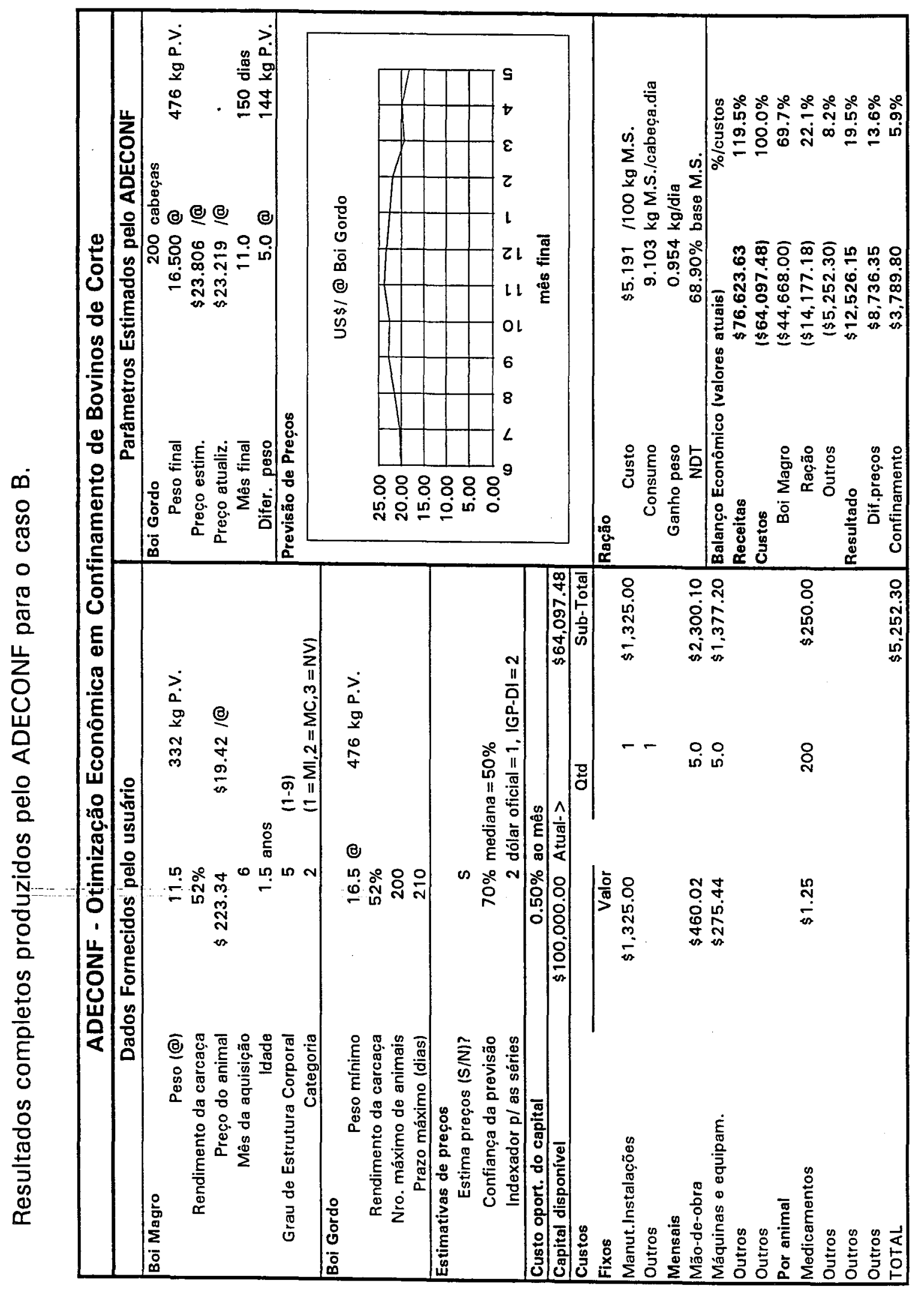




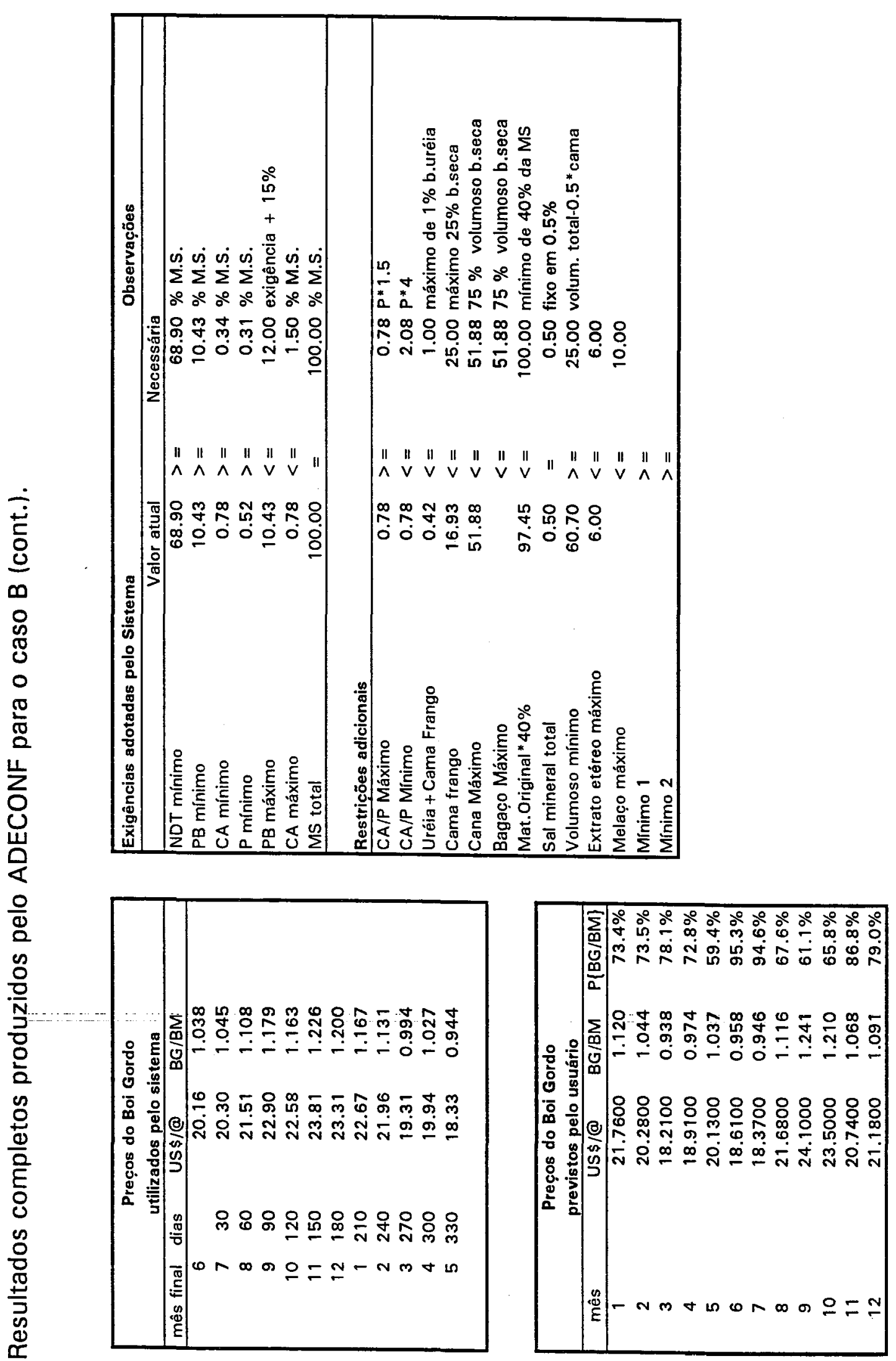




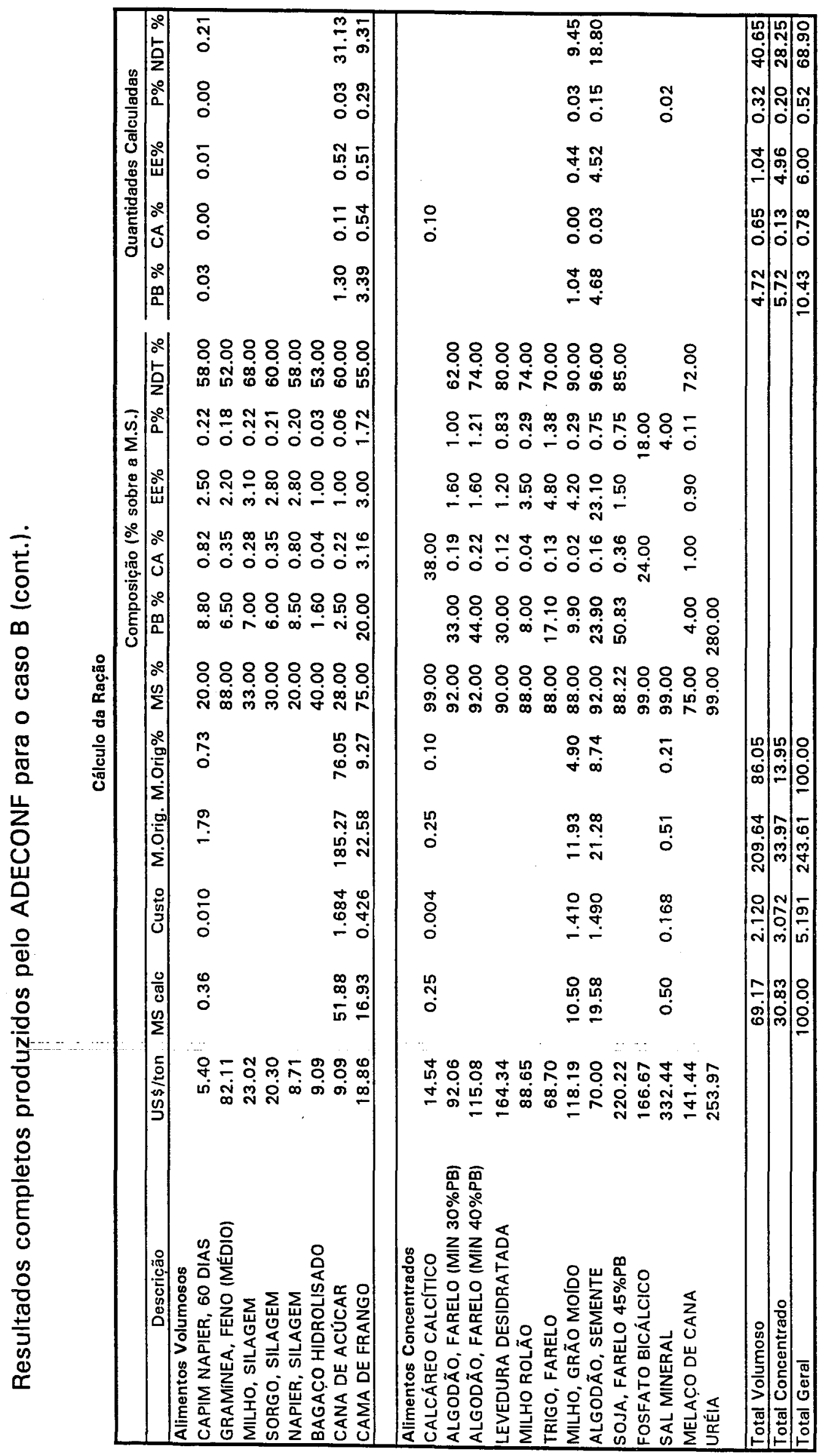




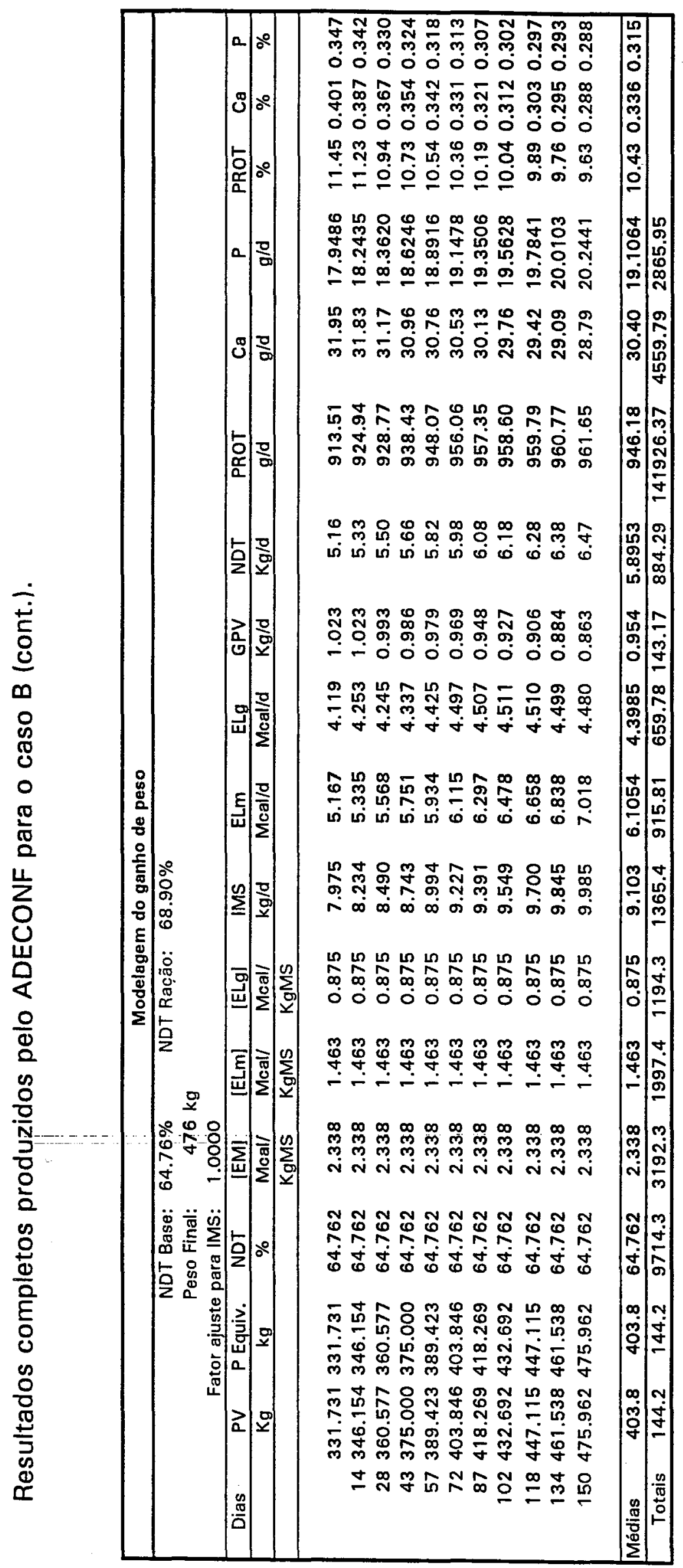




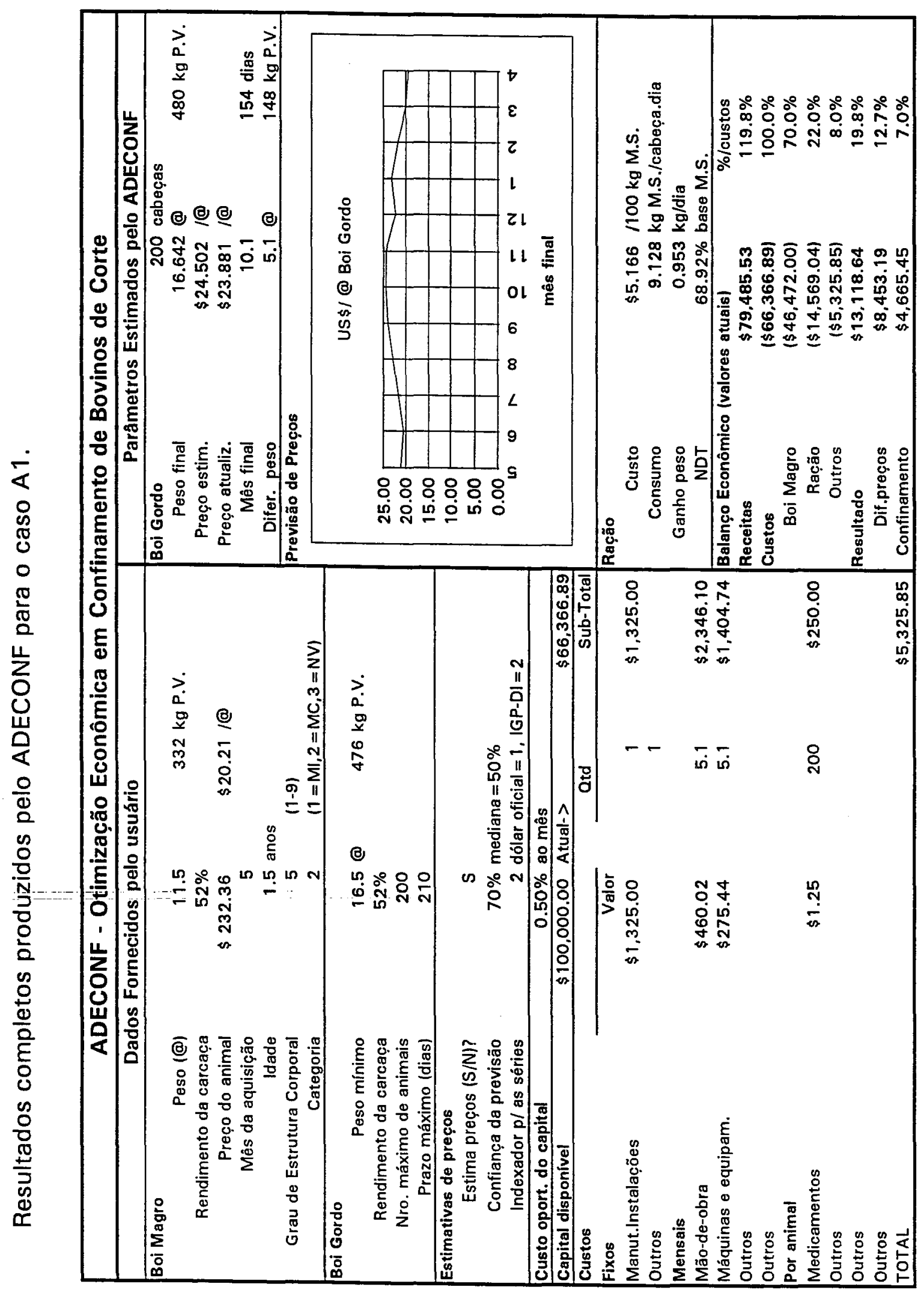




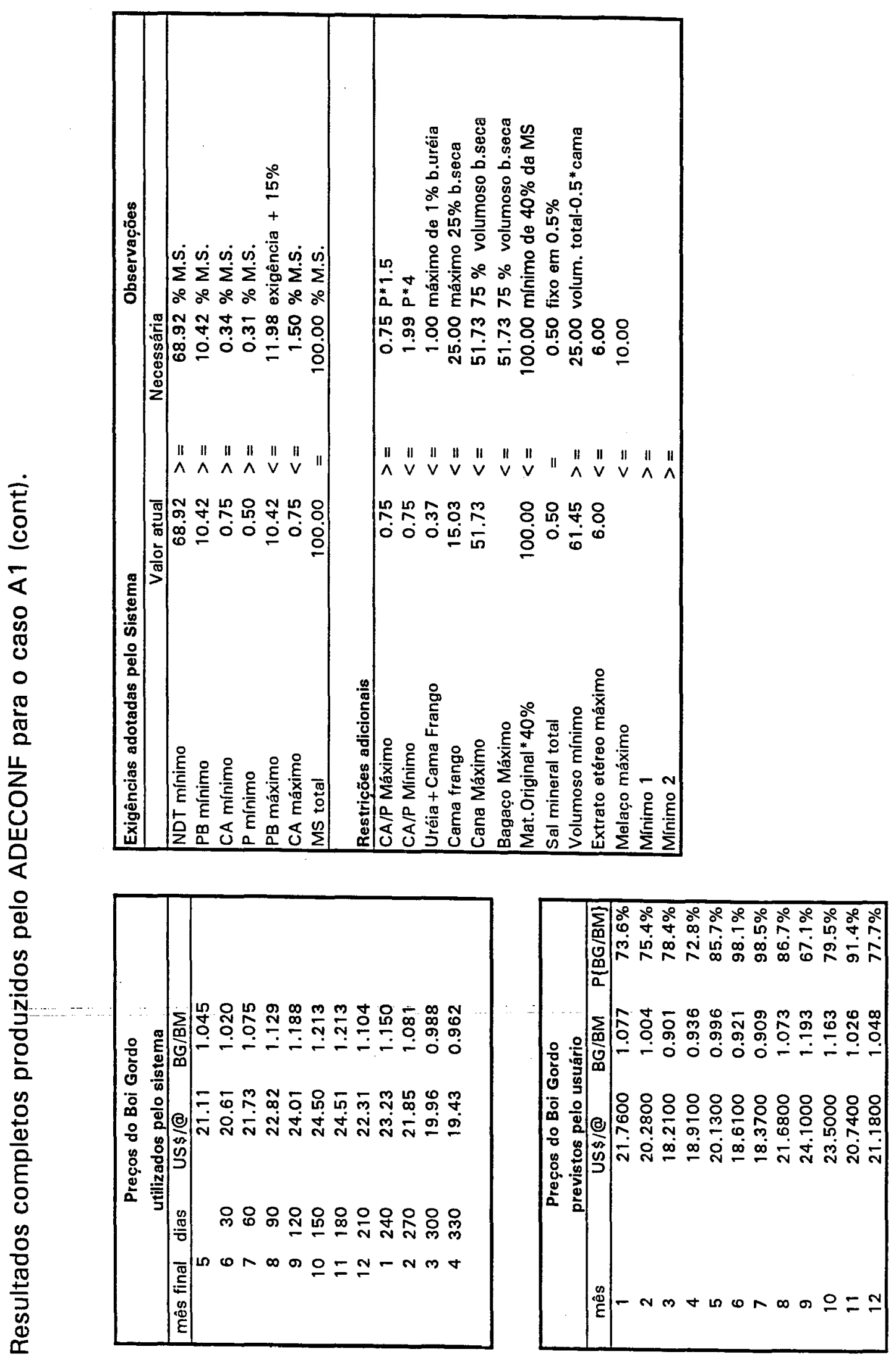




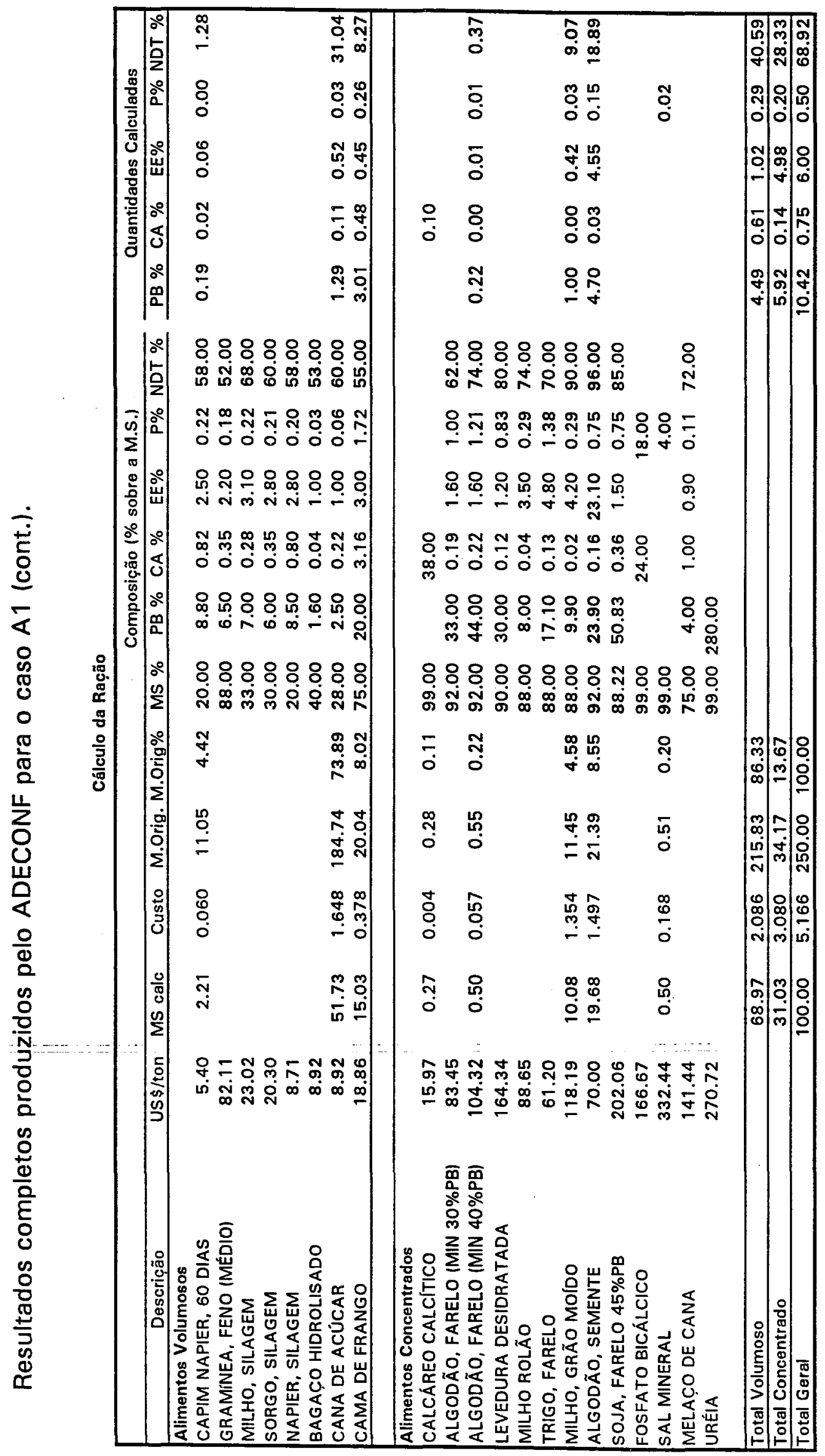




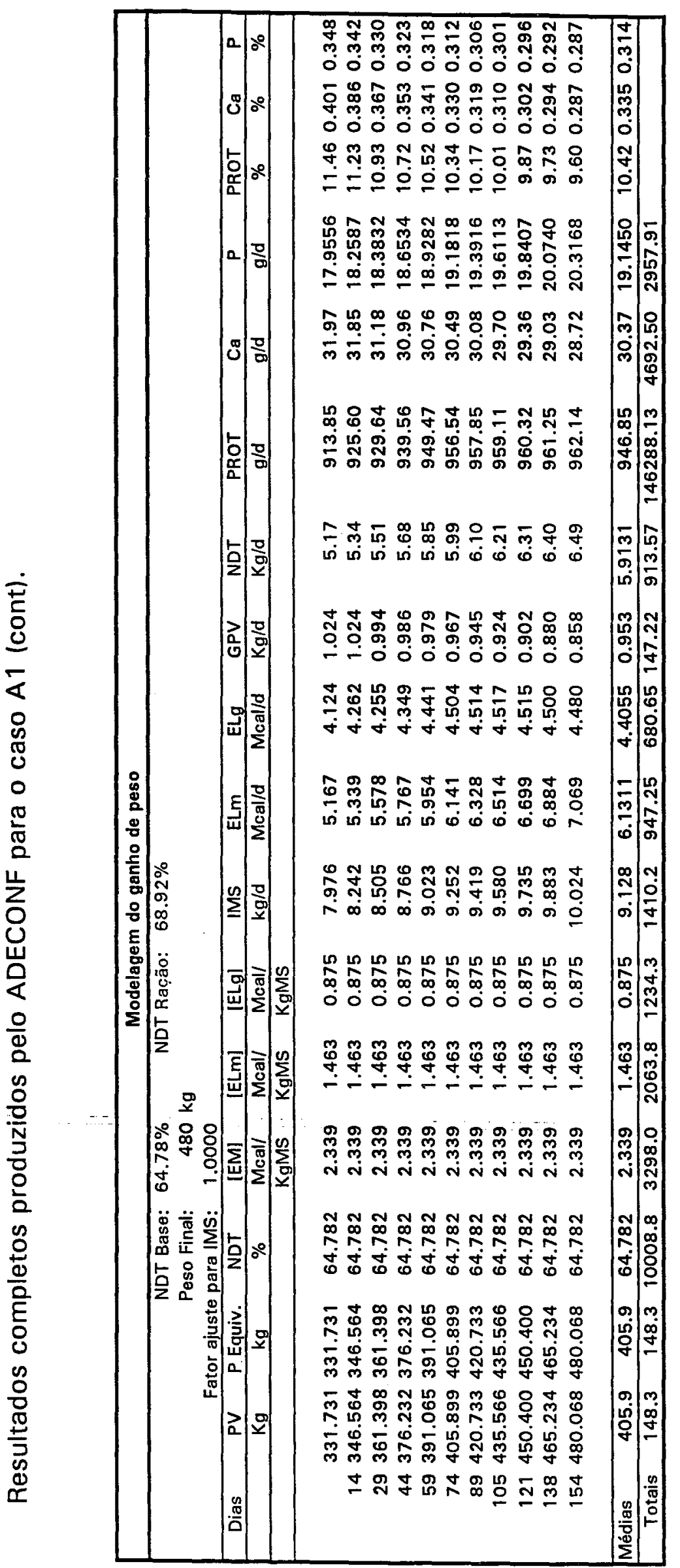




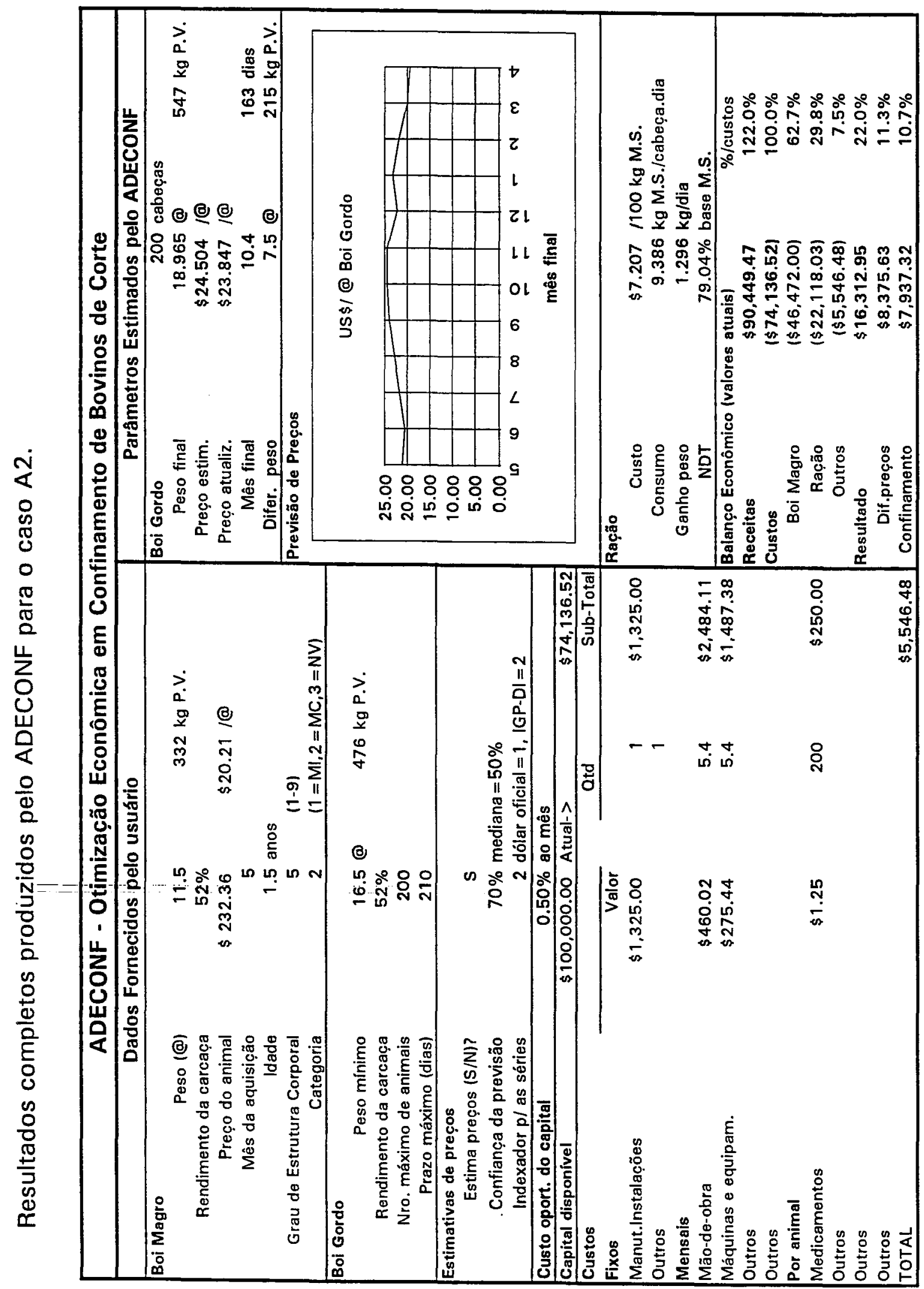




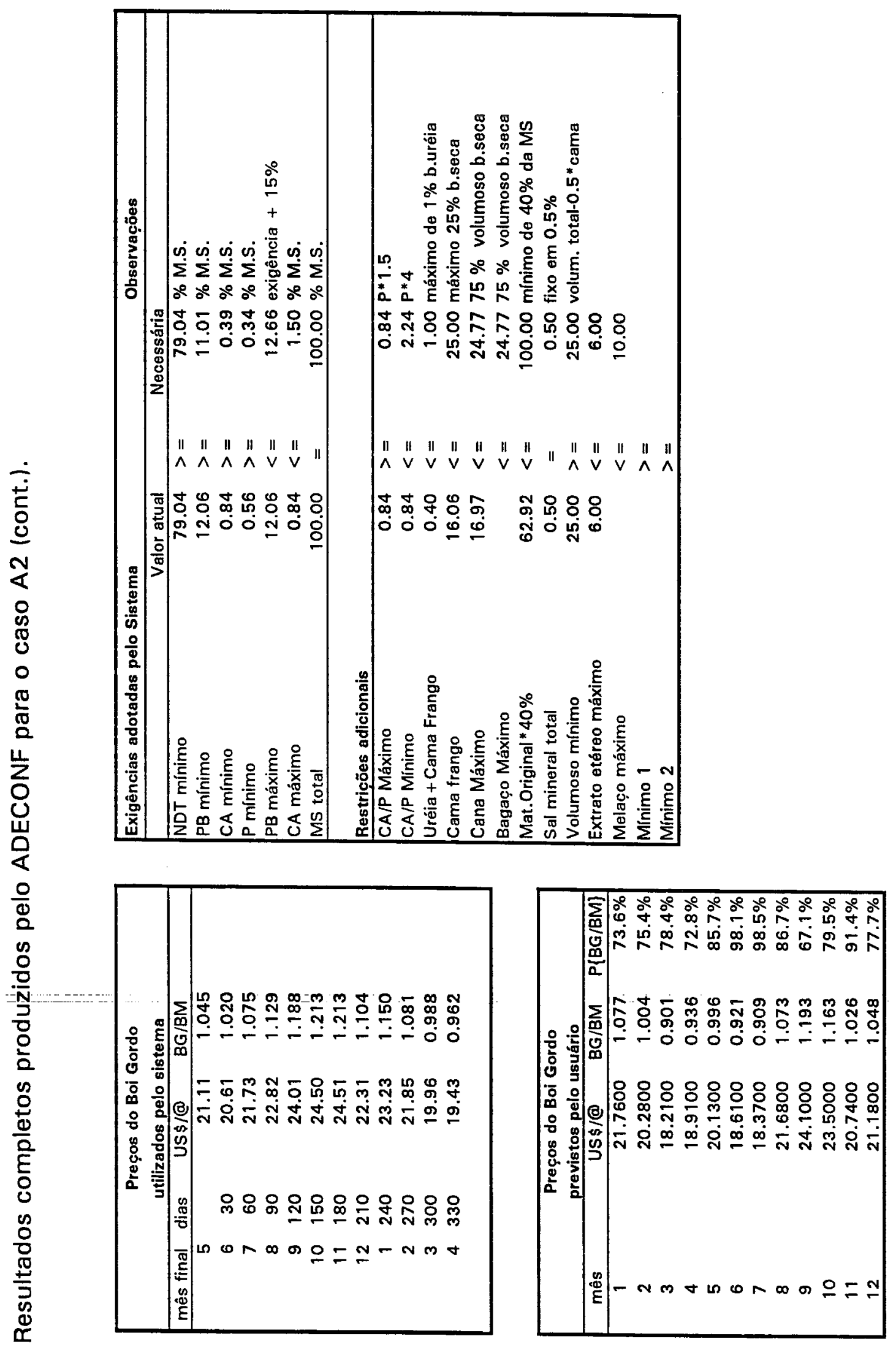




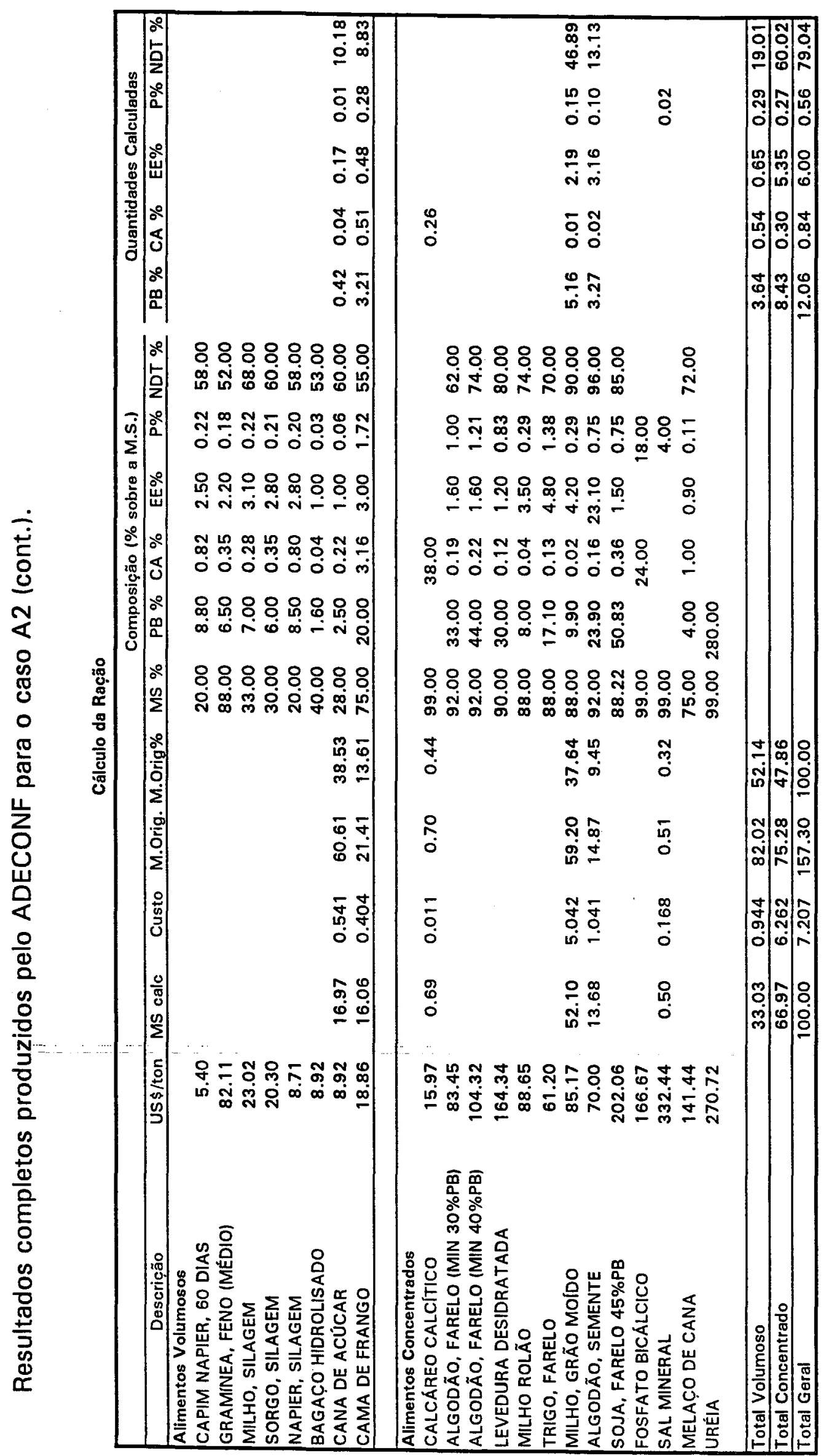




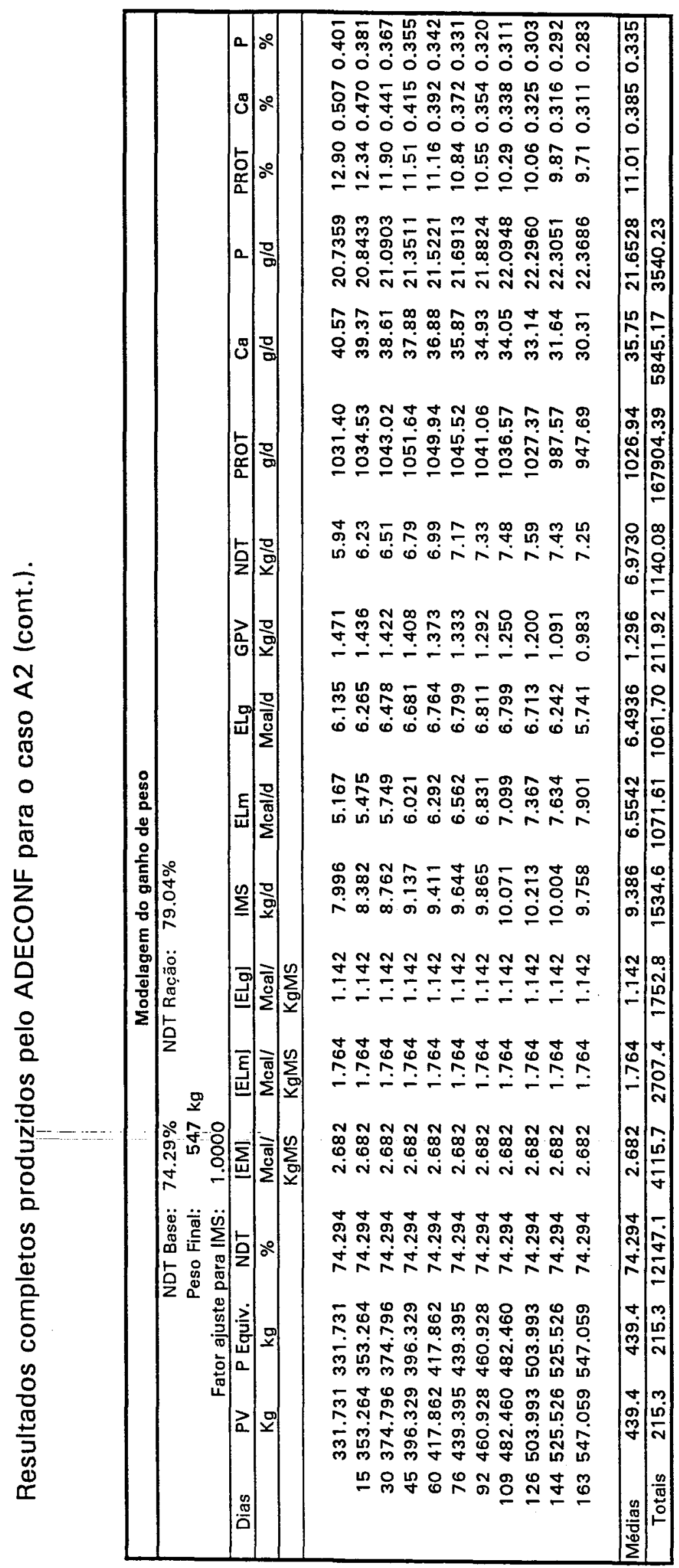

